\title{
RAFT mediated polysaccharide copolymers
}

by

Reda Fleet

Thesis presented in partial fulfillment of the requirements for the degree of

Master of Science (Polymer Science)

at the

University of Stellenbosch

Promoter: Prof RD Sanderson

Co-promoters: Dr JB McLeary and Dr V Grumel

December 2006 


\section{Declaration}

I, the undersigned, hereby declare that the work contained in this thesis is my own original work and that I have not previously in its entirety or in part submitted it at any university for a degree.

\section{Reda Fleet}

Signed on the $27^{\text {th }}$ day of September 2006. 


\section{Abstract}

Cellulose, one of the most abundant organic substances on earth, is a linear polymer of D-glucose units joined through 1,4- $\beta$-linkages. Cellulose is however not easily processed without chemical modification. A number of techniques exist for the modification of cellulose, of which the viscose process is one of the most widely applied. Grafting of synthetic polymeric chains onto or from cellulosic materials is an useful technique that can be used to combine the strengths of synthetic and natural polymers dramatically, so changing the properties of cellulosic materials (pulp, regenerated cellulose, cellulose derivatives).

In this study five model xanthate (Reversible Addition-Fragmentation chain Transfer (RAFT)/Macromolecular Design through Interchange of Xanthates (MADIX)) agents, namely, monofunctional, difunctional, trifunctional and tetrafunctional species of the form $\mathrm{S}=\mathrm{C}(\mathrm{O}-\mathrm{Z})-\mathrm{S}-\mathrm{R}$, with different leaving groups and different activating moieties, were prepared and then studied to determine the feasibility of cellulose modification via addition fragmentation processes. These agents were characterized by Nuclear Magnetic Resonance spectroscopy (NMR), Fourier Transform Infrared spectroscopy (FT-IR) and Ultraviolet spectroscopy (UV). Polyvinyl acetates (PVAc) in the form of linear, three armed and four armed star shaped polymers were then successfully synthesized in reactions mediated by these xanthate RAFT/MADIX agents

Xanthates were applied to polysaccharide materials using the viscose process (xanthate esters were formed directly on a cellulosic substrate, with subsequent alkylation) Grafting reactions were then conducted with the polysaccharides; cellulose was modified with vinyl acetate, [this is an example of a surface modification of natural polymers that is of interest in various industries, such as textiles and paper manufacture].

Analysis of the graft copolymers was conducted via Size Exclusion Chromatography (SEC), Liquid Adsorption Chromatography (LAC), Thermogravimetric Analysis (TGA), and FT-IR.

Polyvinyl acetate was successfully grafted onto three polysaccharides (cellulosic materials), namely Hydroxyl Propyl Cellulose (HPC), Methyl Cellulose (MC) and cellulose. The study showed that the modification of cellulosic substrates with defined grafts of vinyl acetate can be easily achieved through minor modifications to existing industrial techniques. 


\section{Opsomming}

Sellulose, een van die volopste organiese verbindings ter wêreld, is 'n lineêre polimeer bestaande uit D-glukose eenhede, gekoppel deur 1,4- $\beta$-bindings. Sellulose is egter moeilik om te verwerk sonder chemiese verandering. 'n Aantal tegnieke is bekend vir die modifikasie van sellulose, waarvan die viskoseproses (Eng. viscose process) die algemeenste toegepas word. Enting (Eng. grafting) van sintetiese polimeerkettings aan, of van, sellulosemateriale is 'n toeganklike tegniek om die nuttige eienskappe van sintetiese en natuurlike polimere te kombineer, en gevolglik die eienskappe van sellulosemateriale te verander (b.v. pulp, geregenereerde sellulose, sellulose derivate).

In hierdie studie is vyf model xantaat verbindings berei, as MADIX-tipe verbindings (Eng. Macromolecular Design through Interchange of Xanthates) vir RAFT (Eng. Reversible Addition-Fragmentation Chain Transfer) sinteses. Hierdie verbindings was monofunksionele, difunksionele, tri-funksionele en tetra-funksionele spesies van die vorm $\mathrm{S}=\mathrm{C}(\mathrm{O}-\mathrm{Z})-\mathrm{S}-\mathrm{R}$, met verskillende verlatende groepe en verskillende aktiverende funksionele groepe. Die verbindings is gesintetiseer, gekarakteriseer en bestudeer, om die uitvoerbaarheid van sellulose modifikasie via die addisie-fragmentasie proses te bepaal. Hierdie verbindings is gekarakteriseerd m.b.v. KMR, FTIR en UV spektroskopie. Polivinielasetaat (PVAs) polimere, in die lineêre-, drie-arm en vierarm sterpolimere vorms is suksesvol gesintetiseer in hierdie xantaat RAFT/MADIXpolimerisasies.

Xantate is met polisakkariede gereageer deur die gebruik van die viskose-proses (die xantaatesters is direk gekoppel aan 'n sellulosesubstraat, gevolg deur alkilering). Entingsreaksies is dan op die polisakkarides uitgevoer, om die modifikasie van sellulose met vinielasetaat te bewerkstellig. [Hierdie dien as ' $\mathrm{n}$ voorbeeld van 'n oppervlakmodifisering van natuurlike polimere wat van belang is in verskeie industrieë, b.v. tekstiele en papiervervaardiging.] Ontleding van die entkopolimere is gedoen m.b.v. grootte-uitsluitings-chromatografie (Eng. SEC), vloeistof-uitslui-tingschromatogafie (Eng. LAC), termogravimetrieseanalise (Eng. TGA) en Fouriertransformasie-infrarooispektroskopie (FTIR).

Poliviniel asetaat (PVAs) is suksesvol geheg aan drie polisakkarides (sellulose materiale) naamlik, hidroksipropielsellulose, metielsellulose en sellulose. Die studie 
toon dat die modifikasie van sellulosesubstrate met gedefinieerde enting van vinielasetaat maklik uitvoerbaar is deur wysiging van bestaande industriële tegnieke. 


\section{Dedication}

I dedicate this work to my family and friends, and my beloved. 


\section{Table of contents}

\section{Index}

Declaration................................................................................................ ii

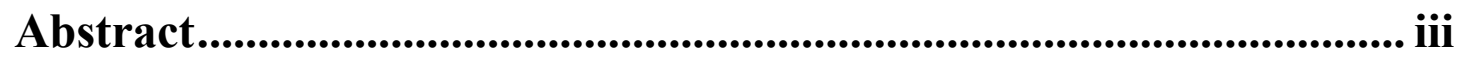

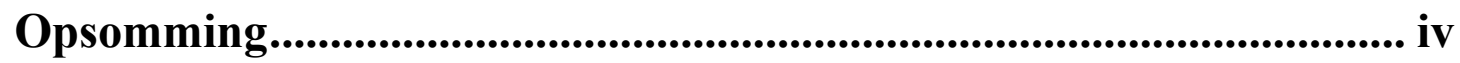

Dedication .................................................................................................... vi

Index vii

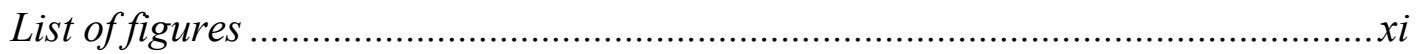

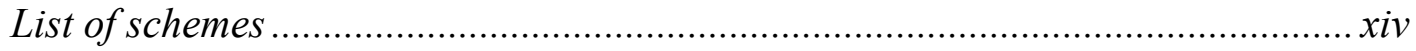

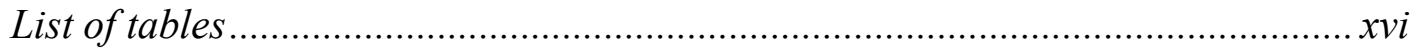

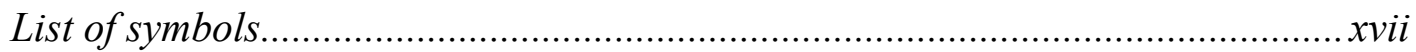

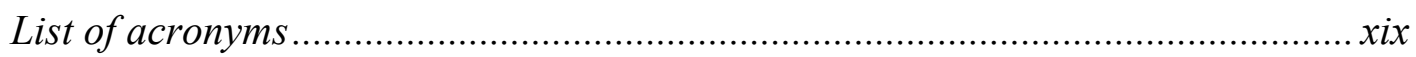

Acknowledgements ............................................................................ xxi

Chapter 1: Introduction and objectives........................................................1

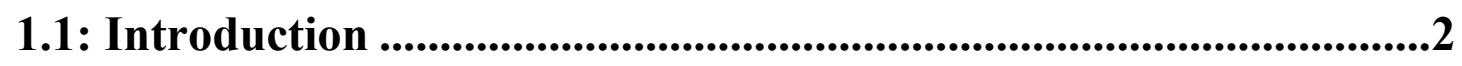

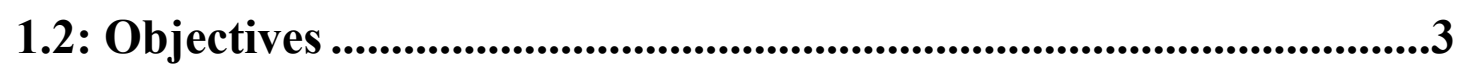

1.3: Layout of the thesis..........................................................................................4

Chapter 1: Introduction and objectives ............................................................... 4

Chapter 2: Historical and theoretical background ............................................. 4

Chapter 3: Synthesis and characterization of the RAFT agents .............................. 4

Chapter 4: RAFT mediated polymerization ............................................................. 4

Chapter 5: Conclusions and recommendations for future work .............................. 4

1.4: References..........................................................................................5

Chapter 2: Historical and theoretical background ....................................7

2.1: Free radical polymerization ..............................................................8

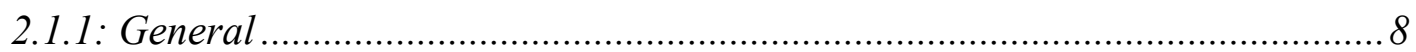

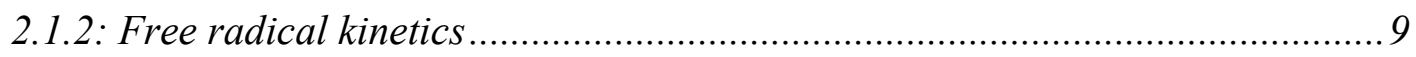

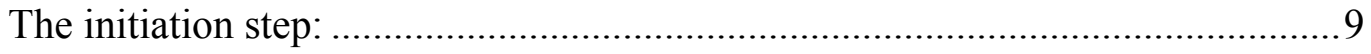

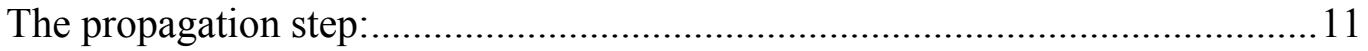

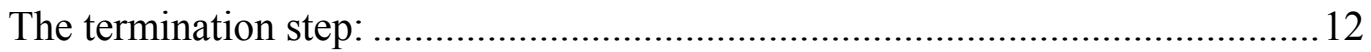




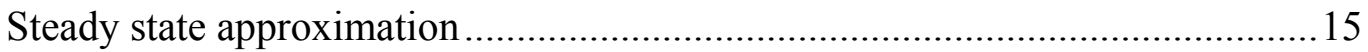

\section{2: Living free radical polymerization (LFRP) ......................................15}

2.2.1: Atom Transfer Radical Polymerization (ATRP) .......................................... 16

2.2.2: Nitroxide Mediated Polymerization (NMP) ................................................... 18

2.2.3: Reversible Addition-Fragmentation Chain Transfer (RAFT) ...................... 19

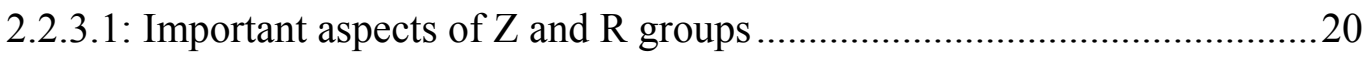

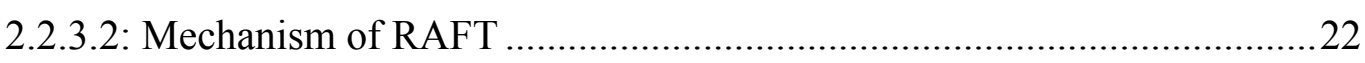

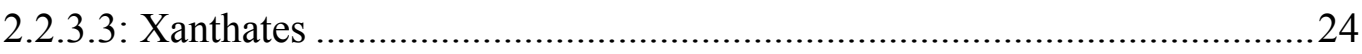

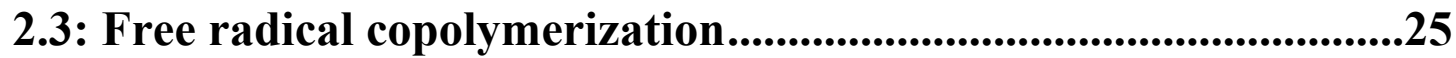

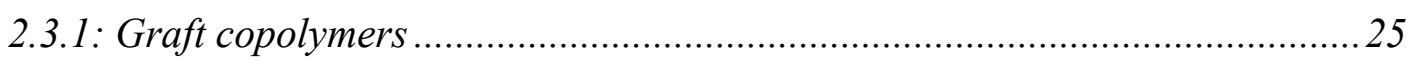

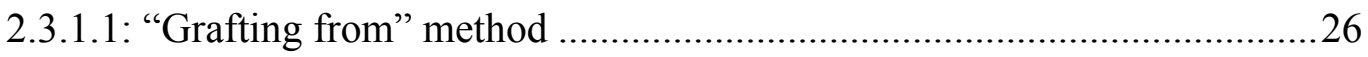

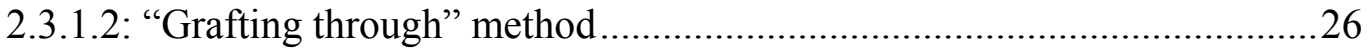

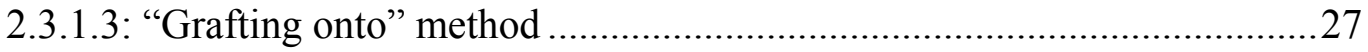

2.4: Cellulose ...................................................................................................................28

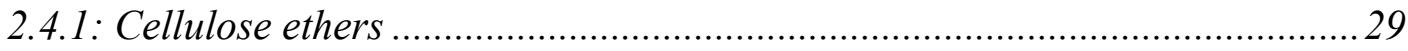

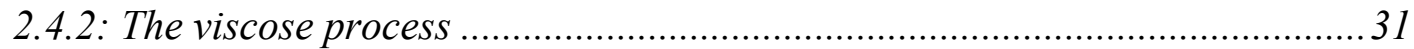

2.5: Characterization and separation techniques....................................32

2.5.1: Size Exclusion Chromatography (SEC) ..................................................... 33

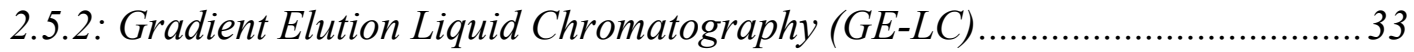

2.5.3: Two-Dimensional Liquid Chromatography $(2 D-L C)$.................................. 34

2.6: References..............................................................................................35

Chapter 3: Synthesis and characterization of xanthate RAFT

agents...........................................................................................................42

3.1: Introduction .....................................................................................43

3.2: Synthesis of the RAFT agents.......................................................44

3.2.1: Synthesis of monofunctional xanthate (RAFT/MADIX) agents (2) and

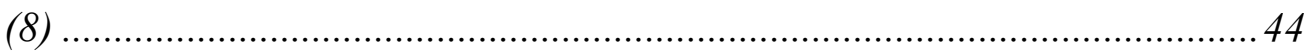

3.2.2: Synthesis of difunctional xanthate (RAFT/MADIX) agent (4)..................... 44

3.2.3:Synthesis of trifunctional and tetrafunctional xanthate (RAFT/MADIX)

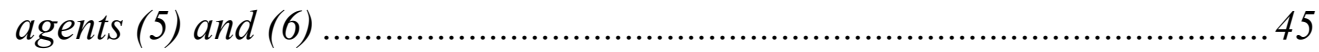

3.2.4: Synthesis of polyol xanthate (RAFT/MADIX) agents (10), (11) and (12) ..... 45

3.3: Characterization of the RAFT agents ...................................................46 
3.3.1: Nuclear Magnetic Resonance Spectroscopy (NMR) ...................................46

3.3.2: Fourier-Transform Infrared Spectroscopy (FTIR)..................................... 46

3.3.3: Ultraviolet/visible spectroscopy .............................................................47

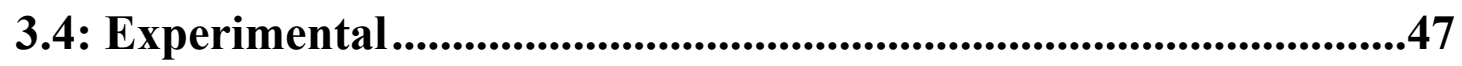

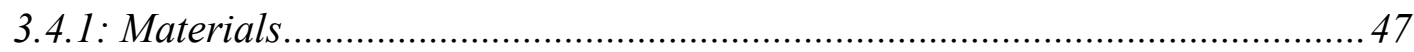

3.4.2: Synthesis of S-sec propionic acid O-ethyl xanthate RAFT agent (2) ............ 47

3.4.3: Synthesis of 1,4 di(S-sec propionic acid xanthate) butane RAFT agent

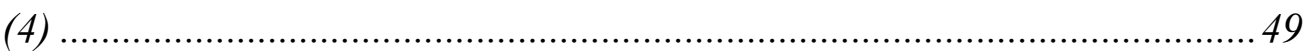

3.4.4: Synthesis of 1,1,1 tri(S-sec ethyl propionoate O-methylene xanthate)

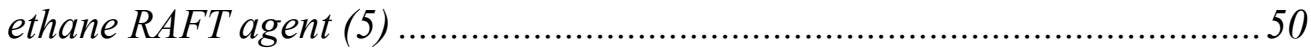

3.4.5: Synthesis of 1,1,1,1 tetra(S-sec ethyl propionoate O-methylene

xanthate) methane RAFT agent (6)

3.4.6: Synthesis of 1,2:5,6-di-O-isopropylidene- $\alpha$-D-glucofuranose-3-(S-sec

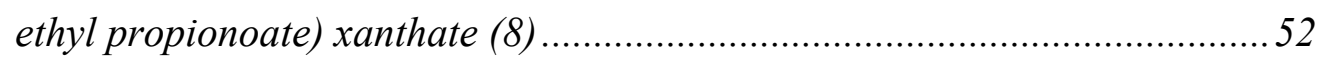

3.4.7: Synthesis of S-sec propionic acid hydroxylpropyl cellulose xanthate

RAFT agent (10).

3.4.8: Synthesis of S-sec propionic acid methyl cellulose xanthate RAFT

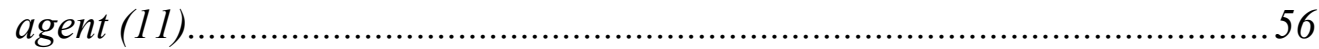

3.4.9: Synthesis of S-sec propionic acid cellulose xanthate RAFT agent (12) ........57

3.5: Discussion of the RAFT syntheses ....................................................58

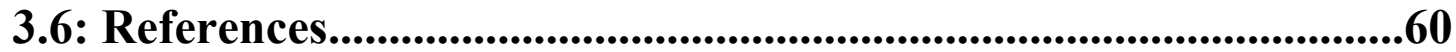

Chapter 4: RAFT mediated polymerization ...........................................61

4.1: Introduction ................................................................................62

4.2: Experimental.............................................................................................63

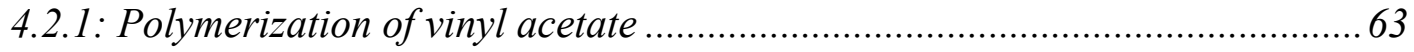

4.2.2: Bulk polymerization of vinyl acetate mediated by xanthate

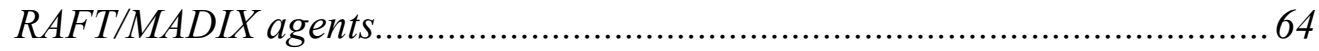

\section{3: Characterization ..........................................................................64}

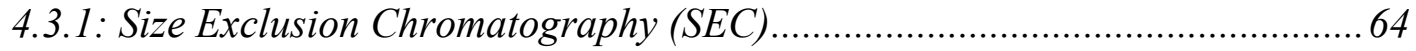

4.3.2: Rates of reaction of vinyl acetate polymerization mediated by xanthate

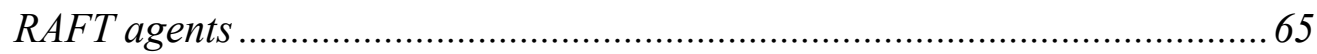

4.3.3: Molar mass distribution of polyvinyl acetates as determined by SEC ......... 67 
4.3.4: UV-RI overlays of polyvinyl acetates as determined by SEC 69

4.4: Grafting of vinyl acetate onto cellulosic materials .........................70

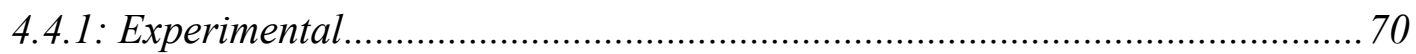

4.5: Analysis of graft copolymers .....................................................71

4.5.1: Size Exclusion Chromatography (SEC) .................................................... 71

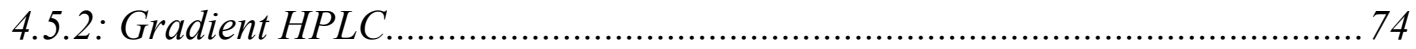

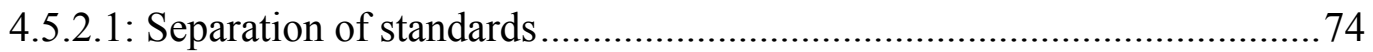

4.5.2.2: Analysis of PVAc-g-HPC and PVAc-g-MC by gradient HPLC ............ 75

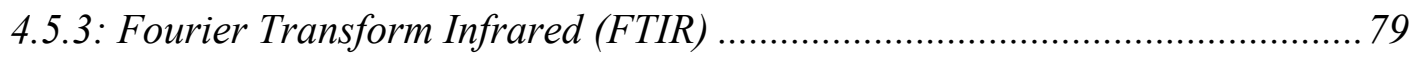

4.6: Cleaving PVAc chains from grafted cellulosic materials ............82

4.7: Thermogravimetric analysis (TGA) .................................................83

4.8: References............................................................................................................86

Chapter 5: Conclusions and recommendations ...................................88

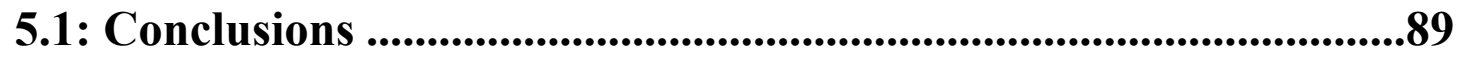

5.2: Recommendations for future work......................................................92

Appendix A: Detailed spectroscopic data of compounds used in

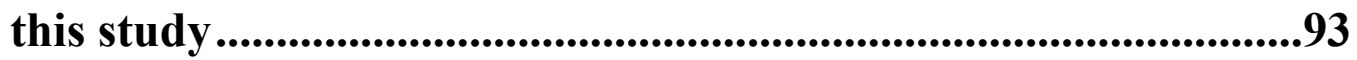

A 1: S-sec propionic acid O-ethyl xanthate RAFT agent (2) ................................. 94

A 2: 1,4 di(S-sec propionic acid xanthate) butane RAFT agent (4) ...................... 96

A 3: 1,1,1 tri(S-sec ethyl propionoate O-methylene xanthate) ethane RAFT agent (5).

A 4: 1,1,1,1 tetra(S-sec ethyl propionoate O-methylene xanthate) methane

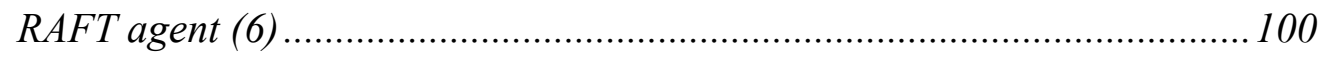

A 5: Compound 7: 1,2:5,6-Di-O-isopropylidene- $\alpha$-D-glucofuranose .................... 102

A 6: 1,2:5,6-Di-O-isopropylidene- $\alpha$-D-glucofuranose-3-(S-sec ethyl

propionoate) xanthate RAFT agent (8) ................................................... 103

A 7: S-sec propionic acid hydroxylpropyl cellulose xanthate RAFT agent (10) ... 105

A 8: Structure of S-sec propionic acid methyl cellulose xanthate RAFT agent

A 9: S-sec propionic acid cellulose xanthate RAFT agent (12) ........................... 107

A 10: Calculations of the grating frequency ................................................... 108 


\section{List of figures}

Fig. 2.1: Propagating polymeric radical with substituents $\mathrm{X}$ and $\mathrm{R}$. 9

Fig. 2.2: General structures of the azo and peroxy-type initiators. 10

Fig. 2.3: Examples of nitroxide mediators. 18

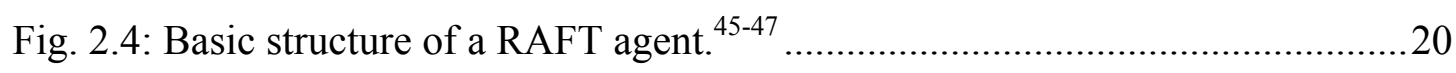

Fig. 2.5: Examples of different RAFT agent Z-groups. ${ }^{24,45}$....................................... 21

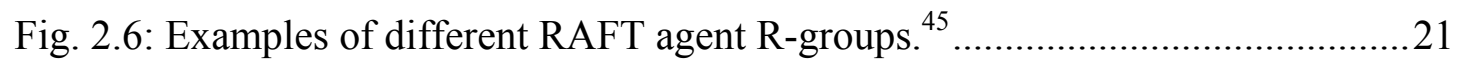

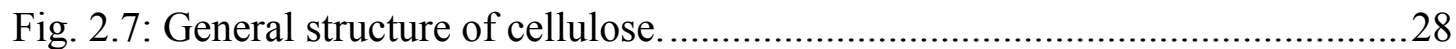

Fig. 2.8: General structure of hydroxypropyl cellulose and methyl cellulose.............30

Fig. 2.9: Representation of chemical inhomogeneities in polymers A and B.............. 32

Fig. 3.1: FTIR spectrum of hydroxylpropyl cellulose and S-sec propionic acid hydroxylpropyl cellulose xanthate RAFT agent (10)...

Fig. 3.2: FTIR spectrum of methyl cellulose and S-sec propionic acid methyl cellulose xanthate RAFT agent (11) 56

Fig. 3.3: FTIR spectrum of cellulose and S-sec propionic acid cellulose xanthate RAFT agent (12) 58

Fig. 4.1: Semilogarithmic plots of fractional conversion versus time for vinyl acetate mediated homopolymerizations by xanthate RAFT agents (2), (4), (5) (6) and (8) (reactions 1, 2, 3, 4 and 5). Dotted lines have been added as guides for the eye All reaction conditions are listed in Table 4.1. 66

Fig. 4.2: Molar mass distribution of samples scaled for conversion taken from reactions (1) to (5), where RAFT (2), RAFT (4), RAFT (5), RAFT (6) and RAFT (8) were used in reactions (1, 2, 3, 4 and 5) respectively. All reactions conditions are listed in Table 4.1 .

Fig. 4.3: Evaluation of $\mathrm{Mn}$ and polydispersity as a function of conversion for RAFT mediated polymerization of vinyl acetate prepared from reactions (1) to (5). Refer to Table 4.1 for reactions conditions.

Fig. 4.4: UV-RI overlays for RAFT mediated polymerization of vinyl acetate prepared from reactions (1) to (5), where RAFT (2), RAFT (4), RAFT (5), RAFT (6) and RAFT (8) were used in reactions 1, 2, 3, 4 and 5 respectively. All reactions conditions are listed in Table 4.1. 70

Fig. 4.5: Molar mass distribution of polyvinyl acetate grafted cellulosic materials; (A) molar mass distribution of unmodified and modified HPC, 
(B) comparison of molar mass distribution of modified HPC (RAFT 10) and grafted HPC from reaction (6), (C) comparison of molar mass distribution of modified MC (RAFT11) and grafted MC from reaction (7). Refer to Table 4.2 for reactions conditions.

Fig. 4.6: Gradient HPLC for the separation of graft copolymers (A) separation of standard modified HPC (RAFT 10), PVAc homopolymer and PVAc-gHPC prepared from reaction (6), (B) separation of standard modified MC (RAFT 11), PVAc homopolymer and PVAc-g-MC prepared from reaction (7). Refer to Table 4.2 for reactions conditions.

Fig. 4.7: 3-D chromatogram plot for the two-dimensional separation of graft copolymers, (A) separation of the polymers prepared from reaction (6) where RAFT (10) was used, which are PVAc-g-HPC and PVAc homopolymer, (B) separation of the polymers prepared from reaction (7) where RAFT (11) was used which are PVAc-g-MC and PVAc homopolymer. Refer to Table 4.2 for reactions conditions. 77

Fig. 4.8: A typical example of an infrared spectrum of: (A) unmodified HPC, (B) modified HPC (RAFT 10), (C) PVAc-g-HPC after extraction of PVAc homopolymer.

Fig. 4.9: Calibration curves for the determination of the percentage PVAc in the grafted cellulosic materials prepared from reactions (6), (7) and (8), where (A) calibration curve of blended PVAc/modified HPC (RAFT 10), (B) calibration curve of blended PVAc/modified MC (RAFT 11), (C) calibration curve of blended PVAc/modified cellulose (RAFT 12).

Fig. 4.10: Molar mass distribution of polyvinyl acetate grafted cellulosic materials; (A) and (C) molar mass distribution of PVAc-g-HPC and PVAc-g-MC respectively before hydrolysis process, (B) and (D) molar mass distribution of PVAc-g-HPC and PVAc-g-MC respectively after hydrolysis process. 83

Fig. 4.11: TGA curves of (A) unmodified HPC, modified HPC (RAFT 10), PVAc homopolymer and PVAc-g-HPC (B) unmodified MC, modified MC (RAFT 11), PVAc homopolymer and PVAc-g-MC.(C) unmodified cellulose, modified cellulose (RAFT 12), PVAc homopolymer and PVAcg-cellulose. .84 
Fig. A1: ${ }^{1} \mathrm{H}-\mathrm{NMR}(\mathrm{A})$ and ${ }^{13} \mathrm{C}-\mathrm{NMR}(\mathrm{B})$ spectra of RAFT agent 2 in chloroform-d.

Fig. A2: Infrared spectrum of RAFT agent 2.

Fig. A3: UV absorbance spectrum of RAFT agent 2 in acetonitrile. $B$ is $\left(n \rightarrow \pi^{*}\right.$,

$\left.\lambda_{\max }=354 \mathrm{~nm} \mathrm{~L}, \mathrm{C}=4.3555 \times 10^{-4} \mathrm{~mol} / \mathrm{L}\right)$ and $\mathrm{A}$ is $\left(\pi \rightarrow \pi^{*}, \lambda=278 \mathrm{~nm}, \mathrm{C}\right.$

$\left.=1.132 \times 10^{-2} \mathrm{~mol} / \mathrm{L}\right)$.

Fig. A4: ${ }^{1} \mathrm{H}-\mathrm{NMR}(\mathrm{A})$ and ${ }^{13} \mathrm{C}-\mathrm{NMR}(\mathrm{B})$ spectra of RAFT agent 4 in DMSO-d........ 96

Fig. A5: Infrared spectrum of RAFT agent 4.

Fig. A6: UV absorbance spectrum of RAFT agent 4 in acetonitrile. $B$ is $\left(n \rightarrow \pi^{*}\right.$,

$\left.\lambda=28 \mathrm{~nm}, \mathrm{C}=1.5705 \times 10^{-6} \mathrm{~mol} / \mathrm{L}\right)$ and $\mathrm{A}$ is $\left(\pi \rightarrow \pi^{*}, \lambda_{\max }=356 \mathrm{~nm}, \mathrm{C}=\right.$

$\left.5.0259 \times 10^{-3} \mathrm{~mol} / \mathrm{L}\right)$.

Fig. A7: ${ }^{1} \mathrm{H}-\mathrm{NMR}$ (A) and ${ }^{13} \mathrm{C}-\mathrm{NMR}(\mathrm{B})$ spectra of RAFT agent 5 in

chloroform-d. 98

Fig. A8: Infrared spectrum of RAFT agent 5.

Fig. A9: UV absorbance spectrum of RAFT agent 5 in acetonitrile. B is $\left(\pi \rightarrow \pi^{*}\right.$,

$\left.\lambda=280 \mathrm{~nm}, \mathrm{C}=5.7755 \times 10^{-4} \mathrm{~mol} / \mathrm{L}\right)$ and $\mathrm{A}$ is $\left(\mathrm{n} \rightarrow \pi^{*}, \lambda_{\max }=431 \mathrm{~nm}, \mathrm{C}=\right.$

$\left.2.59 \times 10^{-3} \mathrm{~mol} / \mathrm{L}\right)$.

Fig. A10: ${ }^{1} \mathrm{H}-\mathrm{NMR}(\mathrm{A})$ and ${ }^{13} \mathrm{C}-\mathrm{NMR}(\mathrm{B})$ spectra of RAFT agent 6 in

chloroform-d.

Fig. A11: Infrared spectrum of RAFT agent 6.

Fig. A12: UV absorbance spectrum of RAFT agent 6 in acetonitrile. B is

$\left(\pi \rightarrow \pi^{*}, \lambda=280 \mathrm{~nm}, \mathrm{C}=2.698 \times{ }^{10-4} \mathrm{~mol} / \mathrm{L}\right)$ and $\mathrm{A}$ is $\left(\mathrm{n} \rightarrow \pi^{*}, \lambda_{\max }=\right.$

$\left.440 \mathrm{~nm}, \mathrm{C}=1.365 \times 10^{-2} \mathrm{~mol} / \mathrm{L}\right)$.

Fig. A13: ${ }^{1} \mathrm{H}-\mathrm{NMR}$ spectrum of 1,2:5,6-di-O-isopropylidene- $\alpha$-D-glucofuranose

in chloroform-d.

Fig. A14: The COSY plots $(1 \mathrm{H}, 1 \mathrm{H})$ NMR of 1,2:5,6-di-O-isopropylidene- $\alpha$-D-

glucofuranose in chloroform-d.

Fig. A15: ${ }^{1} \mathrm{H}-\mathrm{NMR}$ spectrum of RAFT agent 8 in chloroform-d.

Fig. A16: Infrared spectrum of RAFT agent 8. 104

Fig. A17: UV absorbance spectrum of RAFT agent 8 in acetonitrile. B is

$$
\begin{aligned}
& \left(\pi \rightarrow \pi^{*}, \lambda=280 \mathrm{~nm}, \mathrm{C}=3.2 \times 10^{-5} \mathrm{~mol} / \mathrm{L}\right) \text { and } \mathrm{A} \text { is }\left(\mathrm{n} \rightarrow \pi^{*}, \lambda_{\max }=380 \mathrm{~nm}\right. \text {, } \\
& \left.\mathrm{C}=1.48 \times 10^{-2} \mathrm{~mol} / \mathrm{L}\right)
\end{aligned}
$$


Fig. A17: UV absorbance spectrum of RAFT agent 10 in ethanol. B is $\left(\pi \rightarrow \pi^{*}\right.$, $\lambda=283 \mathrm{~nm}, \mathrm{C}=0.011 \mathrm{~g} / 9 \mathrm{~mL})$ and $\mathrm{A}$ is $\left(\mathrm{n} \rightarrow \pi^{*}, \lambda_{\max }=376 \mathrm{~nm}, \mathrm{C}=0.06\right.$ $\mathrm{g} / 2 \mathrm{~mL})$.

Fig. A18: UV absorbance spectrum of RAFT agent 11 in dimethylformamide. B

is $\left(\pi \rightarrow \pi^{*}, \lambda=287 \mathrm{~nm}, \mathrm{C}=5 \times 10^{-3} \mathrm{~g} / 7 \mathrm{~mL}\right)$ and $\mathrm{A}$ is $\left(\mathrm{n} \rightarrow \pi^{*}, \lambda_{\max }=383\right.$ $\mathrm{nm}, \mathrm{C}=0.05 \mathrm{~g} / 5 \mathrm{~mL})$.

Fig. A19: UV absorbance spectrum of RAFT agent 12 in dimethylformamide. B

is $\left(\pi \rightarrow \pi^{*}, \lambda=284 \mathrm{~nm}, \mathrm{C}=3 \times 10^{-3} \mathrm{~g} / 6 \mathrm{~mL}\right)$ and $\mathrm{A}$ is $\left(\mathrm{n} \rightarrow \pi^{*}, \lambda_{\max }=420\right.$ $\mathrm{nm}, \mathrm{C}=0.03 \mathrm{~g} / 5 \mathrm{~mL})$.

\section{List of schemes}

Scheme 2.1: Formation of a benzoyl radical. ................................................................ 11

Scheme 2.2: A typical redox initiation system. .......................................................... 11

Scheme 2.3: A coupling termination reaction......................................................... 12

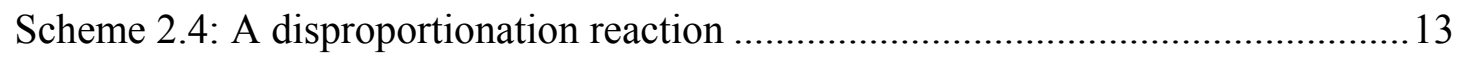

Scheme 2.5: General formation of a dormant species in LFRP ..................................16

Scheme 2.6: Activation-deactivation equilibrium in ATRP.....................................17

Scheme 2.7: Schematic representation of the NMP process........................................18

Scheme 2.8: Schematic representation of the RAFT polymerization mechanism.......22

Scheme 2.9: General structure of a simple graft copolymer......................................26

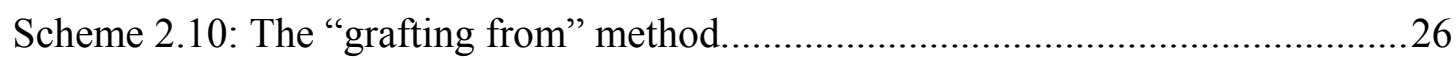

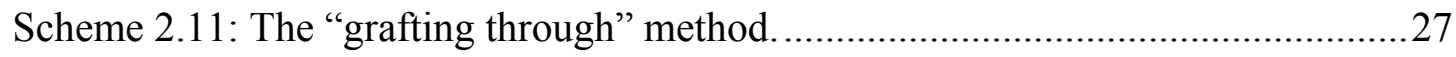

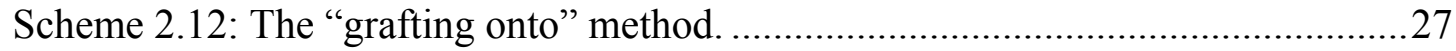

Scheme 2.13: Steps in the synthesis of cellulose ethers. ............................................ 30

Scheme 2.14: Schematic representation of the viscose process. ................................. 31

Scheme 3.1: General preparation of monofunctional xanthate (RAFT/MADIX) agents (2) and (8).

Scheme 3.2: General preparation of difunctional xanthate (RAFT/MADIX)

agents (4)

Scheme 3.3: General preparation of trifunctional and tetrafunctional xanthate

(RAFT/MADIX) agents (5) and (6).

Scheme 3.4: General preparation of polyol xanthate (RAFT/MADIX) agents (10), (11) and (12). 
Scheme 3.5: Preparation of potassium O-ethyl dithiocarbonate (1).

Scheme 3.6: Preparation of S-sec propionic acid O-ethyl xanthate RAFT agent

Scheme 3.7: Preparation of difunctional potassium xanthate salt (3).

Scheme 3.8: Preparation of 1,4 di(S-sec propionic acid xanthate) butane RAFT agent (4)

Scheme 3.9: Preparation of 1,1,1 tri(S-sec ethyl propionoate O-methylene xanthate) ethane RAFT agent (5).

Scheme 3.10: Preparation of 1,1,1,1 tetra(S-sec ethyl propionoate O-methylene xanthate) methane RAFT agent (6).

Scheme 3.11: Preparation of 1,2:5,6-di-O-isopropylidene- $\alpha$-D-glucofuranose (7).

Scheme 3.12: Preparation of 1,2:5,6-di-O-isopropylidene- $\alpha$-D-glucofuranose-3-

(S-sec ethyl propionoate) xanthate RAFT agent (8). .53

Scheme 3.13: Preparation of hydroxypropyl cellulose potassium xanthate salt $(10)$.

Scheme 3.14: Preparation of S-sec propionic acid hydroxylpropyl cellulose xanthate RAFT agent (10).

Scheme 3.15: Structure of S-sec propionic acid methyl cellulose xanthate RAFT agent (11) 56

Scheme 3.16: Structure of S-sec propionic acid cellulose xanthate RAFT agent 


\section{List of tables}

Table 4.1: The quantities of reagents used in bulk polymerization of vinyl acetate.

Table 4.2: The quantities of reagents used in graft polymerization of vinyl acetate onto cellulosic materials. .

Table 4.3: Graft polymerization of VAc onto cellulosic materials and the results of gravimetric measurements of the grafted cellulosic materials. 78 


\section{List of symbols}

$\mathrm{X}$

$\mathrm{M}_{\mathrm{n}}$

$\mathrm{M}_{\mathrm{w}}$

$\mathrm{M}_{\mathrm{n} \text {,theory }}$

$\mathrm{DP}_{\mathrm{n}}$

I

$\mathrm{R}^{\circ}$

S

$\mathrm{R}$

Z

$\mathrm{T}$

[I]

[]$_{\mathrm{o}}$

$[\mathrm{M}]_{\mathrm{o}}$

$[\mathrm{RAFT}]_{\mathrm{o}}$

$\mathrm{R}_{\mathrm{p}}$

$\mathrm{Mw}_{\text {monomer }}$

Mwraft

[Monomer]

[RAFT]

$\mathrm{k}_{\mathrm{d}}$

$\mathrm{k}_{\mathrm{i}}$

$\lambda$

[M]

M

$\mathrm{C}_{\mathrm{m}}$

[S]

C

$\mathrm{k}_{\text {tr }}$

$\mathrm{k}_{\mathrm{p}}$

$\mathrm{k}_{\mathrm{tc}}$
Fractional conversion

Number average molar mass

Weight average molar mass

Calculated number average molar mass

Average degree of polymerization

Initiator

Primary radical

Solvent

RAFT agent leaving group

RAFT agent stabilizing group

Chain transfer agent

Initiator concentration

Initial concentration of initiator

Initial concentration of monomer

Initial concentration of RAFT agent

Rate of polymerization

Molecular weight of monomer

Molecular weight of RAFT agent

Monomer concentration

RAFT agent concentration

Dissociation constant

Initiation constant

Fraction of termination by disproportionation

Concentration of monomer

Monomer

Chain transfer constant

Concentration of the chain transfer agent in form of solvent

Transfer constant

Transfer rate coefficient

Propagation rate coefficient

Termination rate constant 
$\mathrm{k}_{\mathrm{td}}$

$\mathrm{k}_{\mathrm{fm}}$

$\mathrm{k}_{\mathrm{fs}}$

$\mathrm{k}_{\mathrm{ft}}$

$\mathrm{k}_{\mathrm{fp}}$

$\mathrm{M}_{\mathrm{t}}^{\mathrm{n}} / \mathrm{L}$

$\mathrm{G}$

GE

$\mathrm{W}_{1}$

$\mathrm{W}_{2}$

$\mathrm{W}_{3}$

$\mathrm{h} v$

$\lambda$

$v_{i}$

$v_{p}$

$v_{\mathrm{t}}$

$\mathrm{f}$

$\mathrm{t}$

$t_{1 / 2}$
Termination by disproportionation rate coefficient

Transfer to monomer rate coefficient

Transfer to solvent rate coefficient

Transfer to agent rate coefficient

Transfer to polymer rate coefficient

Transition metal complex for atom transfer reaction

Grafting ratio

Grafting efficiency

Initial weight of RAFT cellulosic materials

Dry weight of polymerized sample before extraction

Dry weight of polymerized sample after extraction

Energy

Absorbance

Rate of initiation

Rate of propagation

Rate of termination

Radical efficiency

Time

Initiator half-life 


\section{List of acronyms}

AGUs

AIBN

ATRP

CCD

${ }^{13} \mathrm{C}-\mathrm{NMR}$

CSIRO

$\mathrm{CS}_{2}$

DBN

DEPN

2D-LC

DP

DS

ESR

FTD

FTIR

GE-LC

${ }^{1} \mathrm{H}-\mathrm{NMR}$

HPC

HPLC

LAC

LFRP

MAD

MADIX

MALLS

$\mathrm{MC}$

MMD

NMP

NMR

PAS

PDI

ppm
Anhydroglucose units

2,2-azobis (isobutyronitrile)

Atom transfer radical polymerization

Chemical composition distribution

Carbon nuclear magnetic resonance spectroscopy

Commonwealth Scientific, Industrial Research Organization

Carbon disulfide

Di-tert-butylnitroxide

N-tert-butyl-N-(1-diethylphosphono-2,2-dimethylpropyl)

Two-dimensional liquid chromatography

Degree of polymerization

Degree of substitution

Electron spin resonance

Functionality type distribution

Fourier transform infrared

Gradient elution liquid chromatography

Proton nuclear magnetic resonance spectroscopy

Hydroxypropyl cellulose

High performance liquid chromatography

Liquid adsorption chromatography

Living free radical polymerization

Molecular architecture distribution

Macromolecular design via interchange of xanthates

Multi-Angle Laser Light Scattering

Methyl cellulose

Molar mass distribution

Nitroxide mediated polymerization

Nuclear magnetic resonance spectroscopy

Photoacoustic

polydispersity index

Parts per million 
PS

PVAc

PVAc-g-Cellulose

PVAc-g-HPC

PVAc-g-MC

RAFT

RI

SEC

TEMPO

TGA

UV

VAc
Polystyrene

Polyvinyl acetate

Polyvinyl acetate graft cellulose copolymer

Polyvinyl acetate graft hydroxypropyl cellulose co-polymer

Polyvinyl acetate graft methyl cellulose co-polymer

Reversible addition-fragmentation chain transfer

Refractive index

Size exclusion chromatography

2,2,6,6-tetramethyl-1-piperidinyloxy free radical

Thermogravimetric analysis

Ultraviolet

Vinyl acetate 


\section{Acknowledgements}

Firstly, I would like to thank Allah for blessing me with the gift of life during my study. I know that Allah gave me guidance, courage, strength and joy in times of despair.

I would like to thank and acknowledge the institution that has made this project possible. The Libyan International Centre for Macromolecules Chemistry and Technology without whose generous sponsorship this would not have been possible.

I would like to take this opportunity to thank the following people for their contributions to this project:

Prof Sanderson, my promoter, for giving me the opportunity to study at this world class institution. And his knowledge input, motivation and encouragement during this study

My co-promoters, Dr JB McLeary and Dr V Grumel for their invaluable contributions and input. Their constructive criticism and endless assistance are gratefully acknowledged and much appreciated.

Dr MJ Hurndall for assisting with preparing this manuscript.

Dr EG Weber and Dr MS Frahn for their contributions in the synthesis of the RAFT agents.

Jean McKenzie for NMR analysis.

My friends and colleagues for their support and encouragement when things seemed impossible.

The following people: Angela, Eric, Fozi, Gareth, Gwen, Howard, Ingrid, Jack, JC, Nadine, Niels, Osama, Robin, Zaskia, Vernon for all their help.

Finally, I would like to thank my family for their patience and understanding as well as their unequivocal belief in me. You are my anchor. 
Chapter 1: Introduction and objectives 


\section{1: Introduction}

Numerous synthetic polymeric products have been produced over the past few decades in order to improve the quality of life of the all people who use them. ${ }^{1,2}$ One need only think of life without them to realize that they have become an integral part of our society. ${ }^{3}$ This is not a coincidence, since they are based on nature which is full of polymeric structures. DNA, for example is one of the better known natural polymers and one of the fundamental building blocks of life. The world of synthetic polymers is however not without its problems. The rising cost of oil has resulted in increased production costs for many polymers. This fact, and the ever increasing interest in renewable materials and energy, has resulted in more and more time and resources being allocated to research in the renewable materials field. ${ }^{4}$

Cellulose is the most common polymer found in nature..$^{5-8}$ It is basically a polymer of glucose, which is a simple sugar. Trees and plant fibres, of which cellulose is the predominant material, are renewable energy sources which can be utilised to produce vast quantities of cellulose. ${ }^{8-12}$ The case for cellulose is however not as simple as it first appear. Cellulose in its natural state does not melt and is not easily soluble. ${ }^{13}$ This means that producing the end products could be problematic due to inhibitive processing requirements. ${ }^{14}$ Synthetic polymers, on the other hand, melt easily and can be processed into almost any shape or size desired. One likely route which could be taken to utilise the cellulose would be to produce a hybrid polymer consisting of both natural and synthetic segments. ${ }^{5,11}$ The end result could be a polymer which is both more processable and more environmentally friendly. ${ }^{15}$

The crux of the matter is the design and synthetic route to be followed when producing the hybrid polymer. Many polymerization techniques are available and are used industrially for the production of a wide range of materials. ${ }^{5}$ Many of the techniques, such as the catalytic polymerization of ethylene and propylene, require specialised equipment and are extremely sensitive to impurities. ${ }^{16,17}$ This can increase production costs substantially. One option which is more feasible is the free radical polymerization technique.

This study looks at the production of a hybrid cellulose-based material using existing cellulose manipulation technology, namely the viscose process, ${ }^{14,18,19}$ together with advanced free radical polymerization techniques. The polymer produced will be easier 
to manipulate than cellulose, and have different chemical and thermal properties. ${ }^{20}$ for example vinyl acetate grafted cellulosic polymers are of interest as adhesive materials based on renewable resources.

\section{2: Objectives}

This project explores a number of aspects of vinyl acetate (VAc) polymerization, including the control of molar mass and polydispersity using the reversible AdditionFragmentation chain Transfer/Macromolecular Design via Interchange of Xanthates (RAFT/MADIX) process, and the use of the RAFT process to synthesis vinyl acetategrafted cellulosic materials.

The objectives of the project were as follows:

1. To synthesize different xanthate (MADIX)/RAFT agents; monofunctional, difunctional, trifunctional and tetrafunctional xanthate (MADIX)/RAFT agents of the form $\mathrm{S}=\mathrm{C}(\mathrm{O}-\mathrm{Z})-\mathrm{S}-\mathrm{R}$, with different leaving groups and different activating moieties

2. To investigate the chain transfer ability of these xanthate (MADIX)/RAFT agents to induce living characteristics in free radical vinyl acetate polymerization with respect to molar mass control and kinetic behavior.

3. To convert the hydroxyl groups of the cellulosic materials (hydroxypropyl cellulose, methyl cellulose and cellulose) into thiocarbonyl-thio(xanthate) MADIX/RAFT agents through the use of the viscose process procedure to produce modified (RAFT) cellulosic materials.

4. To use (RAFT/MADIX) process to control the grafting of vinyl acetate onto the modified (RAFT) cellulosic materials and produce amphiphilic graft copolymers.

5. To analyze the graft copolymers by different chromatographic techniques, such as SEC, gradient HPLC and two-dimensional chromatography.

6. To study the effect of the chemical modification of the cellulosic material with polyvinyl acetate on the thermal stability, by means of thermogravimetric analysis (TGA).

7. To hydrolyze the xanthate links located between the cellulosic material backbone and PVAc arms in order to isolate the arms from the cellulosic materials and subsequently characterize these arms by SEC. 
8. To evaluate the grafting efficiency as well as the hydrolysis efficiency by (FTIR) spectroscopy.

\section{3: Layout of the thesis}

\section{Chapter 1: Introduction and objectives}

A brief introduction is given to the major areas pertaining to this research, which include controlled \living radical polymerization, vinyl acetate polymerization and the use of the RAFT process to synthesis vinyl acetate- grafted cellulosic materials. This chapter also includes the objectives of the research project.

\section{Chapter 2: Historical and theoretical background}

This is a review of the historical and theoretical aspects related to this research project. Included are important studies related to this research that have carried out by other researchers to date.

\section{Chapter 3: Synthesis and characterization of the RAFT agents}

This chapter covers the synthesis and characterization of the RAFT agents that have been used in this research.

\section{Chapter 4: RAFT mediated polymerization}

In this chapter the living character of vinyl acetate polymerization as a function of RAFT is examined. Monomer conversion profiles are discussed, and molar masses and molar mass distributions of the polymers are examined. Included in this chapter is the synthesis of polyvinyl acetate grafted cellulosic materials as well as the analysis of the graft copolymers by different chromatographic techniques such as SEC, gradient HPLC and two-dimensional chromatography.

\section{Chapter 5: Conclusions and recommendations for future work}

General conclusion to the study, covering achievement, and recommendations for future work are given. 


\section{4: References}

(1) Asua, J. Prog. Polym. Sci. 2002, 27, 1283-1346.

(2) Antonietti, M.; Landfester, K. Prog. Polym. Sci. 2002, 27, 689-757.

(3) Velasco, M.; Munoz, A.; Jimenez-Castellanos, M.; Castellano, I.; Gurruchaga, M. Int. J. Pharm. 1996, 136, 107-115.

(4) Lin, L.; Yao, Y.; Yoshioka, M.; Shiraishi, N. Carbohydr. Polym. 2004, 57, 123-129.

(5) Roman-Aguirre, M.; Marquez-Lucero, A.; Zaragoza-Contreras, E. Carbohydr. Polym. 2004, 55, 201-210.

(6) Okeke, B.; Obi, S. Bioresour. Technol. 1995, 51, 23-27.

(7) Klemm, D.; Philipp, B.; Heinze, T.; Wagenknecht, W. In Comprehensive Cellulose Chemistry; Wiley-vch: Germany, 1998; Vol. 1, pp 1-6.

(8) Kiran, E.; Pohler, H. Supercritical Fluids 1998, 13, 135-147.

(9) Lee, S.; Koepsel, R.; Morley, W.; Matyjaszewski, K.; Russel, A. Biomacromolecules 2004, 5, 877-882.

(10) Gupta, K. C.; Khandekar, K. Biomacromolecules 2003, 4, 758-765.

(11) Stenzel, M. H.; Davis, T. P.; Fane, A. G. J. Mater. Chem. 2003, 13, 20902097.

(12) Nishioka, N.; Yamaguchi, H.; Kosai, K. J. App. Polym. Sci. 1990, 40, 20072017.

(13) Klemm, D.; Philipp, B.; Heinze, T.; Wagenknecht, W. In Comprehensive Cellulose Chemistry; Wiley-vch: Germany, 1998; Vol. 1, pp 105-118.

(14) Stepanik, T.; Ewing, D.; Whitehouse, R. Radiat. Phys. Chem. 2000, 57, $377-$ 379.

(15) Canche-Escamilla, G.; Cauich-Cupul, J.; Mendizabal, E.; Puig, E.; HerreraFrznco, P. Composites:Part A 1999, 30, 349-359.

(16) Gupta, C.; Sahoo, S. Cellulose 2001, 8, 233-242.

(17) Roy, D.; Guthrie, J. T.; Perrier, S. Macromolecules 2005, 38, 10363-10372.

(18) Klemm, D.; Philipp, B.; Heinze, T.; Wagenknecht, W. In Comprehensive Cellulose Chemistry; Wiley-vch: Germany, 1998; Vol. 1, pp 69-73.

(19) Klemm, D.; Philipp, B.; Heinze, T.; Wagenknecht, W. In Comprehensive Cellulose Chemistry; Wiley-vch: Germany, 1998; Vol. 2, pp 147-161. 
(20) Klemm, D.; Philipp, B.; Heinze, T.; Wagenknecht, W. In Comprehensive Cellulose Chemistry; Wiley-vch: Germany, 1998; Vol. 2, pp 150-160. 
Chapter 2: Historical and theoretical background 


\section{1: Free radical polymerization}

\subsection{1: General}

Free radicals are short-lived atoms or molecules which have one or more unpaired electrons. These unpaired electrons are unstable and highly reactive, and are therefore likely to take part in addition reactions, including polymerization reactions. ${ }^{1}$ Free radical polymerization is one of the most important techniques used for producing polymers; it is commonly used in industry to produce a wide variety of polymers from vinyl monomers. About $50 \%$ of all plastics are made via free radical techniques. ${ }^{2}$ Polystyrene, poly methyl methacrylate and branched polyethylene are examples of polymers made by the free radical polymerization technique. One of the major advantages of free radical polymerization over other polymerization techniques is the relative tolerance to media impurities such as air, water and metal ions. Another advantage of this technique is its compatibility with a broad range of vinyl monomers. ${ }^{2}$ However, free radical polymerization is inherently limited in its ability to synthesise multiblock copolymers, and it produces polymers with a wide molar mass distribution (high polydispersity). It is difficult to control the polymerization stereochemistry in free radical polymerization as the technique produces only atactic or partially syndiotactic polymers, due to the inability of free radical species to retain configuration of the chain end and therefore stereocontrol. ${ }^{3-5}$

For a molecule to break into radicals an amount of energy (bond dissociation energy) must be consumed. The lower the amount of the energy needed to form a free radical, the more stable the free radical will be. ${ }^{6,7}$

$$
\begin{gathered}
\mathrm{CH}_{3}<\mathrm{R}-\mathrm{CH}_{2}<\mathrm{R}_{2}-\mathrm{CH}<\mathrm{R}_{3}-\mathrm{C} \dot{\bullet} \\
\text { Least stable } \longrightarrow \text { Most stable }
\end{gathered}
$$

The reactivity of vinyl monomers in a free radical polymerization reaction depends on the ability of the substituents, $\mathrm{R}$ and $\mathrm{X}$ in Figuer 2.1, to stabilize the propagating radical. For example, in styrene where the substituent $\mathrm{X}$ is $\mathrm{H}$ and $\mathrm{R}$ is a benzene ring, the propagating radical formed on addition will be stable and have low reactivity compared to the vinyl chloride radical where $\mathrm{R}$ is $\mathrm{Cl}$ and $\mathrm{X}$ is $\mathrm{H}$, and as a result the styrene monomer is more 
susceptible to radical addition. Thus different monomers have different radical reactivities and different propagating rate coefficients, depending on the substituent $\mathrm{X}$. The reactivity of derived radicals is the opposite of their respective monomers; the more stable the monomer is, the more reactive the radical will be. ${ }^{8,9}$

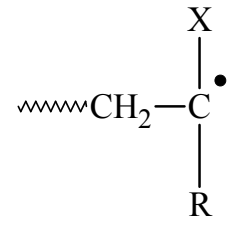

Fig. 2.1: Propagating polymeric radical with substituents $X$ and $R$.

\subsection{2: Free radical kinetics}

Free radical polymerization is generally described in three reaction steps: initiation, propagation and termination.

\section{The initiation step:}

The initiation step is considered to involve two reactions. The first step is the homolytic dissociation of an initiator molecule into one or more radicals (2.1). The second step of the initiation involves the addition of the initiator radical to a single vinyl monomer molecule to form a chain initiating radical (2.2).

$$
\begin{array}{r}
\mathrm{I} \frac{k_{\mathrm{d}}}{\mathrm{h} v, \mathrm{D}}-2 \dot{\mathrm{I}} \\
\mathrm{I}^{\bullet}+\mathrm{M} \stackrel{k_{\mathrm{i}}}{\longrightarrow} \mathrm{R}_{1}
\end{array}
$$

The rate of dissociation of the initiator is described by the following equation:

$$
-\frac{d[\mathrm{I}]}{\mathrm{d}[\mathrm{t}]}=k_{\mathrm{d}}[\mathrm{I}]
$$

Integration of equation (2.3) leads to equation (2.4) which describes the decrease of initiator concentration as a function of time:

$$
[\mathrm{I}]=[\mathrm{I}]_{0} \mathrm{e}^{-k_{\mathrm{d}} \mathrm{t}}
$$


where the initial concentration of the initiator is $[\mathrm{I}],[\mathrm{I}]$ is the concentration of the initiator at time $t$, and $k_{d}$ corresponds to the rate coefficient of initiator decomposition at a specific temperature.

For the case in which two radicals are produced from the decomposition of one initiator molecule (not always the case), the rate of initiation $v_{i}$ is given by:

$$
V_{\mathrm{i}}=2 k_{\mathrm{d}} f[\mathrm{I}]
$$

where the factor $f$ is the initiator efficiency, which gives the efficiency of reactions 2.1 and 2.2.

The efficiency factor is always less than or equal to one. As the viscosity of the reaction medium increases, the diffusion of the radicals away from each other becomes difficult, hence the radicals remain in proximity to each other and recombination can occur. Typically the value of $f$ is between 0.5 and 0.8 and decreases as the reaction viscosity increases until it reaches the limiting value of zero. ${ }^{10}$

Different initiators have different properties. Each has its own unique requirement to decompose and to form a radical. In general, there are four major initiation systems: thermo-initiated, photo-initiated, chemically-initiated (redox), and radiation initiated polymerization. ${ }^{11}$

The most common thermally decomposing initiators are the azo and peroxy-type initiators.

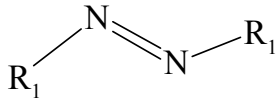

Azo-initiator<smiles>[R]OO[R]</smiles>

Peroxy-initiator

Fig. 2.2: General structures of the azo and peroxy-type initiators.

These compounds are a very versatile source of radicals that are formed after thermal energy is supplied.

A significant property of thermal initiators is the initiator half-life $\left(t_{1 / 2}\right)$, which is temperature dependent.

In photo-initiated free radical polymerization the reaction temperature has almost no effect on the rate of decomposition of most photoinitiators. The rate of decomposition generally depends on the UV light intensity. ${ }^{12}$ 
Photoinitiators decompose upon irradiation with a UV light source. The most commonly used photoinitiators contain a benzoyl group. ${ }^{11}$

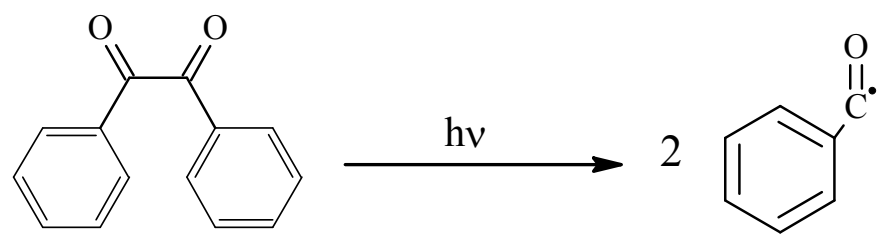

Benzil

Benzoyl radical

\section{Scheme 2.1: Formation of a benzoyl radical.}

In a redox initiation process, free radicals are generated by the reaction between a reducing agent and an oxidizing agent. These free radicals can initiate a free radical polymerization process.

$$
\mathrm{Fe}^{2+}+\mathrm{HO}-\mathrm{OH} \longrightarrow \mathrm{HO}^{\bullet}+\mathrm{HO}^{-}+\mathrm{Fe}^{3+}
$$

\section{Scheme 2.2: A typical redox initiation system.}

Other initiating techniques which are less commonly used include high energy radiation ( $\gamma$-radiation), ultrasonic initiation, plasma initiation and electroinitiation. ${ }^{13}$

Molecular structure, nature of initiators, as well as the solubility of the initiators must be considered when choosing an initiator. The selection of a specific initiator for a particular polymerization system depends on the reaction conditions used in that reaction. ${ }^{12}$

\section{The propagation step:}

After the reaction has been initiated, the propagation reaction takes over. In this step additional monomer units can be sequentially added to the active radicals, generated by the decomposition of initiator, to yield growing propagating polymer chains via the process of electron transfer. In free radical polymerization the entire propagation reaction usually takes place within a fraction of a second. Thousands of monomers are added to the growing chain within this time. The entire propagation process will continue until some termination process occurs. However, the polymerization carries on because the radicals are continuously generated by the dissociation of the initiator, as has been described in equation (2.4). Polymerization continues until it is limited by other factors 
such as the viscosity of the reaction medium or depletion of the monomer and the initiator.

The propagating process is depicted in equation 2.6:

$$
\mathrm{P}_{\mathrm{i}}^{\cdot}+\mathrm{M} \stackrel{k_{\mathrm{p}}}{\longrightarrow} \mathrm{P}_{\mathrm{i}+1}
$$

where $\mathrm{P}_{\mathrm{i}}{ }^{\circ}$ is a polymer radical which includes $\mathrm{i}$ monomer molecules and $k_{\mathrm{p}}$ is the propagation rate coefficient.

The rate of propagation $v_{p}$ is given by equation 2.7 :

$$
V_{\mathrm{p}}=k_{\mathrm{p}}[\mathrm{M}]\left[\mathrm{P}_{\mathrm{i}}^{\cdot}\right]
$$

where $[M]$ is the monomer concentration and $\left[\mathrm{P}_{\mathrm{i}}{ }^{\circ}\right]$ is the concentration of the polymer free radical. The propagation rate coefficient depends on the reaction temperature and the chain length, especially for the first few addition steps, where $k_{p}$ is increased compared to long chain propagation. ${ }^{14,15}$

\section{The termination step:}

Termination refers to any step in which radicals are consumed and no new radicals are produced. Theoretically, in free radical polymerization the chain growth (propagation) should continue until the supply of monomer is exhausted. However, premature chain termination does occur when radicals react in a way that prevents further propagation. ${ }^{16}$ The most common termination reactions are known as coupling (combination) and disproportionation. Another mechanism of termination is chain transfer by hydrogen abstraction from an initiator, monomer, polymer, or solvent molecule. ${ }^{17}$

\section{Coupling (combination) reactions.}

Termination occurs by a coupling reaction of two live polymer chains that react with each other to form a single terminated (dead) polymer chain $\left(P_{n+m}\right)$, of length equal to the sum of the lengths of the live chains.

$$
\stackrel{\mathrm{P}_{\mathrm{n}}}{\cdot}+\mathrm{P}_{\mathrm{m}}^{\cdot} \stackrel{k_{\mathrm{tc}}}{\longrightarrow} \mathrm{P}_{\mathrm{n}+\mathrm{m}}
$$

\section{Scheme 2.3: A coupling termination reaction.}


The rate of termination by coupling is given by:

$$
V_{\mathrm{t}}=k_{\mathrm{tc}}\left[\mathrm{P}^{\bullet}\right]
$$

where $\left(V_{\mathrm{t}}\right)$ is the rate of termination and $k_{t c}$ is the rate constant of termination by coupling.

\section{Disproportionation reactions.}

Termination can occur by a disproportionation reaction in which two radicals meet but, instead of coupling, a proton is exchanged to give two terminated (dead) polymer chains $\mathrm{P}_{\mathrm{n}}$ and $\mathrm{P}_{\mathrm{m}}$. One is saturated and the other has a terminal double bond, each with a length equal to one of the live chains.

$$
\stackrel{\mathrm{P}_{\mathrm{n}}}{\mathrm{P}_{\mathrm{n}} \stackrel{k_{\mathrm{td}}}{\longrightarrow}} \mathrm{P}_{\mathrm{n}}+\mathrm{P}_{\mathrm{m}}
$$

\section{Scheme 2.4: A disproportionation reaction}

The rate of termination is given by:

$$
V_{\mathrm{t}}=k_{\mathrm{td}}\left[\mathrm{P}^{\bullet}\right]^{2}
$$

where $\mathrm{P}_{\mathrm{i}}{ }^{\circ}$ is the free radical concentration and $k_{\mathrm{td}}$ is the termination by disproportionation rate coefficient. For both coupling and disproportionation:

$$
V_{\mathrm{t}}=2 k_{\mathrm{t}}\left[\mathrm{P}^{\bullet}\right]^{2}
$$

where $2 k_{\mathrm{t}}=k_{\mathrm{td}}+k_{\mathrm{tc}}$.

\section{Transfer reactions}

Transfer reactions refer to the processes whereby the active site is transferred to an independent molecule such as a monomer, initiator, polymer or solvent. Chain transfer is not formally a chain terminating reaction because the overall radical concentration is not reduced. ${ }^{18}$ However, it has the tendency to limit the molar mass of polymer chains.

The general transfer constant $\mathrm{C}$ is given by:

$$
\mathrm{C}=\frac{k_{t r}}{\mathrm{k}_{\mathrm{p}}}
$$

where $\mathrm{k}_{\mathrm{tr}}$ is the transfer rate coefficient and $\mathrm{k}_{\mathrm{p}}$ is the propagation rate coefficient.

The transfer constant is the ratio of chain transfer and propagation rate coefficients. 
If the free radical is transferred to a monomer then the original live chain becomes dead and a new chain of length one monomer begins to grow:

$$
\mathrm{P}_{\mathrm{n}}^{\cdot}+\mathrm{M} \stackrel{k_{\mathrm{fm}}}{\longrightarrow} \mathrm{P}_{\mathrm{n}}+\mathrm{P}_{1}^{\cdot}
$$

In a similar reaction, the solvent (S) can serve to transfer a radical:

$$
\mathrm{P}_{\mathrm{n}}^{\cdot}+\mathrm{S} \stackrel{k_{\mathrm{fs}}}{\longrightarrow} \mathrm{P}_{\mathrm{n}}+\mathrm{S}^{\cdot}
$$

A chain transfer agent $T$ can be added to the reactor to enhance radical transfer and thereby reduce the molar mass:

$$
\dot{\mathrm{P}_{\mathrm{n}}}+\mathrm{T} \stackrel{k_{\mathrm{ft}}}{\longrightarrow} \mathrm{P}_{\mathrm{n}}+\mathrm{T}^{\cdot}
$$

The solvent radical $\vec{S}^{\circ}$ or the transfer agent radical $\mathrm{T}^{\circ}$ can initiate a new polymer chain by adding monomer to the radical.

If the chain end radical abstracts an atom from the backbone of another chain, the result is a new radical that can reinitiate to form a branch.

$$
\mathrm{P}_{\mathrm{n}}^{\cdot}+\mathrm{P}_{\mathrm{m}} \stackrel{k_{\mathrm{fp}}}{\longrightarrow} \mathrm{P}_{\mathrm{n}}+\mathrm{P}_{\mathrm{i}} \dot{\mathrm{P}} \mathrm{P}_{\mathrm{j}}
$$

where $1+\mathbf{j}+1=\mathrm{m}$.

If an inhibitor In, such as hydroquinone, is present in the reaction, then the primary radical $R$ will be converted to the unreactive form $\mathrm{Q}$.

$$
\mathrm{R}+\mathrm{In} \stackrel{k_{\text {In }}}{\longrightarrow} \mathrm{Q}
$$

The number average degree of polymerization $D P_{n}$ is given by the Mayo equation: ${ }^{19}$

$$
\frac{l}{\mathrm{DP}_{\mathrm{n}}}=\frac{(1+\lambda)\left(k_{\mathrm{t}}\right)\left[\mathrm{P}^{\circ}\right]}{k_{\mathrm{p}}[\mathrm{M}]}+\mathrm{C}_{\mathrm{m}}+\mathrm{C}_{\mathrm{s}} \frac{[\mathrm{S}]}{[\mathrm{M}]}
$$

where $\lambda$ is the fraction of termination by disproportionation, $k_{t}$ is the average termination rate coefficient, $\left[\mathrm{P}^{\circ}\right]$ is the overall radical concentration, $[\mathrm{M}]$ is the monomer concentration, $\mathrm{C}_{\mathrm{m}}$ is the chain transfer coefficient for chain transfer to monomer and $[\mathrm{S}]$ is the concentration of chain transfer agent in the form of solvent. 


\section{Steady state approximation}

The system is at steady state if the propagating radical concentration becomes essentially constant and the rate at which radicals are created and destroyed is approximately equal, i.e $V_{\mathrm{i}}=V_{\mathrm{t}}$ In this case the rate of propagation, which is derived from equations $2.5,2.8$ and 2.11 , is described by equation 2.13 :

$$
V_{\mathrm{p}}=k_{\mathrm{p}}\left[\frac{f k_{d}[\mathrm{I}]}{\mathrm{k}_{\mathrm{t}}}\right]^{0.5}[M]
$$

Equation 2.14 shows that the polymerization rate in free radical polymerization is proportional to the monomer concentration and to the square root of initiator concentration. Throughout the propagation step where the change in initiator concentration $d[\mathrm{I}] / d \mathrm{t}$ is small, the monomer concentration is given by the following equation:

$$
[M]=[M]_{0} \mathrm{e}^{-k_{\mathrm{p}}}\left[\frac{f k_{d}}{k_{\mathrm{t}}}\right]^{0.5}[I]^{0.5} t
$$

\section{2: Living free radical polymerization (LFRP)}

Living/controlled free radical polymerization processes have drawn significant attention from both the industrial and academic fields. ${ }^{20}$ In the last few years, considerable effort has been expended to develop free radical processes that display the characteristics of living polymerization. ${ }^{21-23}$ This research area has become one of the most rapidly growing areas of polymer chemistry. Through the use of living radical polymerization techniques one is able to maintain the advantages of traditional free radical polymerization, such as being compatible with a wide range of vinyl monomers and insensitive to small trace of impurities, while minimizing the disadvantages such as producing polymers with a wide molar mass distribution. Living free radical polymerization is a viable route to obtain polymers with narrow polydispersity (PDI), ${ }^{21}$ and controlled molar mass under simple reaction conditions. ${ }^{22,23}$

Living radical polymerization also offers control over the chain-ends of the synthesized polymer, and most importantly gives polymer products that can be reactivated for chain extension with either the same or another monomer. This opens the way to the synthesis 
of block copolymers and other more complex architectures. ${ }^{24}$ Thus the preparation of multiblock copolymers becomes facile.

In the past this was only possible by means of living ionic polymerization techniques, ${ }^{25}$ which require stringent reaction conditions such as high vacuum, inert atmosphere, absence of impurities, and was limited to a relatively small number of monomers.

Ideally, living free radical polymerization allows a wide variety of existing as well as totally new polymer systems with accurately known structures to be designed and produced.

Several LFRP techniques have been developed over the past decade and all of them are based either on a reversible termination reaction such as Atom Transfer Radical Polymerization (ATRP) and Nitroxide Mediated Polymerization (NMP) or based on a reversible chain transfer reaction such as Reversible Addition-Fragmentation chain Transfer (RAFT). Chains undergo successive activation/deactivation cycles, where an equilibrium between active species and dormant species is formed, as shown in Scheme 2.3. ${ }^{26}$

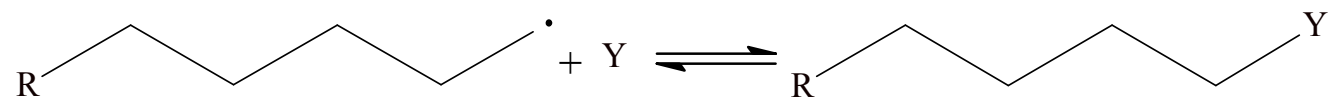

\section{Scheme 2.5: General formation of a dormant species in LFRP}

A very small fraction of chains are active at any one time. During the deactivated period they are end-functionalized by a specific group (trapping species) and they are referred to as dormant.

An important feature of LFRP is that the PDI is narrow. This is because all the chains are given an equal chance to grow. The initiator should be consumed at early stages of polymerization, and the rate of initiation and the rate of exchange between species of various reactivity, should be at least as fast as propagation.

\subsection{1: Atom Transfer Radical Polymerization (ATRP)}

Atom transfer radical polymerization is one of the most efficient controlled radical polymerization systems. It was discovered by Matyjazewski ${ }^{27}$ and Sawamoto ${ }^{28}$ in 1995. Matyjazewski used the term ATRP whereas Sawamoto called the process transition metal catalyzed radical polymerization. This technique is based on the reversible transfer of a 
halogen between a dormant alkyl halide (P-X) and a transition metal catalyst $\left(\mathrm{M}_{\mathrm{t}}{ }^{\mathrm{n}} /\right.$ Ligand) by redox chemistry. ${ }^{29,30}$ The alkyl halide is activated by reduction to the growing radical and the transition metal catalyst is simultaneously oxidized by accepting halogen into its inner coordinating sphere. ${ }^{31-35}$ Polymer chains grow by the addition of the radicals to monomers in a manner similar to conventional free radical polymerization.

The number average degree of polymerization $\left(D P_{\mathrm{n}}\right)$ increases linearly with monomer conversion and can be predicted at any conversion by using equation $2.15 .^{26}$

$$
D P_{\mathrm{n}}=\frac{[\mathrm{M}]_{0}}{[\mathrm{I}]_{0}} \mathrm{x} \text { conversion }
$$

where $[\mathrm{M}]_{0}$ is the initial monomer concentration and $[\mathrm{I}]_{0}$ is the initial initiator concentration. The equilibrium represented in Scheme 2.4 is predominantly shifted to the left (dormant) side so as to suppress termination and transfer reactions.

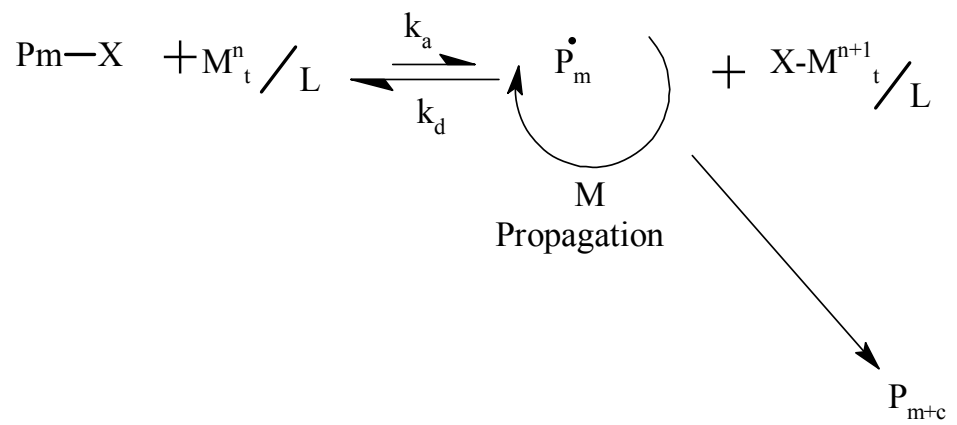

Termination

\section{Scheme 2.6: Activation-deactivation equilibrium in ATRP.}

Here $\mathrm{X}$ represents the halide atom, $\mathrm{M}$ is the metal atom, $\mathrm{L}$ represents the ligands, $P_{\mathrm{m}}{ }^{\circ}$ is the propagating chain and $\mathrm{n}$ is the degree of oxidation of the metal. A successful ATRP will have uniform growth of all the chains, which is achieved by fast initiation and rapid, reversible deactivation. ATRP can be used for a large range of monomers and is tolerant to trace impurities. The metal is however sensitive to other redox reactions. The drawback of ATRP is the need to remove the metal ions in the final product as well as the poor solubility of the initiating systems in certain common polymerization solvents. ${ }^{36}$ 


\subsection{2: Nitroxide Mediated Polymerization (NMP)}

The ability of nitroxide stable radicals to react with carbon centered radicals and to act as radical inhibitors has been known since the beginning of 1980s. ${ }^{30,37}$ However it was only in the 1990s, when Georges et al. ${ }^{31}$ showed the ability of nitroxides to react reversibly with growing polymer chains that, nitroxides became useful to produce polymers with narrow polydispersity. As shown in Scheme 2.5, in NMP reactions an equilibrium exists between the dormant alkoxyamine, on the left, and the nitroxide and carbon centered radical, on the right. Via this equilibrium, the carbon centered radical forms and polymerizes with the monomer units present. This equilibrium lies greatly toward the alkoxyamine, resulting in a low concentration of radicals, and therefore minimizing the termination rate for the polymerization.

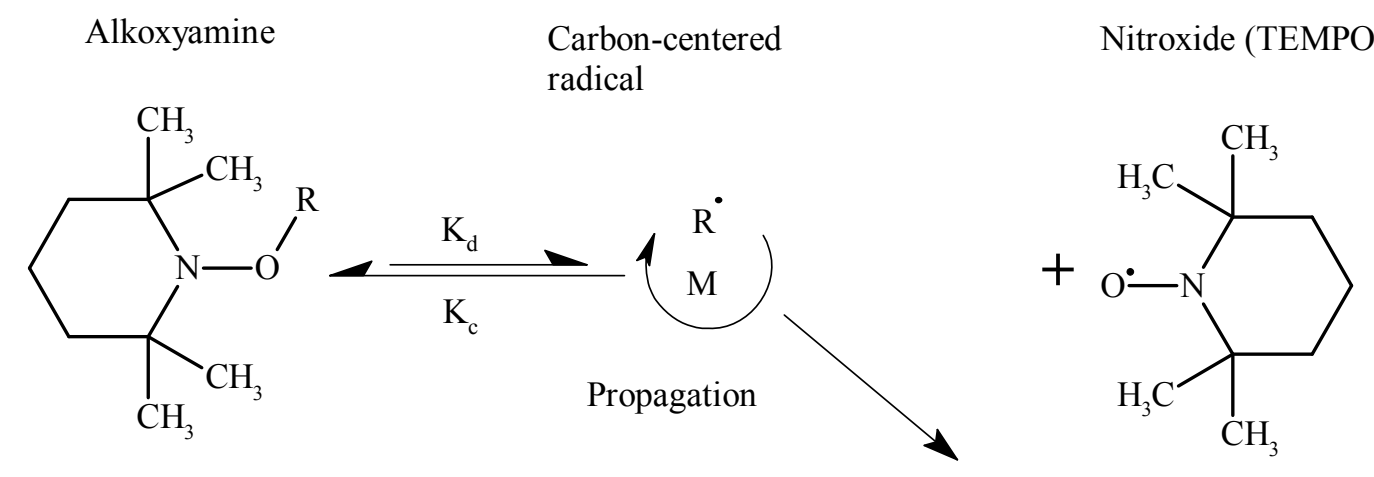

Termination

\section{Scheme 2.7: Schematic representation of the NMP process.}

Some common nitroxide mediators used in NMP are: 2,2,6,6-tetramethyl-1-piperdinyloxy (TEMPO), ${ }^{21,22}$ di-tert-butylnitroxide (DBN) ${ }^{38,39}$ and n-tert-butyl-N-(1-diethylphosphono2,2 dimethylpropyl) nitroxide (DEPN). ${ }^{34,40}$

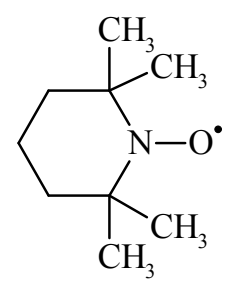

TEMPO<smiles>CC(C)(C)N([O])C(C)(C)C</smiles>

DBN<smiles>CCOP(=O)(OCC)C(NC(C)(C)C)C(C)(C)C</smiles>

EDPN

Fig. 2.3: Examples of nitroxide mediators. 
Among these, TEMPO is by far the most widely used, although it has very limited applicability to monomers other than styrene. Benoit and Hawker et al. ${ }^{35}$ Developed $\alpha$-hydrido alkoxyamines that are a more flexible alternative for NMP. These nitroxides react in much the same way as TEMPO, however, the change in structure alters the equilibrium position (to the right side) and therefore allows for the use of different monomers such as acrylates, and acrylamides, and provides fast rates of reaction. ${ }^{35,37}$ NMP can be successfully used for making block copolymers based on styrene and its derivatives. ${ }^{41}$ A major disadvantage of NMP is that the required optimum temperatures are usually high. The $\mathrm{C}-\mathrm{O}$ bond formed between the nitroxide compound and the propagating radical is relatively stable and a substantial amount of energy is required to break it.

\subsection{3: Reversible Addition-Fragmentation Chain Transfer (RAFT)}

As polymers are beginning to be used in fine biological and medical applications, and becoming more important by the day, it has become increasingly important to have control over the lengths and functionality of the polymer chains. However, when using LFRP techniques the choice of the monomer remains the first problem because some techniques such as NMP cannot be applied to monomers such as methacrylate, and vinyl acetate cannot be polymerized by the use of the ATRP technique. ${ }^{42}$ In 1998 Rizzardo et $\mathrm{al}^{43}$ reported a new controlled free radical polymerization technique that has the distinction of being applicable to a vast range of monomer types; it is based on reversible addition-fragmentation chain transfer, and designated as the RAFT process.

RAFT has become one of the most rapidly developing areas of polymer science. ${ }^{44}$ This can be ascribed to the possibility of its controlling chain length, architecture, composition and functionalities of various polymers and copolymers under conditions similar to those employed in conventional free radical polymerization (monomers, initiators, solvents and temperature).

A RAFT mediated polymerization is usually carried out by the addition of a small quantity of a chain transfer agent (RAFT agent) to a conventional free radical polymerization mixture. RAFT agents are simple organic compounds, possessing the 
thiocarbonyl thio moiety $(\mathrm{S}=\mathrm{C}-\mathrm{S})$ that imparts the living behaviour to free radical polymerization. $^{45}$

The general molecular structure of RAFT agents is illustrated in Figure 2.5, where Z refers to the stabilizing group that governs the reactivity of the $\mathrm{C}=\mathrm{S}$ toward radical addition, and $\mathrm{R}$ refers to the free radical homolytic leaving group that is capable of reinitiating the polymerization.

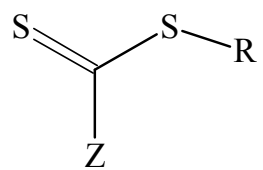

Fig. 2.4: Basic structure of a RAFT agent. ${ }^{45-47}$

There are five classes of the thiocarbonylthio RAFT agents, with different efficiencies, depending on the nature of the $Z$ group: dithioesters ${ }^{48-52}(Z=$ aryl or alkyl), trithiocarbonates $^{46,53-57}\left(Z=\right.$ substituted sulfur), dithiocarbamates ${ }^{45,58}(Z=$ substituted nitrogen), xanthates ${ }^{46,47,58,59}(Z=$ substituted oxygen $)$ and phosphoryl and (thiophosphoryl)dithioformates ${ }^{60,61}(\mathrm{Z}=$ substituted phosphorus).

\subsubsection{1: Important aspects of $Z$ and $R$ groups}

The degree of control exhibited in the RAFT process and the end-functionality of the resulting chains will greatly depend on the structure of the RAFT agent (i.e. R- and Zgroups in the RAFT). The Z-group should be correctly chosen to be capable of stabilizing the intermediate radical and to activate the $\mathrm{C}=\mathrm{S}$ double bond towards the propagating polymeric radical addition in the RAFT polymerization.

It is essential to choose the right Z-group in RAFT mediated polymerization, because different Z-groups have different effects on the rate of radical addition to the $\mathrm{C}=\mathrm{S}$ double bound in the RAFT polymerization. ${ }^{62}$ The chain transfer coefficients decrease in the series where $\mathrm{Z}$ is aryl $>$ alkyl $\sim$ alkylthio $\sim$ pyrrole $>$ amido $>$ alkoxy $>$ dialkylamino. ${ }^{24}$ 
Examples of $\mathrm{Z}$ groups are:

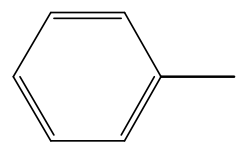

$$
\mathrm{H}_{3} \mathrm{C}-\mathrm{S}-
$$
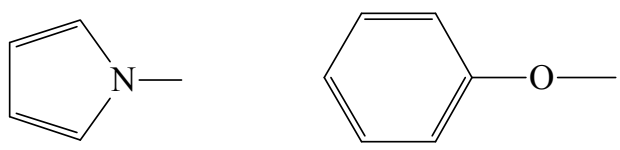<smiles>C=C1CC1</smiles>

Dithioesters

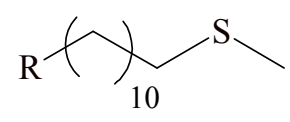

Trithiocarbonates

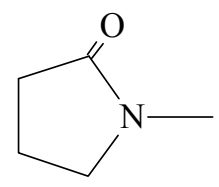

Dithiocarbamates

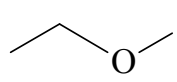

Xanthate

\section{Fig. 2.5: Examples of different RAFT agent Z-groups. ${ }^{24,45}$}

The same consideration must be taken into account with regards to the nature of the R-group on the RAFT agent, which has an effect on the chain transfer constant. ${ }^{63}$ The R-group should be a good free radical leaving group, relative to the radical of the propagating species, and capable of reinitiating polymerization. ${ }^{43,64}$

The $\mathrm{R}$ group must be chosen such that its stability is appropriate to the monomers to be polymerized. An inappropriate choice of the R-group can lead to significant retardation. ${ }^{45,65}$ The leaving group ability decreases in the series $\mathrm{R}=$ tertiary $>$ secondary $>$ primary, because there is a difference in stability of these types of radicals.

Examples of R-groups are:

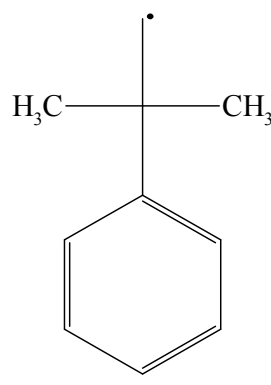

Cumyl

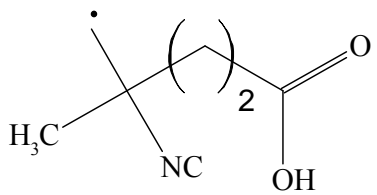

Cyanovaleric acid

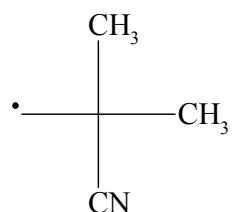

Cyanoisopropyl

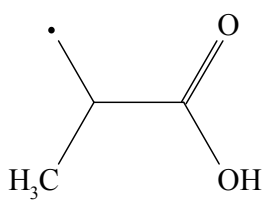

Propionic acid

Fig. 2.6: Examples of different RAFT agent R-groups. ${ }^{45}$ 


\subsubsection{2: Mechanism of RAFT}

Evidence for the RAFT mechanism has been shown using techniques such as Nuclear Magnetic Resonance spectroscopy (NMR), ${ }^{66}$ Ultraviolet spectroscopy (UV-visible) ${ }^{43}$ and Electron Spin Resonance spectroscopy (ESR). ${ }^{67}$ The mechanism is given in Scheme 2.6: Initiation

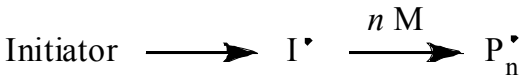

Reversible chain transf er

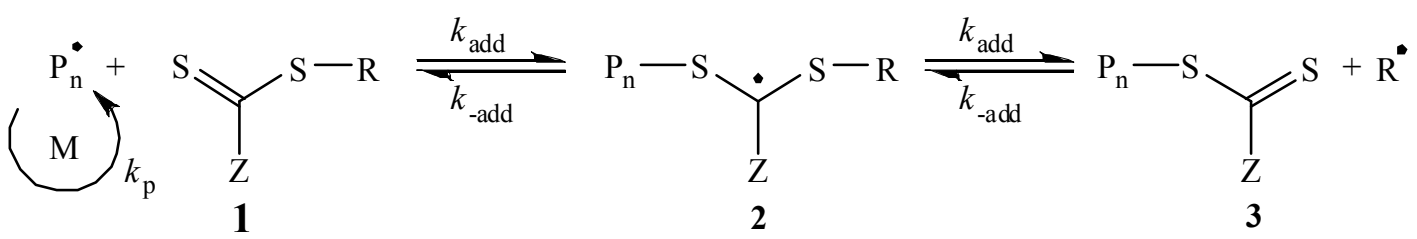

Reinitiation
$\stackrel{\mathrm{R}}{\mathrm{M}} \longrightarrow \stackrel{\mathrm{M}}{\longrightarrow} \stackrel{\mathrm{P}_{\mathrm{m}}}{\longrightarrow}$
$\mathrm{n}, \mathrm{m}=1,2,3 \ldots$..etc

\section{Chain equilibration}

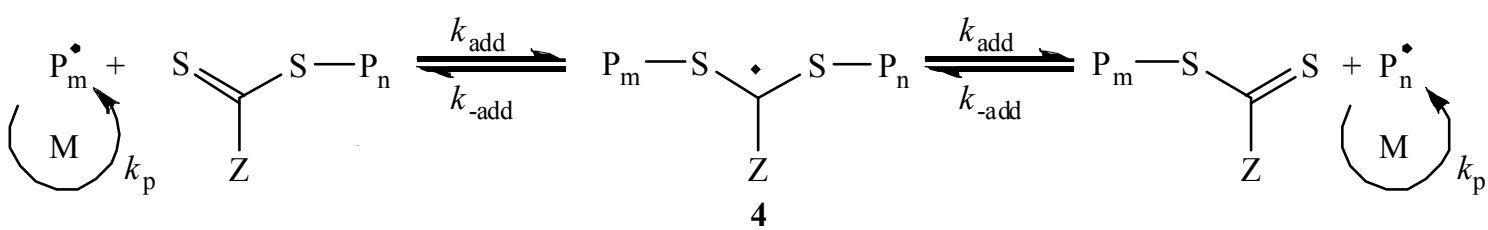

Termination

$\mathrm{P}_{\mathrm{n}}^{*}+\mathrm{P}_{\mathrm{m}}^{\cdot} \longrightarrow$ Dead polymer

\section{Scheme 2.8: Schematic representation of the RAFT polymerization mechanism.}

In conventional free radical polymerization, initiation by the decomposition of an initiator leads to the formation of free radicals which tend to undergo addition to the monomer, to produce propagating radicals $P_{n}{ }^{\circ}$ or react with the $(\mathrm{C}=\mathrm{S})$ double bond of the RAFT agent at a rate similar to or greater than the rate of addition to the monomer. ${ }^{68}$ An intermediate 
radical is formed upon every addition of radical to the RAFT agent. This intermediate radical undergoes fragmentation in either of two ways.

Firstly, it can fragment back to the original radical species and the RAFT agent, or secondly, it can fragment to yield a dormant polymeric thiocarbonylthio compound and an active radical $R^{\circ}$. The radical $R^{\circ}$ will propagate (reinitiate) to form a new polymeric radical $P_{\mathrm{m}}{ }^{\circ}$ and then add again to the RAFT agent, forming an intermediate radical which will then fragment, releasing any one of the dormant polymeric thiocarbonylthio compounds, and the process continues in this manner.

For stepwise growth of polymer chains, the addition of propagating radicals to the $(\mathrm{C}=\mathrm{S})$ double bond in a thiocarbonylthio compound should be fast compared to the rate of propagation. ${ }^{68}$ This provides an equal probability for all chains to grow, leading to living characteristics and narrow polydispersity.

As in all radical polymerizations, some termination always occurs via radical-radical coupling, however, termination is limited in this system by the low concentration of active radicals with respect to the stabilized intermediate radical. ${ }^{43}$

In the RAFT process, when the polymerization is complete, the great majority of the polymer chains contain the thiocarbonylthio moiety as the end group. The latter has been detected by means of ${ }^{1} \mathrm{H}-\mathrm{NMR}$ and UV-visible spectroscopy. ${ }^{43,45}$

One of the characteristics of the RAFT process is that the molar mass is controlled by the stoichiometry of the reaction and it increases in a linear manner with monomer conversion. $56,64,65,67,68$

Molar mass can be predicted theoretically using equation $2.16 .{ }^{69}$

$$
M_{\mathrm{n}, \text { theory }}=\frac{\mathrm{x}[M]_{0}}{[\mathrm{RAFT}]_{0}} M W_{M}+M W_{R A F T}
$$

where $[\mathrm{M}]_{0}$ and $[\mathrm{RAFT}]_{0}$ are the initial concentrations of the monomer and the RAFT agent respectively, $\mathrm{MW}_{\mathrm{M}}$ and $\mathrm{MW}_{\mathrm{RAFT}}$ are the molar masses of the monomer and the RAFT agent respectively, $\mathrm{x}$ is the fractional conversion and $M_{\mathrm{n}, \text { theory }}$ is the theoretical number average molar mass of the formed polymer. 


\subsubsection{3: Xanthates}

Xanthates (MADIX agents) are an important class of RAFT agent. They were first discovered by Rhodia, ${ }^{70}$ who patented their discovery in 1998. This approach was named MADIX $^{44,71}$ (Macromolecular Design via Interchange of Xanthates) which is a terminology used to describe the xanthate process. It is based on free radical degenerative transfer promoted by dithiocarbonate groups.

Xanthates are inexpensive organic compounds which are easy to synthesize in comparison to dithioesters. They are used in a variety of commercial processes, including, for example, the manufacture of Rayon ${ }^{\circledR}$, cellulose films and textiles. ${ }^{72}$ They can also be used to control the free radical polymerization of a wide range of vinylic monomers, including styrenics, acrylates and vinyl esters.

Vinyl acetate (VAc) is one of the most representative monomers that can be polymerized only via a radical mechanism; ${ }^{73}$ however, it is a typical example of a monomer that cannot easily be polymerized using NMP or ATRP. ${ }^{74}$ Vinyl acetate is a very important monomer and its polymers are used in applications ranging from adhesives, paints, concrete additives, to pharmaceuticals. Therefore polymerizing vinyl acetate in a controlled manner is extremely desirable. ${ }^{74,75}$

Wakiota et $\mathrm{al}^{73}$ succeeded in controlling the polymerization of vinyl acetate by using an iron (I) complex. There has been limited success to effecting a living polymerization of vinyl acetate using the RAFT process. For example, Destarac et al. ${ }^{76}$ used dithiocarbamates as RAFT agents, whereas the Commonwealth Scientific and Industrial Research Organization (CSIRO) group also used xanthates. ${ }^{77}$ In contrast to the dithioesters, xanthate agents have low chain transfer constants in the polymerization of some monomers such as styrene and methyl methacrylate. ${ }^{44,46,69,78}$ 


\section{3: Free radical copolymerization}

Free radical copolymerization is of great interest with regard to the increasing need for new polymeric materials bearing properties for use in specific applications. ${ }^{79,80}$ Copolymerization is one of the most common methods to make new polymers with unique properties from existing monomers. It allows the formulation of polymer materials with the combined properties characteristic of two different polymers. Copolymers can be classified into four types: statistical, alternating, block and graft. ${ }^{81}$ This classification depends on the distribution of the monomers (A, B) within a copolymer, and is described as follows:

- Statistical (random) copolymers contain two monomers that are randomly distributed.

$$
\text { A-B-B-A-B-A-A-B-A-B-A-B-B-A-A-A-B-B-A-B-A }
$$

- Alternating copolymers contain two monomers that are arranged in alternating fashion.

$$
\text { A-B-A-B-A-B-A-B-A-B-A-B-A-B-A-B-A-B-A }
$$

- Block copolymers contain a long sequence (blocks) of the same monomer unit. The blocks can be connected in different ways, such as AB diblock or ABA triblock.

$$
\text { A-A-A-A-A-A-B-B-B-B-B-B A-A-(A)-A-B-(B) }
$$

- Graft copolymers are a linear chain of one type of monomer structure and one or more side chains that consist of linear chains of another monomer structure.

\subsection{1: Graft copolymers}

Graft copolymers are similar to block copolymers in that they possess long sequences of monomer units. However, graft copolymer architecture differs substantially from that of typical block copolymers. In graft copolymers, monomer sequences are grafted or attached to points along a main polymer chain. The chemical natures and composition of the branches and the backbone differ in most cases. ${ }^{82}$ Grafted chains (branches) generally possess molar masses that are less than the main chain (backbone). The simplest case of a graft copolymer can be represented by Figure 2.8, where sequence A represents the main polymer chain or the backbone, sequence $\mathrm{B}$ is the grafted or the side chain, and $\mathrm{X}$ is the unit in the backbone where the graft is attached. 


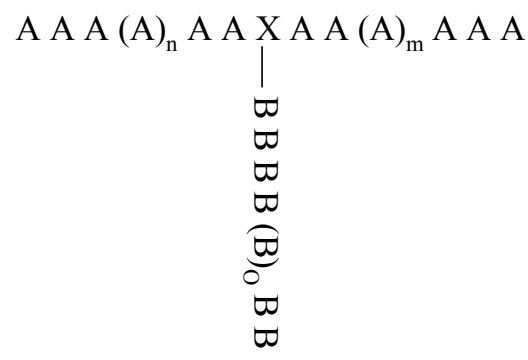

\section{Scheme 2.9: General structure of a simple graft copolymer.}

Graft copolymers can be synthesized by three basic methods:

\subsubsection{1: "Grafting from" method}

In the "grafting from" method, after the synthesis of the backbone, active sites are formed along the backbone. These active sites must be able to initiate the polymerization of the second monomer. As a result of polymerization of the second monomer, branches and the final graft copolymer are formed. The number of the branches can be controlled by the number of the active sites formed along the backbone. In certain cases cleavage of the formed branches can be carried out in order to facilitate characterization. ${ }^{82}$

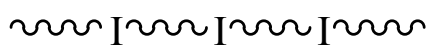

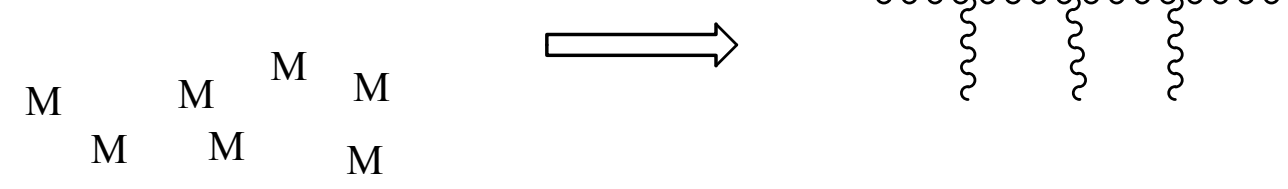

\section{Scheme 2.10: The "grafting from" method.}

\subsubsection{2: "Grafting through" method}

The "grafting through" method is also known as the macromonomer method, as it entails the preparation of macromonomers, which are oligomeric or polymeric chains that have polymerizable functional end groups. These macromonomers are copolymerized with other monomers in order to yield graft copolymers. The ratio of the molar concentrations of the comonomers and their reactivities control the number of branches per backbone. Different methods can been used to synthesize macromonomers, such as ATRP, addition-fragmentation techniques and standard organic routes. ${ }^{82}$ 


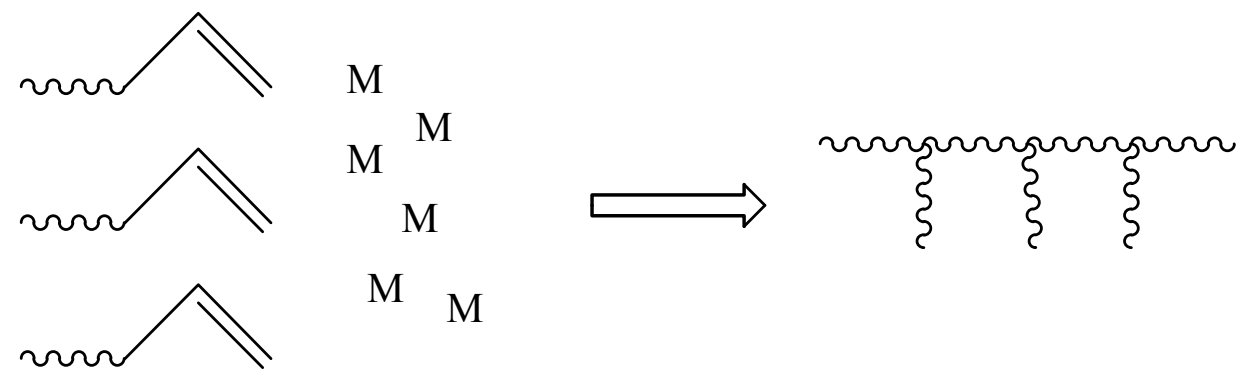

Scheme 2.11: The "grafting through" method.

\subsubsection{3: "Grafting onto" method}

In the "grafting onto" method the backbone and the arms are prepared separately. The backbone carries functional groups (e.g. $-\mathrm{OH})$ distributed along the chain. Through the reaction of these functional groups with the functional groups (e.g. $-\mathrm{COOH})$ on the prepared side chain or living branches the actual grafting process occurs. The characterization of both branches and backbone can be done separately before the actual grafting occurs. ${ }^{82}$

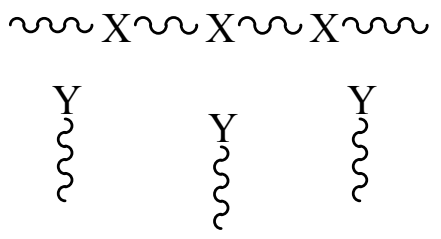

Scheme 2.12: The "grafting onto" method. 


\section{4: Cellulose}

Cellulose is one of the most abundant naturally occurring organic compounds on earth. It is the main component of higher plant cell walls, and it is also produced by some algae, fungi and bacteria. ${ }^{83-86}$ Cellulose is a polysaccharide made up of D-glucose units joined through 1-4 $\beta$-linkages in a linear chain formation.

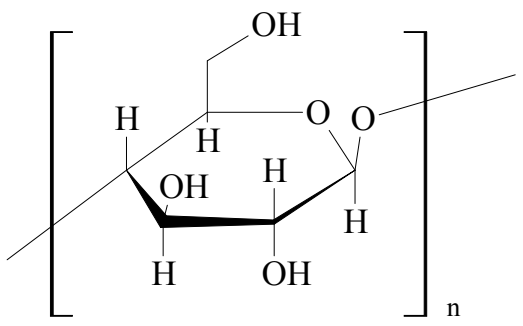

Fig. 2.7: General structure of cellulose.

The degree of polymerization (DP) of cellulose is normally designated as the number of anhydroglucose units (AGUs) in the chain. For each anhydroglucose unit there are three hydroxyl groups (OH groups) which provide reactive centers where chemical reactions can take place and allow the cellulose to be modified for different purposes.

Cellulose molecules in their native state form long chains in polycrystalline fibrous bundles that possess highly crystalline as well as amorphous regions. Cellulose is incapable of flowing on heating, it degrades before it can melt because the crystalline melting point of cellulose is far above its decomposition temperature. Thus cellulose can not be easily converted into products. ${ }^{87}$

The regular spacing of hydroxyl groups, particularly in the crystalline region, facilitates extensive hydrogen bonding and results in high intermolecular forces. Thus, cellulose does not dissolve in water and most ordinary organic solvents, and it cannot be easily converted into products. ${ }^{88}$ However, cellulose does swell in hydrogen bonding solvents, including water. The swelling is restricted to the amorphous region of the structure.

Free radical polymerization techniques have been used for the synthesis of cellulosic graft copolymers. Cellulose represents one of the most important renewable sources of raw materials in the world. ${ }^{83-85,89}$ However the polar nature of cellulose makes its interaction with low polar polymers difficult. Grafting of synthetic polymeric chains is one of the most recurrently used methods to increase the compatibility between cellulose 
and a variety of synthetic polymers. ${ }^{89,90}$ The synthesis of cellulosic graft copolymers with tailored surface properties is of great interest due to the wide range of application of such materials. For instance, graft copolymers can be used as antibacterial surfaces, ${ }^{91}$ thermoresponsive smart materials, ${ }^{92}$ membrane materials, ${ }^{90,93}$ controlled drug-delivery vehicles, ${ }^{94,95}$ reinforcing agents in composite materials and ion-exchange materials. ${ }^{94}$

In conventional free radical polymerization methods, free radical sites are produced along the cellulose backbone either by chemical means or by radiation. ${ }^{96,97}$ In the presence of vinyl monomers the polymeric chains grow from these radical sites through "grafting from" approach. The major drawbacks ${ }^{97-99}$ of these methods include the following: the chain degradation of the cellulose backbone during the formation of free radical grafting sites, the presence of a considerable amount of ungrafted material in the product, little control over the grafting process in terms of yield and the molar mass of the graft copolymers, and the preparation of grafted block copolymers is almost impossible due to unreactive end groups of the polymeric chains.

Living polymerization methods such as RAFT could be useful attractive alternatives to overcome some of the above-mentioned drawbacks of conventional free radical polymerization systems. The RAFT technique permits the synthesis of well-defined cellulosic graft copolymers of predetermined molar mass, thus giving the opportunity to tailor the surface properties of the cellulose toward the required properties. In the present study RAFT polymerization was used to control the grafting of vinyl acetate onto cellulosic materials.

\subsection{1: Cellulose ethers}

Cellulose can be converted into useful derivatives by etherification via the hydroxyl groups on the backbone. ${ }^{100}$ The average number of hydroxyl groups substituted per AGUs is known as the degree of substitution (DS). There are many possible ways to make cellulose ethers. In general, purified cellulose is converted to "alkali cellulose" and then reacted with an etherifying reagent such as propylene oxide $\left(\mathrm{CH}_{2} \mathrm{CHCH}_{3} \mathrm{O}\right)$ or methyl chloride $\left(\mathrm{CH}_{3} \mathrm{Cl}\right)$ to form hydroxypropyl cellulose and methyl cellulose respectively, as shown in Scheme 2.11. 

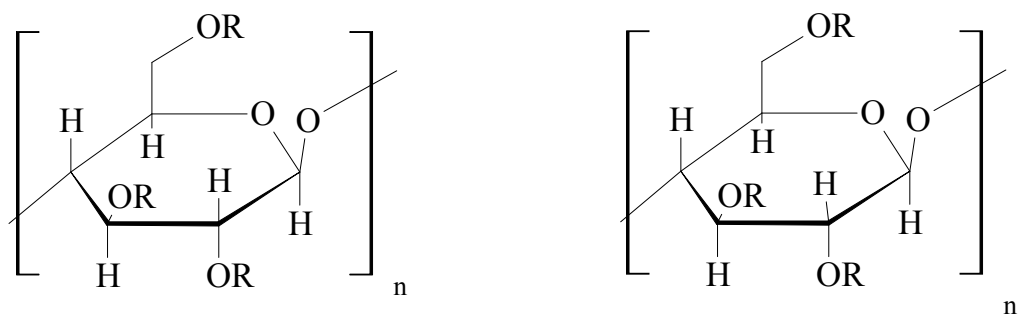<smiles>[R][CH]C(C)O</smiles>

Hydroxypropyl cellulose

Methyl cellulose

Fig. 2.8: General structure of hydroxypropyl cellulose and methyl cellulose.

A simplified general scheme for the preparation of cellulose ethers is presented in Scheme 2.12:

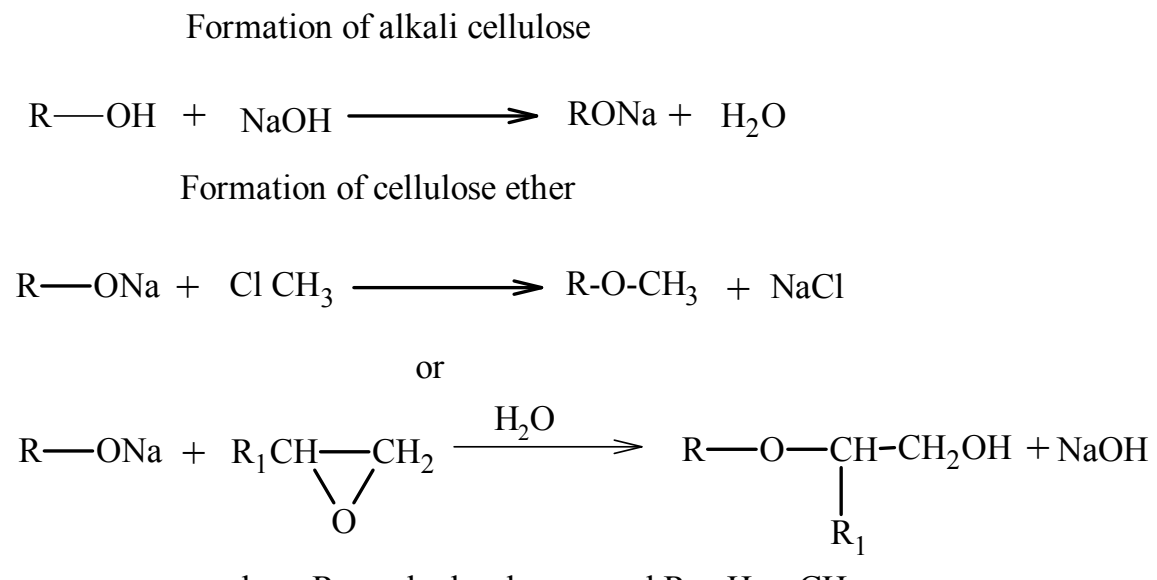

where $\mathrm{R}=$ anhydroglucose and $\mathrm{R}_{1}=\mathrm{H}$ or $\mathrm{CH}_{3}$

\section{Scheme 2.13: Steps in the synthesis of cellulose ethers.}

During the preparation of alkali cellulose with concentrated sodium or potassium hydroxide, and subsequent etherification, the crystalline regions are usually extensively lost due to the disruption of the intermolecular hydrogen bonding. Cellulose ethers have a lower degree of polymerization than cellulose and they are less crystalline. High molecular weight cellulose ethers are insoluble in water. As the degree of substitution increases the polymer goes through a stage of solubility in dilute alkali, then through a water soluble stage and finally through an organic soluble stage. ${ }^{101}$ 


\subsection{2: The viscose process}

The viscose method is used to convert insoluble cellulose fibers into regenerated fibers and films used for packaging and casings, as well as to produce viscose silk Rayon ${ }^{\circledR}$. In the first step in the production of regenerated cellulose, purified cellulose, usually obtained from pulp, is steeped in an aqueous solution of sodium hydroxide (18\%) at room temperature, which causes the fibers to swell and converts the cellulose to alkali cellulose. The excess alkali is then pressed out and the mass is shredded into crumbs to provide sufficient surface area for uniform reaction in the subsequent steps. The alkali cellulose is aged for several days at room temperature to depolymerize the cellulose by oxidation to a suitable degree of polymerization. The alkali cellulose is then converted to cellulose xanthate by the addition of carbon disulfide $\left(\mathrm{CS}_{2}\right)$. The cellulose xanthate, which is in the form of yellow to orange crumbs, is dissolved in dilute sodium hydroxide to yield a viscose orange coloured solution (with a highly unpleasant odour). The color and odour are due to products of side reactions such as $\mathrm{Na}_{2} \mathrm{CS}_{3}, \mathrm{NaSH}, \mathrm{H}_{2} \mathrm{~S}$ and polysulfide. The solution is filtered and allowed to ripen for a few days to the desired coagulation point. The viscose solution is then spun or extruded through very small holes of a spinneret into a spin bath consisting of sulphuric acid and sodium sulphate which converts cellulose xanthate into viscose form to regenerated cellulose in the desired solid form. ${ }^{88,102,103}$

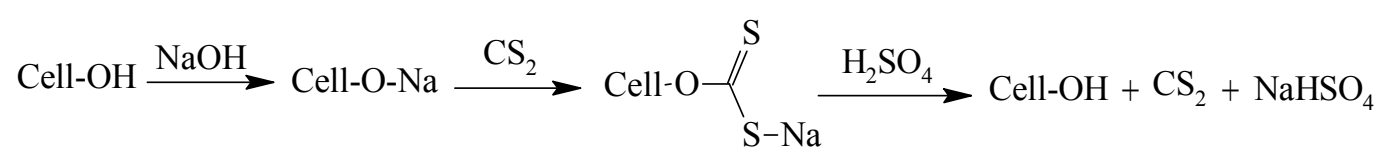

\section{Scheme 2.14: Schematic representation of the viscose process.}

The ordering of the chains in regenerated cellulose is not as great as in native cellulose. The differences in density, stiffness and strength between regenerated cellulose and native cellulose are due to the differences in chain length, chain length distribution, crystal structure, degree of crystallinity, crystal size, degree of swelling, and chemical reactivity. ${ }^{103}$

The properties of cellulosic materials (pulp, regenerated cellulose, cellulose derivatives) can be dramatically changed by graft copolymerization. ${ }^{104}$ Grafting of synthetic polymeric chains with cellulosic materials is one of the most useful methods to combine 
synthetic and natural polymers. A wide variety of monomers, either hydrophobic or hydrophilic, can be graft-polymerized with cellulose. ${ }^{89}$

The properties of these modified polymers (regenerated cellulose, cellulose derivatives and graft cellulose copolymers) depend on several parameters, such as the type of substitution, degree of substitution, molar mass, molar mass distribution and chemical composition distribution. ${ }^{100}$ Consequently there is a need for various analytical methods for the characterization of these parameters.

\title{
2.5: Characterization and separation techniques
}

Modern polymeric materials are designed to meet the needs of specific applications, therefore most polymers are highly complex multi-component materials. They consist of molecules varying in chain length, chemical composition and architecture. The structure complexity of synthetic polymers is due to the distribution, in more than one direction of molecular heterogeneity, which means different aspects of molar mass distribution, (MMD), chemical composition distribution (CCD), molecular architecture distribution (MAD) and functionality type distribution (FTD), as illustrated in Figure 2.9. ${ }^{105}$

\author{
Molar mass Distribution \\ A-A-A-A A-A-A-A-A-A-A-A \\ Chemical Composition Distribution \\ A-B-A-A-B-A A-B-B-B-A A-A-A-B-A-A \\ Functionality Type Distribution \\ C-A-A-A-C C-A-A-A-D D-A-A-A-D
}

\section{Fig. 2.9: Representation of chemical inhomogeneities in polymers $A$ and $B$.}

During the past 30 years a number of organic chemistry techniques have been discovered and applied to polymer analysis. High-performance liquid chromatography has become one of the most powerful analytical techniques. The term HPLC was coined to describe the separation of molecules by a liquid (mobile phase) at high pressure in a stainless steel column filled with a matrix (stationary phase). ${ }^{106}$ Using size-exclusion chromatography SEC, liquid adsorption chromatography (LAC) or liquid chromatography at the critical point of adsorption (LC-CC), polymers can be fractionated with respect to different 
aspects of molecular heterogeneity. ${ }^{107} \mathrm{~A}$ minimum of two different characterization methods must be used for complete analysis of complex polymers, where each method is sensitive towards a specific type of heterogeneity. Another method is to couple different chromatographic modes in two-dimensional chromatography, or the coupling of each technique with a selective detector. ${ }^{108}$

\subsection{1: Size Exclusion Chromatography (SEC)}

Molar mass and molar mass distribution (MMD) of polymers are mostly determined by size-exclusion chromatography. However, due to the rapid development of new types of polymers, e.g. random, block, graft, branched, etc., liquid chromatography in the size exclusion mode on its own is inadequate for the characterization of such complex polymers. Size-exclusion chromatography is not able to separate polymers if they have the same hydrodynamic volume but with different chemical compositions. In this case, complementary techniques such as gradient elution liquid chromatography (GE-LC) and two-dimensional liquid chromatography (2D-LC) are more suitable. ${ }^{107}$

\subsection{2: Gradient Elution Liquid Chromatography (GE-LC)}

Gradient elution liquid chromatography was first used for the separation and characterization of complex polymers and low molecular weight polymers (oligomers), as reported in 1978 by Boiemond and Van der Maeden. ${ }^{109}$ In gradient elution, the activity of the stationary phase can be changed in a suitable manner which offers a useful option for the analysis of different mixtures of molecules. Gradient elution (called the solvent gradient) involves the continuous variation of the composition of the eluting medium during a chromatographic run. The polymer is dissolved in a solvent which dissolves the polymer completely. This solution is injected into a chromatographic system under a thermodynamically poor conditions (weak solvent), and complete retention of the polymer occurs on the top of the column.

During gradient elution the solvent strength of the mobile phase increases from that of the weak solvent, which leads to gradual dissolution of the polymer. When the strength of the mobile phase is great enough the polymer starts to elute, and the separation occurs. Retention is influenced by solubility effects, size exclusion and interaction between the 
polymer and the column. Solubility and interaction depend on both molar mass and chemical composition. ${ }^{106}$

\subsection{3: Two-Dimensional Liquid Chromatography (2D-LC)}

For complex polymers, disperse in more than one compositional feature, a combination of separation methods must be used to completely unravel their structures. Only in specific cases does a combination of mechanisms in one separation step allow a separation with respect to more than one feature. Ideally, the separation methods of the combination are completely independent; each separation technique responds to only one specific molecular characteristic, such as chemical composition or hydrodynamic volume. ${ }^{107,110}$

2D-LC is one of the most powerful methods for characterizing complex polymers in different coordinates of molecular heterogeneity. An excellent example of twodimensional liquid chromatography involves the combination of HPLC and SEC, where separations in diverging directions are combined. In most cases HLPC is used as the first separation step with regard to chemical composition, followed by SEC which is sensitive towards hydrodynamic volume. The combination of gradient HPLC with SEC gives qualitative information on CCD and MMD, while coupling LC-CC and SEC is useful for the analysis of functional homopolymers and block copolymers in the coordinates FTDMMD and CCD-MMD, respectively. ${ }^{107}$ 


\section{6: References}

(1) Morrison, R.; Boyd, R. In Organic Chemistry, Third edition ed.; Allyn and Bacon: New York pp 46-50.

(2) Hong, K.; Zhang, H.; Mays, J. W.; Visser, A. E.; Brazel, S.; Holbrey, D.; Reichert, W. M.; Rogers, R. D. Chem. Comm. 2002, 1368-1369.

(3) Isobe, Y.; Fujioka, D.; Habaue, S.; Okamoto, Y. J. Am. Chem. Soc. 2001, 123, 7180-7181.

(4) Ray, B.; Isobe, Y.; Morioka, K.; Habaue, S.; Okamoto, Y.; Kamigaito, M.; Sawamoto, M. Macromolecules 2003, 36, 543-545.

(5) Matyjaszewski, K.; Davis, T. P. In Handbook of Radical Polymerization; John Wiley and Sons, Inc.: Canada, 2002; pp 691-698.

(6) Morrison, R.; Boyd, R. In Organic Chemistry, Third edition ed.; Allyn and Bacon: New York pp 20-21.

(7) Morrison, R.; Boyd, R. In Organic Chemistry, Third edition ed.; Allyn and Bacon: New York pp 102-104.

(8) Beuermann, S.; Buback, M. Prog. Polym. Sci. 2002, 27, 191-254.

(9) Matyjaszewski, K.; Davis, T. P. In Handbook of Radical Polymerization; John Wiley and Sons, Inc.: Canada, 2002; pp 3-4.

(10) Matyjaszewski, K.; Davis, T. P. In Handbook of Radical Polymerization; John Wiley and Sons, Inc.: Canada, 2002; pp 188-191.

(11) Bai, R.-K.; You, Y.-Z.; Pan, C.-Y. Macromol. Rapid Comm. 2001, 22, 315-319.

(12) Matyjaszewski, K.; Davis, T. P. In Handbook of Radical Polymerization; John Wiley and Sons, Inc.: Canada, 2002; pp 190-196.

(13) Sandler, S.; Karo, W. In Polymer Syntheses, Second edition ed.; Wasserman, H., Ed.; Academic Press, Inc.: London, 1992; Vol. I, pp 547-576.

(14) Matyjaszewski, K.; Davis, T. P. In Handbook of Radical Polymerization; John Wiley and Sons, Inc.: Canada, 2002; pp 196-197.

(15) Olaj, O. F.; Vana, P.; Zoder, M. Macromolecules 2002, 35, 1208-1214.

(16) Solomon, D.; Moad, G. In The chemistry of free radical polymerization; Elsevier Science Ltd., 1995; p 207. 
(17) Matyjaszewski, K.; Davis, T. P. In Handbook of Radical Polymerization; John Wiley and Sons, Inc.: Canada, 2002; pp 200-207.

(18) Shipp, A.; Devon, S. J. Macromol. Sci. 2005, 45, 171-194.

(19) Heuts, J. P. A.; Davis, T. P.; Russell, G. T. Macromolecules 1999, 32, 60196030.

(20) Matyjaszewski, K.; Davis, T. P. In Handbook of Radical Polymerization; John Wiley and Sons, Inc.: Canada, 2002; pp 407-412.

(21) Pradel, J. L.; Boutevin, B.; Ameduri, B. J. Polym. Sci. Part A: Polym Chem 2000, 38, 3293-3302.

(22) Miura, Y.; Nakamura, N.; Taninguchi, I. Macromolecules 2001, 34, 447-455.

(23) de Brouwer, H.; Schellekens, M. A. J.; Klumperman, B.; Monteiro, M. J.; German, A. L. J. Polym. Sci. Part A: Polym Chem 2000, 38, 3596-3603.

(24) Moad, G.; Chiefari, J.; Chong, B. Y.; Krstina, J.; Mayadunne, R. T.; Postma, A.; Rizzardo, E.; Thang, S. H. Polym. Int. 2000, 49, 993-1001.

(25) Moad, G.; Solomon, D. In The Chemistry of Radical Polymerization, Second ed.; Elsevier Ltd: London, 2006; pp 451-470.

(26) Matyjaszewski, K.; Davis, T. P. In Handbook of Radical Polymerization; John Wiley and Sons, Inc.: Canada, 2002; pp 363-366.

(27) Wang, J.-S.; Matyjaszewski, K. J. Am. Chem. Soc. 1995, 117, 5614-5615.

(28) Kato, M.; Kamigaito, M.; Sawamoto, M.; Higashimura, T. Macromolecules 1995, 28, 1721-1723.

(29) Percec, V.; Barboiu, B.; Kim, H.-J. J. Am. Chem. Soc. 1998, 120, 305-316.

(30) Moad, G.; Rizzardo, E.; Solomon, D. H. Macromolecules 1982, 15, 909-914.

(31) Georges, M. K.; Veregin, R. P. N.; Kazmaier, P. M.; Hamer, G. K. Macromolecules 1993, 26, 2987-2988.

(32) Bon, S. A. F.; Bosveld, M.; Klumperman, B.; German, A. L. Macromolecules 1997, 30, 324-326.

(33) Marestin, C.; Noel, C.; Guyot, A.; Claverie, J. Macromolecules 1998, 31, 40414044.

(34) Farcet, C.; Lansalot, M.; Charleux, B.; Pirri, R.; Vairon, J.-P. Macromolecules 2000, 33, 8559-8570. 
(35) Hawker, C. J.; Bosman, A. W.; Harth, E. Chem. Rev. 2001, 101, 3661-3688.

(36) Matyjaszewski, K.; Xia, J. Chem. Rev. 2001, 101, 2921-2990.

(37) Matyjaszewski, K.; Davis, T. P. In Handbook of Radical Polymerization; John Wiley and Sons, Inc.: Canada, 2002; pp 477-484.

(38) Greszta, D.; Matyjaszewski, K. Macromolecules 1996, 29, 7661-7670.

(39) Jousset, S.; Hammouch, S.; Catala, O. Macromolecules 1997, 30, 6685-6687.

(40) Matyjaszewski, K.; Davis, T. P. In Handbook of Radical Polymerization; John Wiley and Sons, Inc.: Canada, 2002; pp 422-425.

(41) Yoshida, E.; Ishizone, T.; Hirao, A.; Nakaharna, S.; Takataj, T.; Endoj, T. Macromolecules 1994, 27, 3119-3124.

(42) Shim, S. E.; Jung, H.; Lee, H.; Biswas, J.; Choe, S. Polymer 2003, 44, 55635572.

(43) Chiefari, J.; Chong, Y. K. B.; Ercole, F.; Krstina, J.; Jeffery, J.; Le, T. P. T.; Mayadunne, R. T. A.; Meijs, G. F.; Moad, C. L.; Moad, G.; Rizzardo, E.; Thang, S. H. Macromolecules 1998, 31, 5559-5562.

(44) Adamy, M.; Van Herk, A. M.; Destarac, M.; Monteiro, M. J. Macromolecules 2003, 36, 2293-2301.

(45) Matyjaszewski, K.; Davis, T. P. In Handbook of Radical Polymerization; John Wiley and Sons, Inc.: Canada, 2002; pp 661-668.

(46) Smulders, W.; Gilbert, R. G.; Monteiro, M. J. Macromolecules 2003, 36, 43094318 .

(47) Bouhadir, G.; Legrand, N.; Quiclet-Sire, B.; Zard, S. Z. Tetrahedron Lett. 1999, 40, 277-280.

(48) Tonge, M. P.; McLeary, J. B.; Vosloo, J. J.; Sanderson, R. D. Macromol. Symp. 2003, 193, 289-304.

(49) Barner, L.; Quinn, J. F.; Barner-Kowollik, C.; Vana, P.; Davis, T. P. Eur. Polym. J. 2003, 39, 449-459.

(50) Perrier, S.; Davis, T. P.; Carmichael, A. J.; Haddleton, D. M. Eur. Polym. J. 2003, 39, 417-422.

(51) Prescott, S. W.; Ballard, M. J.; Rizzardo, E.; Gilbert, R. G. Macromolecules 2002, 35, 5417-5425. 
(52) Severac, R.; Lacroix-Desmazes, P.; Boutevin, B. Polym. Int. 2002, 51, 1117 1122.

(53) Degani, I.; Fochi, R.; Gatti, A.; Regondi, V. Synthesis 1986, 894-899.

(54) Stenzel, M. H.; Davis, T. P. J. Polym. Sci. Part A: Polym Chem 2002, 40, 44984512.

(55) You, Y.-Z.; Chun-Yan, H.; Bai, R.-K.; Pan, C.-Y.; Wang, J. Macromol. Chem. Phys. 2002, 203, 477-483.

(56) Mayadunne, R. T. A.; Rizzardo, E.; Chiefari, J.; Krstina, J.; Moad, G.; Postma, A.; Thang, S. H. Macromolecules 2000, 33, 243-245.

(57) You, Y.-Z.; Bai, R.-K.; Pan, C.-Y. Macromol. Chem. Phys. 2001, 202, 19801985.

(58) Thang, S. H.; Chong, Y. K. B.; Mayadunne, R. T. A.; Moad, G.; Rizzardo, E. Tetrahedron Lett. 1999, 40, 2435-2438.

(59) Quiclet-Sire, B.; Wilczewska, A.; Zard, S. Z. Tetrahedron Lett. 2000, 41, 56735677.

(60) Laus, M.; Papa, R.; Sparnacci, K.; Alberti, A.; Benaglia, M.; Macciantelli, D. Macromolecules 2001, 34, 7269-7275.

(61) Alberti, A.; Benaglia, M.; Laus, M.; Macciantelli, D.; Sparnacci, K. Macromolecules 2003, 36, 736-740.

(62) Chiefari, J.; Mayadunne, R. T. A.; Moad, C. L.; Moad, G.; Rizzardo, E.; Postma, A.; Skidmore, M. A.; Thang, S. H. Macromolecules 2003, 36, 22732282.

(63) Chong, Y. K. B.; Krstina, J.; Le, T. P. T.; Moad, G.; Postma, A.; Rizzardo, E.; Thang, S. H. Macromolecules 2003, 36, 2256-2272.

(64) Chong, B. Y. K.; Le, T. P. T.; Moad, G.; Rizzardo, E.; Thang, S. H. Macromolecules 1999, 32, 2071-2074.

(65) Vana, P.; Davis, T. P.; Barner-Kowollik, C. Macromol. Theory Simul. 2002, 11, 823-835.

(66) McLeary, J. B.; Calitz, F. M.; McKenzie, J. M.; Tonge, M. P.; Sanderson, R. D.; Klumperman, B. Macromolecules 2004, 37, 2383-2394.

(67) Calitz, F. M.; Tonge, M. P.; Sanderson, R. D. Macromolecules 2003, 36, 5-8. 
(68) Mayadunne, R. T. A.; Rizzardo, E.; Chiefari, J.; Chong, Y. K.; Moad, G.; Thang, S. H. Macromolecules 1999, 32, 6877-6980.

(69) Le, T. P.; Moad, G.; Rizzardo, E.; Thang, S. H. In PCT. Int. Appl., 1998; pp 188.

(70) Corpart, P.; Charmot, D.; Biadatti, T.; Zard, S. Z.; Michelet, D. In PCT International, 1998.

(71) Charmot, D.; Corpart, P.; Adam, H.; Zard, S. Z.; Biadatti, B. G. Macromol. Symp. 2000, 150, 23-32.

(72) Young, T.; Greene, G.; Bauer, K.; Young, K. In PCT.Int.Appl., 2001; pp 1-9.

(73) Wakioka, M.; Youl Beak, K.; Ando, T.; Kamigaito, M.; Sawamoto, M. Macromolecules 2002, 35, 330-333.

(74) Stenzel, M.; Cummins, L.; Evan Roberts, G.; Davis, T.; Vana, P.; BarnerKowollik, C. Macromol. Chem. Phys. 2003, 204, 1160-1168.

(75) Favier, A.; Barner-Kowollik, C.; Davis, T.; Stenzel, M. Macromol. Chem. Phys. 2004, 205, 925-936.

(76) Destarac, M.; Charmot, D.; Franck, X.; Zard, S. Z. Macromol. Rapid Comm. 2000, 21, 1035-1039.

(77) Rizzardo, E.; Chiefari, J.; Moad, G.; Thang, S. H. ACS Symp. Ser. 2000, 786, 278-296.

(78) Michelle, L.; Leo, R. Macromolecules 2004, 37, 590-596.

(79) Convertine, A. J.; Sumerlin, B. S.; Thomas, D. B.; Lowe, A. B.; McCormick, C. L. Macromolecules 2003, 36, 4679-4681.

(80) Barner-Kowollik, C.; Heuts, J. P. A.; Davis, T. P. J. Polym. Sci. Part A: Polym Chem 2001, 39, 656-664.

(81) Celik, C.; Hizal, G.; Tunca, U. J. Polym. Sci. Part A: Polym Chem 2003, 41, 2542-2548.

(82) Nikos, P.; Marinos, P.; Hermis, S. J. Am. Chem. Soc. 2001, 101, 3747-3792.

(83) Okeke, B.; Obi, S. Bioresour. Technol. 1995, 51, 23-27.

(84) Klemm, D.; Philipp, B.; Heinze, T.; Wagenknecht, W. In Comprehensive Cellulose Chemistry; Wiley-vch: Germany, 1998; Vol. 1, pp 1-6.

(85) Kiran, E.; Pohler, H. Supercritical Fluids 1998, 13, 135-147. 
(86) Kawamoto, H.; Saka, S.; Hatanaka, W. Analytical and Applied Pyrolysis 2003, 70, 303-313.

(87) Klemm, D.; Philipp, B.; Heinze, T.; Wagenknecht, W. In Comprehensive Cellulose Chemistry; Wiley-vch: Germany, 1998; Vol. 1, pp 105-118.

(88) Stepanik, T.; Ewing, D.; Whitehouse, R. Radiat. Phys. Chem. 2000, 57, 377-379.

(89) Roman-Aguirre, M.; Marquez-Lucero, A.; Zaragoza-Contreras, E. Carbohydr. Polym. 2004, 55, 201-210.

(90) Stenzel, M. H.; Davis, T. P.; Fane, A. G. J. Mater. Chem. 2003, 13, 2090-2097.

(91) Lee, S.; Koepsel, R.; Morley, W.; Matyjaszewski, K.; Russel, A. Biomacromolecules 2004, 5, 877-882.

(92) Gupta, K. C.; Khandekar, K. Biomacromolecules 2003, 4, 758-765.

(93) Nishioka, N.; Yamaguchi, H.; Kosai, K. J. App. Polym. Sci. 1990, 40, 2007-2017.

(94) Roy, D.; Guthrie, J. T.; Perrier, S. Macromolecules 2005, 38, 10363-10372.

(95) Hideo, T.; Katsuhiro, I.; Hisayuki, N. Journal of Colloids and Surfaces 2004, 39, 159-164.

(96) McDowall, J.; Gupta, S.; Stannett, T. Prog. Polym. Sci. 1984, 10, 1-50.

(97) Carlmark, A.; Malmström, E. Biomacromolecules 2003, 4, 1740-1745.

(98) Koenig, H.; Roberts, W. J. Polym. Sci. 1974, 18, 651-666.

(99) Biermann, J.; Chung, B.; Narayan, R. Macromolecules 1987, 20, 954-957.

(100) Richardson, S.; Andersson, T.; Wittgren, B.; Brinkmalm, G. Anal. Chem. 2003, 75, 6077-6083.

(101) Feller, R.; wilt, M. In Evaluation of Cellulose Ethers for Conservation, Second ed.; Paul Getty, 1990; Vol. 3, pp 9-18.

(102) Klemm, D.; Philipp, B.; Heinze, T.; Wagenknecht, W. In Comprehensive Cellulose Chemistry; Wiley-vch: Germany, 1998; Vol. 1, pp 69-73.

(103) Klemm, D.; Philipp, B.; Heinze, T.; Wagenknecht, W. In Comprehensive Cellulose Chemistry; Wiley-vch: Germany, 1998; Vol. 2, pp 147-161.

(104) Shi, R.; Burt, H. J. App. Polym. Sci. 2003, 89, 718-727.

(105) Falkenhagen, J.; Much, H.; Stauf, W.; Muller, H. Macromolecules 2000, 33, 3687-3693. 
(106) Pasch, H.; Trathnigg, S. In HPLC Of Polymers, Springer- Verlag Berlin Heidelberg ed.: Berlin, 1998; pp 80-116.

(107) Graef, S.; Van Zyl, A.; Sanderson, R.; Klumperman, B.; Pasch, H. J. Polym. Sci. 2003, 88, 2530-2538.

(108) Janco, M.; Hirano, T.; Kitayama, T.; Hatada, K.; Berek, D. Macromolecules 2000, 33, 1710-1715.

(109) Boiemond, J.; Van der, M. Chromatography 1978, 149, 539-546.

(110) Harry, J.; Philipsen, H. Chromatography 2004, 1073, 329-350. 
Chapter 3: Synthesis and characterization of xanthate RAFT agents.

Chapter 3: Synthesis and characterization of xanthate RAFT agents 


\section{Chapter 3: Synthesis and characterization of xanthate RAFT agents.}

\section{1: Introduction}

This chapter describes the synthesis of various xanthate (RAFT/MADIX) agents, with different activating moieties by using the Z-design approach. This method involved attaching the xanthate functionality to the core via a nonfragmenting covalent bond, where the core acts as the Z-group of the xanthate RAFT agents. ${ }^{1}$ RAFT/MADIX agents were synthesized through the use of the viscose process (the formation of xanthate esters directly on a cellulosic substrate and subsequent alkylation) to the polysaccharide materials. $^{2}$

The synthesized xanthate RAFT agents were characterized by Fourier-Transform Infrared spectroscopy FT-IR, Nuclear Magnetic Resonance (NMR) spectroscopy and Ultraviolet spectroscopy UV. Their spectra are shown in the Appendix (Figures A1 through A19). 


\section{2: Synthesis of the RAFT agents}

\subsection{1: Synthesis of monofunctional xanthate (RAFT/MADIX) agents (2) and (8)}

The usual syntheses of RAFT agent (2) involve reactions between a suitable alkali metal salt of the O-alkyl dithiocarbonates (xanthate salt) and alkyl halides in appropriate organic solvents. ${ }^{3}$ According to Degani and Fochi, ${ }^{4}$ alkali metal salts of the O-alkyl dithiocarbonates are generally prepared by the reaction of carbon disulphide with an alcohol and alkali hydroxide, as shown in Scheme 3.1. In the case of RAFT agent (8) the synthesis of the dithiocarbonates, as proposed by Cesare and co-workers, ${ }^{5}$ starting from partly protected substrates most often entails the use of strong basic reagents (alkali metal, sodium hydride or sodium amide) in order to obtain the intermediate alcoholate which reacts with carbon disulphide giving a xanthate salt. The xanthate salt can then be alkylated by alkyl halide (Scheme 3.1) to yield the corresponded RAFT agent.

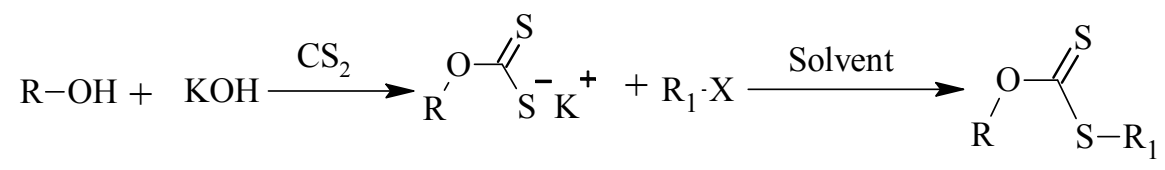

Scheme 3.1: General preparation of monofunctional xanthate (RAFT/MADIX) agents (2) and (8).

\subsection{2: Synthesis of difunctional xanthate (RAFT/MADIX) agent (4)}

Difunctional xanthate RAFT agent (4) was synthesized according to the procedure described by Houben-Weyl, as shown in Scheme 3.2. ${ }^{6}$ Reaction of vicinal diols with carbon disulphide and alkali hydroxides, such as potassium hydroxide, in sequence, give the derived xanthate salt (3). Alkylation of this xanthate salt with an alkyl halide in suitable organic solvent leads to the desired difunctional xanthate RAFT agent.

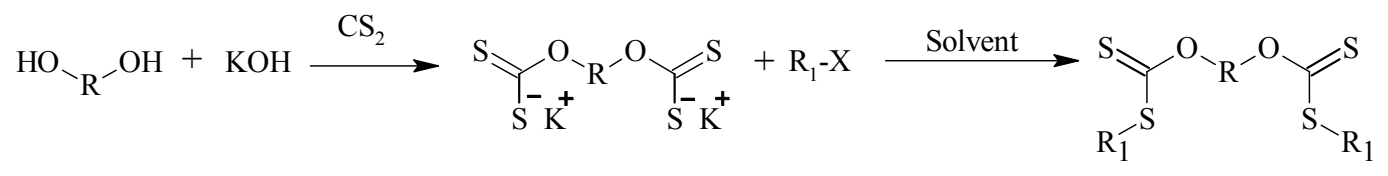

Scheme 3.2: General preparation of difunctional xanthate (RAFT/MADIX) agents (4). 


\subsection{3: Synthesis of trifunctional and tetrafunctional xanthate (RAFT/MADIX) agents (5) and (6)}

Applying the methodology in Section 3.3.3 to triol and tetraol compounds leads to the respective dithiocarbonate xanthate salts. A slight modification of the method proposed by Bernard et al, ${ }^{1}$ i.e the alkylation of dithiocarbonate xanthate salts with an alkyl halide in suitable organic solvent, was successfully applied.<smiles>[R1]SC(=S)OC[Z](C)(COC(=S)S[R1])COC(=S)S[R1]</smiles><smiles>[R]SC(=S)OCC(COC(=S)S[R])(COC(=S)S[R])COC(=S)S[R]</smiles>

Scheme 3.3: General preparation of trifunctional and tetrafunctional xanthate (RAFT/MADIX) agents (5) and (6).

\subsection{4: Synthesis of polyol xanthate (RAFT/MADIX) agents (10), (11) and (12)}

The polyol alkali xanthate salts were prepared according to the method of Whistler and co-workers. ${ }^{2}$ Polyol compounds are treated with strongly basic reagents and carbon disulphide in order to obtain polyol alkali xanthate, where the hydroxyl groups are substituted by the alkali reagent. In the case of cellulosic materials the average number of hydroxyl groups substituted per anhydroglucose unit is known as the degree of substitution (DS). With three hydroxyl groups present, the maximum DS is three.

When cellulosic materials are treated with potassium hydroxide instead of sodium, the resulting cellulosic potassium xanthate may have a degree of substitution of 1 to 1.2 instead of 0.4 to $0.6^{2,7}$ 


\section{Chapter 3: Synthesis and characterization of xanthate RAFT agents.}

When thoroughly dried, the polyol alkali xanthate salt does not alkylate readily. Therefore alkylation of the polyol alkali xanthate salt should be carried out immediately before it has time to dry fully. The preparation is depicted in Scheme 3.4.

$$
\text { Polyol } \underset{\mathrm{CS}_{2}}{\stackrel{\mathrm{KOH}}{\longrightarrow}} \text { Polyol } \underset{\mathrm{SK}^{+}}{\mathrm{S}}+\mathrm{R}_{1} \mathrm{X} \stackrel{\text { Solvent }}{\longrightarrow} \text { Polyol }
$$

Scheme 3.4: General preparation of polyol xanthate (RAFT/MADIX) agents (10), (11) and (12).

\section{3: Characterization of the RAFT agents}

\subsection{1: Nuclear Magnetic Resonance Spectroscopy (NMR)}

The structures of the (xanthate/MADIX) RAFT agents were determined by NMR spectroscopy.

Proton ${ }^{1} \mathrm{H}-\mathrm{NMR}$ and Carbon ${ }^{13} \mathrm{C}-\mathrm{NMR}$ spectra of the xanthate RAFT agents were obtained by using a Varian VXR 300 M equipped with a Varian magnet (7.0 T), and 600 M Varian unity Inova spectrometer equipped with an Oxford magnet (14.09T). Depending on the solubility of the synthesized xanthate RAFT agents, deuterated chloroform $\left(\mathrm{CDCl}_{3}\right)$ and deuterated methyl sulfoxide (DMSO) were used as solvents. All spectra were referenced to tetramethylsilane (TMS) at $0 \mathrm{ppm}$.

\subsection{2: Fourier-Transform Infrared Spectroscopy (FTIR)}

Fourier-Transform Infrared is a good commonly used method to analyze the chemical composition of a product and is typically used to monitor the presence of the chemical functional groups on a molecule. As a beam of infrared radiation is passed though a sample or reflected off it, the sample's bonds absorb certain frequencies. These absorbed frequencies are measured and related to the chemical bonding present in the sample. In this study the resultant infrared spectra were recorded on a Perkin Elmer Paragon 1000 FTIR using a photoacoustic cell (PAS), which has the advantage that sample preparation is eliminated and a sample can be scanned in whatever form it appears. The sample was placed in an MTEC 300 chamber which was flushed with ultra-high-purity helium. 


\section{Chapter 3: Synthesis and characterization of xanthate RAFT agents.}

\subsection{3: Ultraviolet/visible spectroscopy}

UV/visible spectrometer operates on the double-beam principle, with one beam passing though the sample and the other passing though a reference cell. ${ }^{8}$

A Perkin Elmer UV/visible spectrometer Lambda 20 Spectrometer was used to identify the UV absorption band of the $\mathrm{C}=\mathrm{S}$ bond in the structure of the RAFT agents. The data was analyzed with UVWinlab v.4.2 software. Quartz cuvettes (supplied by CND Scientific) with a $10 \mathrm{~mm}$ path length were used.

\section{4: Experimental}

\subsection{1: Materials}

The following reagents were used:

Potassium hydroxide 85\% (SAARchem), 1,4 butandiol 99\% (Acros), carbon disulfide 99.5\% (Merck), 2-bromopropionic acid 99\% (Aldrich), hydrochloric acid 32\% (Merck), magnesium sulphate (anhydrous) 62-70\% (Merck), pentaerythitol 98\% (Merck), 1,1,1tris(hydroxymethyl)ethane 98\% (Fluka), 2-ethyl-bromo-propionate 99\% (Aldrich), hydroxypropyl cellulose (Aldrich), methyl cellulose (SAARchem), cellulose (SigmaAldrich), the THF was distilled from $\mathrm{LiAlH}_{4}$ (Sigma-Aldrich), Acetone 99.5\% (SAARchem), diethyl ether 99.5\% (Merck), ethanol 99.8\% (Sigma-Aldrich), acetonitrile 99.9\% (Aldrich), sodium carbonate 99.5\% (Sigma), dimethylformamide 99.5 (Sigma), zing chloride (Merck), ortho-phosphoric acid 85\% (Fluka), D(+) anhydrous glucose (Associated Chemical Enterprises (PTY)Ltd, sodium metal lumps (SAARchem).

\subsection{2: Synthesis of S-sec propionic acid O-ethyl xanthate RAFT agent} (2)

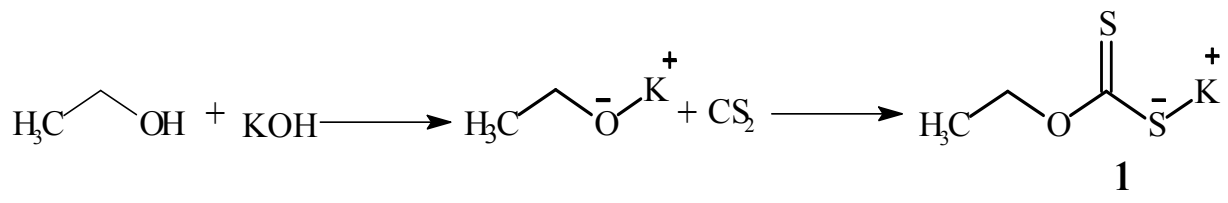

Scheme 3.5: Preparation of potassium O-ethyl dithiocarbonate (1). 


\section{Chapter 3: Synthesis and characterization of xanthate RAFT agents.}

Potassium hydroxide pellets $(21 \mathrm{~g}, 0.375 \mathrm{~mol})$, ethanol $(60 \mathrm{~g}, 76 \mathrm{~mL})$ and a stirrer bar were placed in a $250 \mathrm{~mL}$ round-bottomed flask fitted with a reflux condenser. The mixture was heated under reflux for one hour.

After cooling in an ice bath carbon disulphide (28.5 g, $22.6 \mathrm{~mL})$ was added slowly resulting in an almost solid mass. This was filtered and washed with three $20 \mathrm{~mL}$ portions of ether. The solid potassium O-ethyl dithiocarbonate product (1) was then recrystallized from absolute ethanol ${ }^{3}$ (yield was $41 \mathrm{~g}, 68 \%$ ).

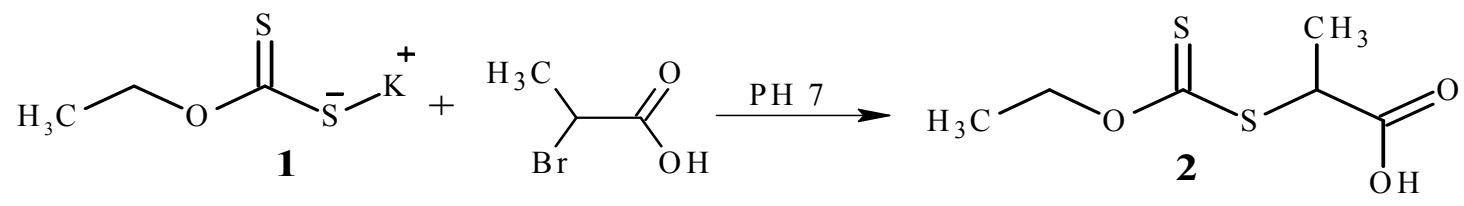

Scheme 3.6: Preparation of S-sec propionic acid O-ethyl xanthate RAFT agent (2).

Potassium O-ethyl dithiocarbonate (1) $(8.3 \mathrm{~g}, 0.052 \mathrm{~mol})$ was then dissolved in $30 \mathrm{~mL}$ methanol in a $250 \mathrm{~mL}$ round-bottomed flask. The reaction mixture was stirred overnight with 2-bromopropionic acid (7.95 g, $4.67 \mathrm{~mL})$, which had been neutralized by the addition of sodium carbonate $(0.026 \mathrm{~mol}, 2.75 \mathrm{~g})$. The mixture was then acidified by the dropwise addition of $1 \mathrm{M}$ hydrochloric acid (5.92 g, $5.1 \mathrm{~mL})$.

The reaction mixture was extracted with $50 \mathrm{~mL}$ ether and washed with $20 \mathrm{~mL}$ distilled water. The organic layer was dried over anhydrous magnesium sulphate and the solvent was evaporated. The residue was cooled to $-25{ }^{\circ} \mathrm{C}$ in order to form crystals and the product was recrystallized from hexane. ${ }^{4,9}$ A white crystalline solid ( $3 \mathrm{~g}, 30 \%$ yield) was obtained (m.p $\left.45-47^{\circ} \mathrm{C}\right)$.

${ }^{1} \mathrm{H}-\mathrm{NMR}\left(\mathrm{CDCl}_{3}\right): \delta(\mathrm{ppm})=1.38\left(\mathrm{t}, 3 \mathrm{H}, \mathbf{C H}_{3}-\mathrm{CH}_{2-}, \mathrm{J}_{\mathrm{CH} 3-\mathrm{CH} 2-}=7.1 \mathrm{~Hz}\right), 1.56(\mathrm{~d}, 3 \mathrm{H}$, $\left.\mathbf{C H}_{3}-\mathrm{CH}-, \mathrm{J}_{\mathrm{CH} 3-\mathrm{CH}-}=7.4 \mathrm{~Hz}\right), 4.39\left(\mathrm{q}, 1 \mathrm{H}, \mathrm{CH}_{3}-\mathbf{C H}-, \mathrm{J}_{\mathrm{CH} 3-\mathrm{CH}-}=7.4 \mathrm{~Hz}\right), 4.62(\mathrm{q}, 2 \mathrm{H}$, $\left.\mathrm{CH}_{3}-\mathbf{C H}_{2-}, \mathrm{J}_{\mathrm{CH} 3-\mathrm{CH} 2-}=7.1 \mathrm{~Hz}\right)$.

${ }^{13} \mathrm{C}-\mathrm{NMR}\left(\mathrm{CDCl}_{3}\right): \delta(\mathrm{ppm})=13.3\left(\mathbf{C H}_{3}-\mathrm{CH}_{2}-\right), 16.2\left(\mathbf{C H}_{3}-\mathrm{CH}-\right), 46.7\left(\mathrm{CH}_{3}-\mathbf{C H}-\right), 70.4$ $\left(\mathrm{CH}_{3}-\mathbf{C H}_{2-}\right), 178.1(\mathrm{C}=\mathrm{O}), 211.9(\mathrm{C}=\mathrm{S})$.

FT-IR (photoacoustic cell PAS $\left(\mathrm{cm}^{-1}\right)$ wavenumbers and their assignments: $3518(-\mathrm{OH})$, $2980\left(-\mathrm{CH}_{2-},-\mathrm{CH}_{3}\right), 1724(\mathrm{C}=\mathrm{O}), 1265(\mathrm{C}-\mathrm{O}), 1048(\mathrm{C}=\mathrm{S}), 862(\mathrm{C}-\mathrm{S})$.

$\mathrm{UV}(\mathrm{C}=\mathrm{S}):\left(\mathrm{n} \rightarrow \pi^{*}, \lambda_{\max }=354 \mathrm{~nm} \mathrm{~L}\right)$ and $\left(\pi \rightarrow \pi^{*}, \lambda=278 \mathrm{~nm}\right)$. Acetonitrile was used as solvent. 
3.4.3: Synthesis of 1,4 di(S-sec propionic acid xanthate) butane RAFT agent (4)

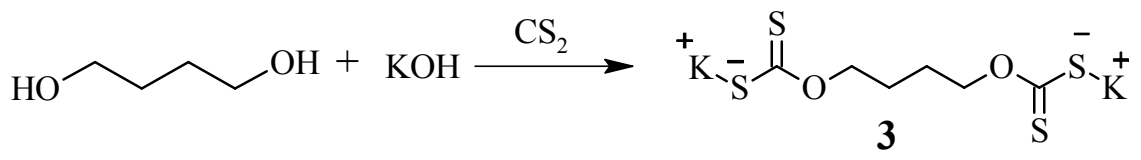

\section{Scheme 3.7: Preparation of difunctional potassium xanthate salt (3)}

Acetone $(30 \mathrm{~mL})$ was added to 1,4 butanediol $(6.2 \mathrm{~g}, 0.1 \mathrm{~mol})$ in a $250 \mathrm{~mL}$ round bottomed flask. A solution of potassium hydroxide $(11.2 \mathrm{~g}, 0.2 \mathrm{~mol})$ in water $(20-\mathrm{mL})$ was added to the reaction solution, which was then stirred for 2 hours. Carbon disulphide (15.2 g, $12 \mathrm{~mL}$ ) was added dropwise to the mixture which had been cooled with an ice bath. The reaction was left stirring at low temperature for one hour. The formed yellow crystals were separated by filtration and washed with a solution of potassium chloride ( $25 \mathrm{~g}$ in $50 \mathrm{~mL}$ ) made up in distilled water, to yield $15 \mathrm{~g}$ of compound (3) $(47 \%)$.

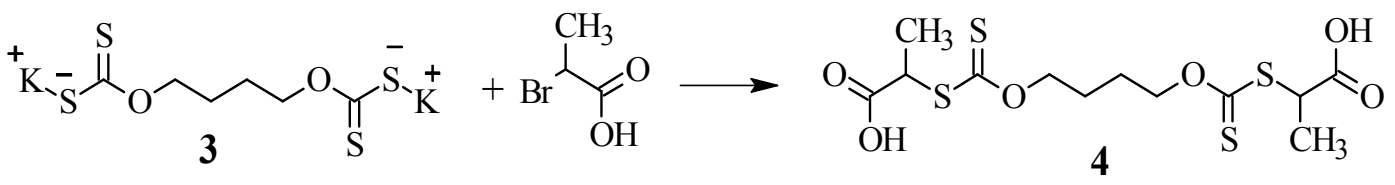

Scheme 3.8: Preparation of $1,4 \mathrm{di}(\mathrm{S}-\mathrm{sec}$ propionic acid xanthate) butane RAFT agent (4).

2-bromopropionic acid (3 g, $1.7 \mathrm{~mL}$ ) was neutralized by a solution of potassium hydroxide $(1.12 \mathrm{~g}, 0.02 \mathrm{~mol})$ in distilled water $(1 \mathrm{~mL})$. This was added to the yellow crystals of (3) $(3.1 \mathrm{~g}, 0.01 \mathrm{~mol})$ in a $100 \mathrm{~mL}$ round-bottomed flask. The reaction mixture was stirred overnight, and then acidified by the dropwise addition of $1 \mathrm{M}$ hydrochloric acid $(2.28 \mathrm{~g}, 2 \mathrm{~mL})$. The reaction mixture was extracted with $40 \mathrm{~mL}$ ether, washed three times with $20 \mathrm{~mL}$ distilled water. The organic layer was dried over magnesium sulphate (anhydrous) and the solvent was evaporated. The residue was cooled to $-25{ }^{\circ} \mathrm{C}$ in order to

form crystals, and the product was recrystallized from $20 \mathrm{~mL}$ acetonitrile., ${ }^{2,6}$ A yellow crystalline product $(1.3 \mathrm{~g}, 33 \%$ yield $)$ was obtained, m.p. $100-102{ }^{\circ} \mathrm{C}$. 
${ }^{1} \mathrm{H}-\mathrm{NMR}(\mathrm{DMSO}): \delta(\mathrm{ppm})=1.46\left(\mathrm{~d}, 3 \mathrm{H}, \mathbf{C H}_{3^{-}}, \mathrm{J}_{\mathrm{CH} 3-\mathrm{CH}-}=7.3 \mathrm{~Hz}\right), 1.87\left(\mathrm{p}, 2 \mathrm{H},-\mathrm{CH}_{2^{-}}\right.$ $\left.\mathbf{C H}_{2}-\mathrm{CH}_{2}-\mathrm{J}_{\mathrm{CH} 2-\mathrm{CH} 2-\mathrm{CH} 2}=2.7 \mathrm{~Hz}\right), 4.31\left(\mathrm{q}, 1 \mathrm{H},-\mathbf{C H}-, \mathrm{J}_{\mathrm{CH} 3-\mathrm{CH}-}=7.3 \mathrm{~Hz}\right), 4.61(\mathrm{~m}, 2 \mathrm{H}$, $\left.\mathrm{CH}_{2}-\mathrm{O}-\right)$.

${ }^{13} \mathrm{C}-\mathrm{NMR}(\mathrm{DMSO}): \delta(\mathrm{ppm})=16.68\left(\mathbf{C H}_{3^{-}}\right), 24.13\left(\mathrm{CH}_{2}-\mathbf{C H}_{2^{-}}-\mathrm{CH}_{2^{-}}\right), 46.56$ (-CH-), $73.81\left(\mathbf{C H}_{2}-\mathrm{O}-\right), 172.21(\mathrm{C}=\mathrm{O}), 212.33(\mathrm{C}=\mathrm{S})$.

FT-IR (photoacoustic cell PAS $\left(\mathrm{cm}^{-1}\right)$ wavenumbers and their assignments: $3470(-\mathrm{OH})$, $2970\left(-\mathrm{CH}_{2^{-}},-\mathrm{CH}_{3}\right), 1712(\mathrm{C}=\mathrm{O}), 1256(\mathrm{C}-\mathrm{O}), 1072(\mathrm{C}=\mathrm{S}), 884(\mathrm{C}-\mathrm{S})$.

$\mathrm{UV}(\mathrm{C}=\mathrm{S}):\left(\mathrm{n} \rightarrow \pi^{*}, \lambda_{\max }=356 \mathrm{~nm}\right)$ and $\left(\pi \rightarrow \pi^{*}, \lambda=281\right)$. Acetonitrile was used as solvent.

\subsection{4: Synthesis of $1,1,1$ tri(S-sec ethyl propionoate O-methylene xanthate) ethane RAFT agent (5)}

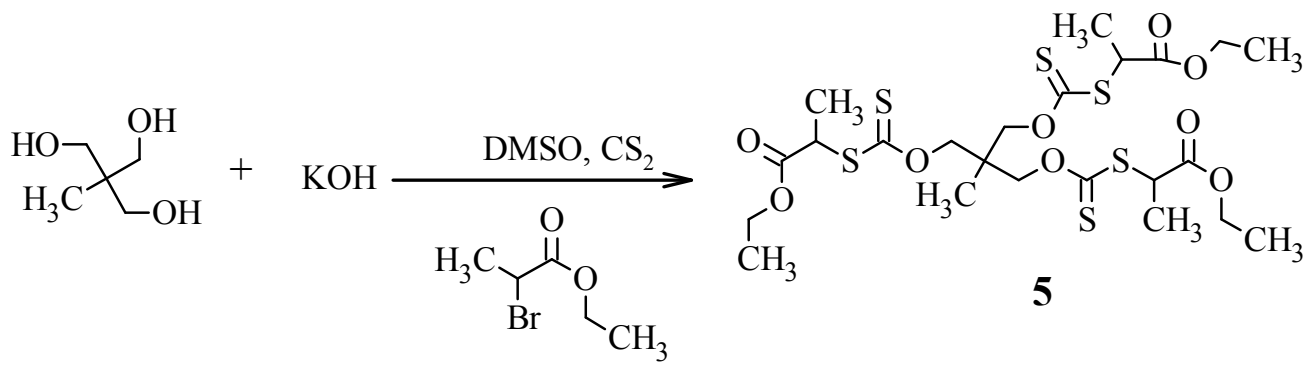

Scheme 3.9: Preparation of 1,1,1 tri(S-sec ethyl propionoate O-methylene xanthate) ethane RAFT agent (5).

The reaction set up comprised a $250 \mathrm{~mL}$ three-necked round-bottomed flask, fitted with a reflux condenser, stirrer bar, stopper and dripping funnel. 1,1,1-Tris(hydroxymethyl)ethane $(2.4 \mathrm{~g}, 0.02 \mathrm{~mol})$ was dissolved in DMSO $(30 \mathrm{~mL})$ at $60{ }^{\circ} \mathrm{C}$. A solution of potassium hydroxide $(5.04 \mathrm{~g}, 0.09 \mathrm{~mol})$ in distilled water $(10 \mathrm{~mL})$ was added at room temperature. The reaction was cooled down in an ice bath and a large excess of carbon disulfide $(60 \mathrm{~g}, 48 \mathrm{~mL})$ was then slowly added over 20 minutes. The resulting dark red solution was stirred for two hours at room temperature.

Then 2-ethyl-bromo-propionate $(16.29 \mathrm{~g}, 11.6 \mathrm{~mL})$ was slowly added over one hour at room temperature. The resulting yellow solution was stirred overnight. The reaction was extracted with ether $(250 \mathrm{~mL})$ and, washed three times with $20 \mathrm{~mL}$ distilled water. The organic solution was then dried over magnesium sulphate (anhydrous), filtered, and the solvent was evaporated under vacuum. The trifunctional xanthate RAFT agent (5) was 


\section{Chapter 3: Synthesis and characterization of xanthate RAFT agents.}

finally purified by column chomatography on silica gel with hexane/ethyl acetate $(7 / 3)$ mixture as eluent. ${ }^{1}$ A viscous yellow oil ( $6.8 \mathrm{~g}, 52 \%$ yield) was obtained.

${ }^{1} \mathrm{H}-\mathrm{NMR}\left(\mathrm{CDCl}_{3}\right): \delta(\mathrm{ppm})=1.21\left(\mathrm{t}, 9 \mathrm{H}, \mathbf{C H}_{3}-\mathrm{CH}_{2-}, \mathrm{J}_{\mathrm{CH} 3-\mathrm{CH} 2}=7.1 \mathrm{~Hz}\right), 1.51(\mathrm{~d}, 9 \mathrm{H}$, $\left.\mathbf{C H}_{3}-\mathrm{CH}-, \mathrm{J}_{\mathrm{CH} 3-\mathrm{CH}-}=7.4 \mathrm{~Hz}\right), 4.15\left(\mathrm{q}, 6 \mathrm{H}, \mathrm{CH}_{3}-\mathbf{C H}_{2^{-}}, \mathrm{J}_{\mathrm{CH} 3-\mathrm{CH} 2-}=7.1 \mathrm{~Hz}\right), 4.33(\mathrm{q}, 3 \mathrm{H}$, $\left.\mathrm{CH}_{3}-\mathbf{C H}-, \mathrm{J}_{\mathrm{CH} 3-\mathrm{CH}-}=7.4 \mathrm{~Hz}\right), 4.54\left(\mathrm{~m}, 6 \mathrm{H},-\mathrm{C}-\mathbf{C H}_{2^{-}}\right), 4.71\left(\mathrm{~m}, 3 \mathrm{H},-\mathrm{C}-\mathbf{C H}_{3^{-}}\right)$.

${ }^{13} \mathrm{C}-\mathrm{NMR}\left(\mathrm{CDCl}_{3}\right): \delta(\mathrm{PPM})=13.79\left(\mathbf{C H}_{3}-\mathrm{CH}_{2}-\right), 16.63\left(\mathbf{C H}_{3}-\mathrm{C}-\right), 17.07\left(\mathbf{C H}_{3}-\mathrm{CH}-\right)$, 39.68 (-C-), 49.39 ( $\left.\mathrm{CH}_{3}-\mathbf{C H}-\right), 61.73\left(\mathrm{CH}_{3}-\mathbf{C H}_{2}-\right), 74.45\left(-\mathrm{C}-\mathbf{C H}_{2}-\right), 171.22(\mathrm{C}=\mathrm{O})$, $212.23(\mathrm{C}=\mathrm{S})$.

FT-IR (photoacoustic cell PAS $\left(\mathrm{cm}^{-1}\right)$ wavenumbers and their assignments: $2977\left(-\mathrm{CH}_{2}-\right.$, $\left.-\mathrm{CH}_{3}\right), 1735(\mathrm{C}=\mathrm{O}), 1249(\mathrm{C}-\mathrm{O}), 1049(\mathrm{C}=\mathrm{S}), 864(\mathrm{C}-\mathrm{S})$.

$\mathrm{UV}(\mathrm{C}=\mathrm{S}):\left(\mathrm{n} \rightarrow \pi^{*}, \lambda_{\max }=431 \mathrm{~nm}\right)$ and $\left(\pi \rightarrow \pi^{*}, \lambda=280 \mathrm{~nm}\right)$. Acetonitrile was used as solvent.

\subsection{5: Synthesis of $1,1,1,1$ tetra(S-sec ethyl propionoate O-methylene xanthate) methane RAFT agent (6)}

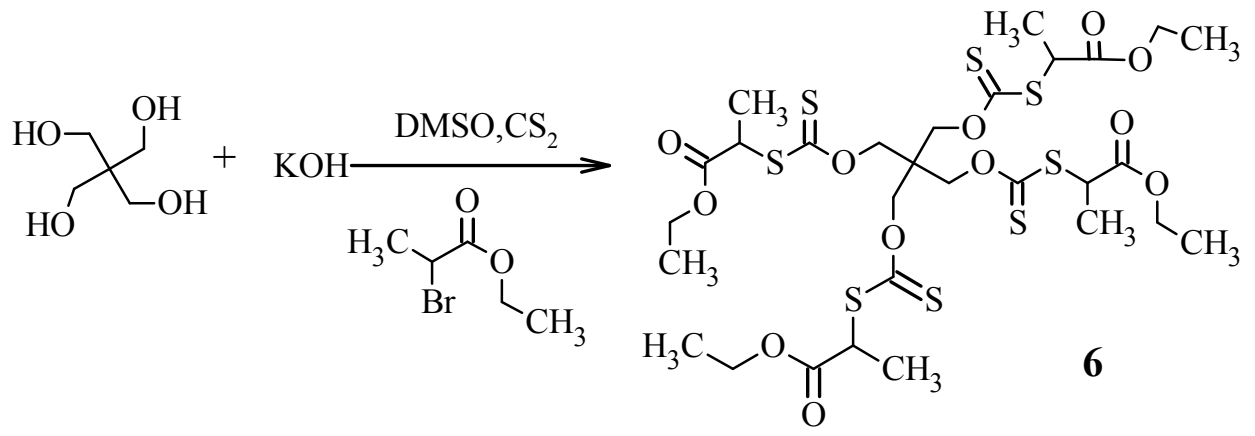

Scheme 3.10: Preparation of 1,1,1,1 tetra(S-sec ethyl propionoate O-methylene xanthate) methane RAFT agent (6).

The tetrafunctional xanthate RAFT agent was synthesized in the same way that was used for the trifunctional xanthate RAFT agent (Section 3.3.4). Reagents and quantities were as follows:

Pentaerythitol (0.02 mol, $2.72 \mathrm{~g})$, DMSO $(30 \mathrm{~mL})$, potassium hydroxide $(6.72 \mathrm{~g}$, $0.12 \mathrm{~mol})$, distilled water $(10 \mathrm{~mL})$, carbon disulfide $(60.8 \mathrm{~g}, 48 \mathrm{~mL})$, 2-ethyl-bromopropionate $(16.33 \mathrm{~g}, 11.7 \mathrm{~mL})$, ether $(250 \mathrm{~mL})$. 


\section{Chapter 3: Synthesis and characterization of xanthate RAFT agents.}

The tetrafunctional xanthate RAFT agent (6) was purified by column chomatography on silica gel with a hexane/ethyl acetate (8/2) mixture as eluent. ${ }^{1}$ A very viscous yellow oil $(10.7 \mathrm{~g})$ was obtained in $63 \%$ yield.

${ }^{1} \mathrm{H}-\mathrm{NMR}\left(\mathrm{CDCl}_{3}\right): \delta(\mathrm{ppm})=1.14\left(\mathrm{t}, 12 \mathrm{H}, \mathbf{C H}_{3}-\mathrm{CH}_{2^{-}}, \mathrm{J}_{\mathrm{CH} 3-\mathrm{CH} 2-}=7.1 \mathrm{~Hz}\right), 1.43(\mathrm{~d}, 12 \mathrm{H}$, $\left.\mathbf{C H}_{3}-\mathrm{CH}-, \mathrm{J}_{\mathrm{CH} 3-\mathrm{CH}-}=7.4 \mathrm{~Hz}\right), 4.08\left(\mathrm{q}, 8 \mathrm{H}, \mathrm{CH}_{3}-\mathbf{C H}_{2^{-}}, \mathrm{J}_{\mathrm{CH} 3-\mathrm{CH} 2-}=7.1 \mathrm{~Hz}\right), 4.25(\mathrm{q}, 4 \mathrm{H}$, $\left.\mathrm{CH}_{3}-\mathbf{C H}-, \mathrm{J}_{\mathrm{CH} 3-\mathrm{CH}-}=7.4 \mathrm{~Hz}\right), 4.66\left(\mathrm{~m}, 8 \mathrm{H},-\mathrm{C}-\mathbf{C H}_{2}-\right)$.

${ }^{13} \mathrm{C}-\mathrm{NMR}\left(\mathrm{CDCl}_{3}\right): \delta(\mathrm{ppm})=13.57\left(\mathbf{C H}_{3}-\mathrm{CH}_{2}-\right), 16.32\left(\mathbf{C H}_{3}-\mathrm{CH}-\right), 43.41(-\mathbf{C}-), 39.68(-$ C-), $47.19\left(\mathrm{CH}_{3}-\mathbf{C H}-\right), 61.48\left(\mathrm{CH}_{3}-\mathbf{C H}_{2}-\right), 70.46\left(-\mathrm{C}-\mathbf{C H}_{2}-\right), 170.74(\mathrm{C}=\mathrm{O}), 211.5(\mathrm{C}=\mathrm{S})$. FT-IR (photoacoustic cell PAS $\left(\mathrm{cm}^{-1}\right)$ wavenumbers and their assignment: $2981\left(-\mathrm{CH}_{2^{-}}\right.$, $\left.\mathrm{CH}_{3}\right), 1738(\mathrm{C}=\mathrm{O}), 1242(\mathrm{C}-\mathrm{O}), 1071(\mathrm{C}=\mathrm{S}), 864(\mathrm{C}-\mathrm{S})$.

$\mathrm{UV}(\mathrm{C}=\mathrm{S}):\left(\mathrm{n} \rightarrow \pi^{*}, \lambda_{\max }=440 \mathrm{~nm}\right)$ and $\left(\pi \rightarrow \pi^{*}, \lambda=280 \mathrm{~nm}\right)$. Acetonitrile was used as solvent.

\subsection{6: Synthesis of 1,2:5,6-di-O-isopropylidene- $\alpha$-D-glucofuranose-3-(S- sec ethyl propionoate) xanthate (8)}

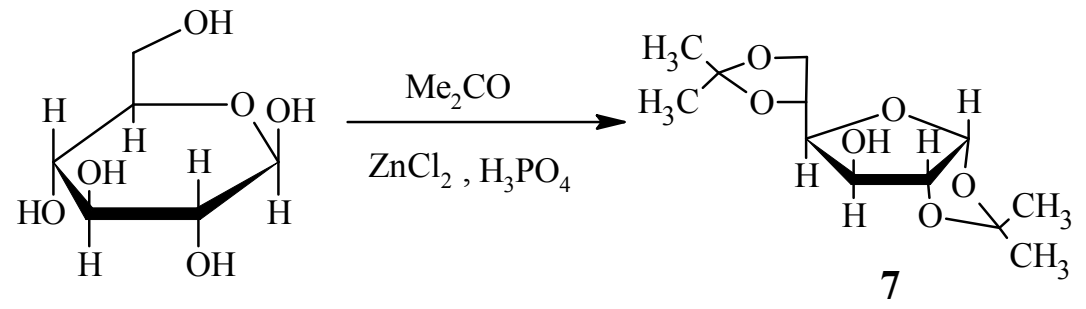

Scheme 3.11: Preparation of 1,2:5,6-di-O-isopropylidene- $\alpha$-D-glucofuranose (7).

Anhydrous acetone $(500 \mathrm{~mL})$ was added to a mixture of D $(+)$ glucose (anhydrous $75 \mathrm{~g}$ ), zinc chloride $(60 \mathrm{~g})$ and $85 \%$ phosphoric acid (3.75 g). This mixture was stirred for $30 \mathrm{~h}$ at room temperature and then the undissolved D-glucose (45 g) was collected on a filter and washed with a little anhydrous acetone.

The filtrate was made alkaline $(\mathrm{pH} 10-11)$ with sodium hydroxide solution (42.5 $\mathrm{g}$ sodium hydroxide in $100 \mathrm{~mL}$ water). Precipitation of the insoluble inorganic material occurred, which was removed by filtration. The colorless filtrate and washings were concentrated under reduced pressure. The residue was diluted with $75 \mathrm{~mL}$ water and extracted with chloroform $(3 \times 75 \mathrm{~mL})$. The chloroform extracts were washed with a little water and then concentrated to yield a white crystalline residue, which was recrystallized 


\section{Chapter 3: Synthesis and characterization of xanthate RAFT agents.}

from chloroform: hexane 1:2 to yield $27 \mathrm{~g} \mathrm{(41 \% )}$ of crude 1,2:5,6-di-O-isopropylidene- $\alpha$ D-glucofuranose, m.p $107-110{ }^{\circ} \mathrm{C} .{ }^{10}$

${ }^{1} \mathrm{H}-\mathrm{NMR}\left(\mathrm{CDCl}_{3}\right): \delta(\mathrm{ppm})=1.3\left(\mathrm{~s}, 3 \mathrm{H}, \mathbf{C} \mathbf{H}_{3}\right), 1.35\left(\mathrm{~s}, 3 \mathrm{H}, \mathbf{C} \mathbf{H}_{3}\right), 1.43\left(\mathrm{~s}, 3 \mathrm{H}, \mathbf{C H}_{3}\right)$, $1.48\left(\mathrm{~s}, 3 \mathrm{H}, \mathbf{C H}_{3}\right), 2.74\left(\mathrm{~d}, 1 \mathrm{H}, \mathbf{O H}, \mathrm{J}_{\mathrm{H} 3-\mathrm{OH}}=2.8 \mathrm{~Hz}\right), 3.98\left(\mathrm{dd}, 1 \mathrm{H}, \mathbf{H}_{6 \mathrm{a}}, \mathrm{J}_{\mathrm{H} 6 \mathrm{a}-\mathrm{H} 6 \mathrm{~b}}=8.7 \mathrm{~Hz}\right.$, $\left.\mathrm{J}_{\mathrm{H} 6 \mathrm{a}-\mathrm{H} 5}=5.3 \mathrm{~Hz}\right), 4.05\left(\mathrm{dd}, 1 \mathrm{H}, \mathbf{H}_{4}, \mathrm{~J}_{\mathrm{H} 4-\mathrm{H} 5}=7.8 \mathrm{~Hz}, \mathrm{~J}_{\mathrm{H} 4-\mathrm{OH}}=2.8 \mathrm{~Hz}\right), 4.15\left(\mathrm{dd}, 1 \mathrm{H}, \mathbf{H}_{\mathbf{6 b}}\right.$, $\left.\mathrm{J}_{\mathrm{H} 6 \mathrm{~b}-\mathrm{H} 6 \mathrm{a}}=8.7 \mathrm{~Hz}, \mathrm{~J}_{\mathrm{H} 6 \mathrm{~b}-\mathrm{H} 5}=6.3 \mathrm{~Hz}\right), 4.31\left(\mathrm{~m}, 1 \mathrm{H}, \mathbf{H}_{3}\right), 4.32\left(\mathrm{~m}, 1 \mathrm{H}, \mathbf{H}_{5}\right), 4.51\left(\mathrm{~d}, 1 \mathrm{H}, \mathbf{H}_{2}\right.$, $\left.\mathrm{J}_{\mathrm{H} 2-\mathrm{H} 1=}=3.6 \mathrm{~Hz}\right), 5.92\left(\mathrm{~d}, 1 \mathrm{H}, \mathbf{H}_{1}, \mathrm{~J}_{\mathrm{H} 1-\mathrm{H} 2}=3.6 \mathrm{~Hz}\right)$.
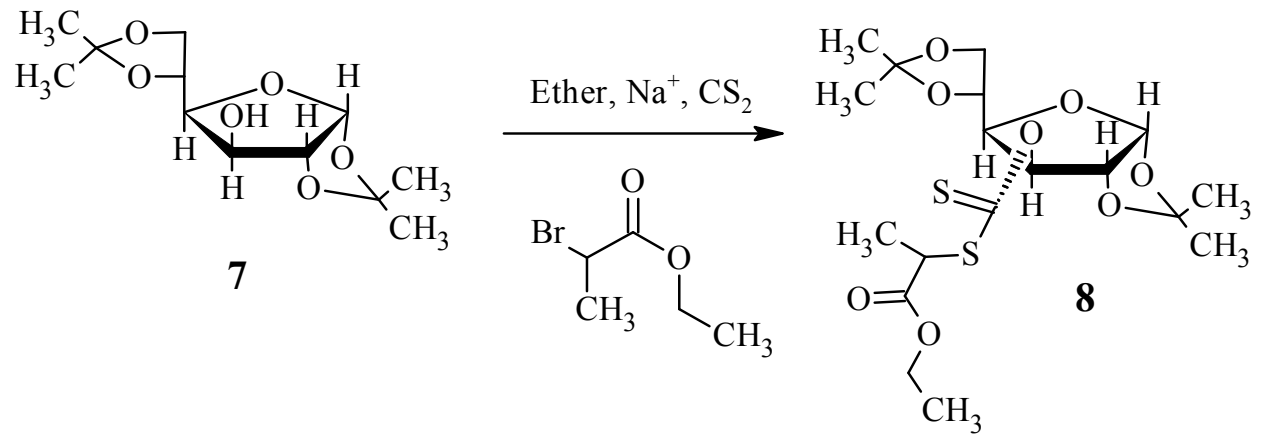

Scheme 3.12: Preparation of 1,2:5,6-di-O-isopropylidene- $\alpha$-D-glucofuranose-3-(Ssec ethyl propionoate) xanthate RAFT agent (8).

An excess of sodium metal in the form of thin plates $(1.2 \mathrm{~g})$ was added in nine installments over $12 \mathrm{~h}$, to a solution of $5 \mathrm{~g}$ 1,2:5,6-di-O-isopropylidene- $\alpha$-Dglucofuranose (7) in $20 \mathrm{ml}$ dry ether. The reaction mixture was kept under reflux in an oil bath for $12 \mathrm{~h}$, then the ether solution was decanted and the residual sodium was washed with dry ether. The solution and the washing were combined and cooled in an ice bath.

Carbon disulphide $(10 \mathrm{~mL})$ was added slowly and the mixture stirred at room temperature for $12 \mathrm{~h}$ resulting in a semi-solid, cream-colored mass of crude xanthate salt. 2-Ethylbromo-propionate $(3.4 \mathrm{~g}, 2.4 \mathrm{~mL})$ was slowly added to the crude xanthate salt at room temperature.

After being vigorously stirred at room temperature for $8 \mathrm{~h}$, the reaction mixture was extracted with $30 \mathrm{~mL}$ ether and, washed with $5 \mathrm{~mL}$ distilled water. The organic layer was dried over magnesium sulphate (anhydrous) and the solvent was evaporated. The xanthate RAFT agent (8) was finally purified by column chomatography on silica gel with a hexane/ethyl acetate (8/2) mixture as eluent. ${ }^{1}$ A viscous yellow oil (3 g, 37\% yield) was obtained. 
Chapter 3: Synthesis and characterization of xanthate RAFT agents.

${ }^{1} \mathrm{H}-\mathrm{NMR}\left(\mathrm{CDCl}_{3}\right): \delta(\mathrm{ppm})=1.1\left(\mathrm{t}, 3 \mathrm{H}, \mathrm{CH}_{2}-\mathbf{C H}_{3}, \mathrm{~J}_{\mathrm{CH} 2-\mathrm{CH} 3}=6.9 \mathrm{~Hz}\right), 1.3\left(\mathrm{~s}, 3 \mathrm{H}, \mathbf{C H}_{3}\right)$, 1.35 (s, 3H, $\left.\mathbf{C H}_{3}\right), 1.43$ (s, 3H, $\left.\mathbf{C H}_{3}\right), 1.48$ (s, 3H, $\left.\mathbf{C H}_{3}\right), 1.5$ (d, 3H, CH-CH $\mathbf{C H}_{3}, \mathrm{~J}_{\mathrm{CH}-\mathrm{CH} 3}=$ $7.8 \mathrm{~Hz}), 3.98\left(\mathrm{dd}, 1 \mathrm{H}, \mathbf{H}_{6 \mathbf{6}}, \mathrm{J}_{\mathrm{H} 6 \mathrm{a}-\mathrm{H} 6 \mathrm{~b}}=8.7 \mathrm{~Hz}, \mathrm{~J}_{\mathrm{H} 6 \mathrm{a}-\mathrm{H} 5}=5.3 \mathrm{~Hz}\right), 3.9$ (q, 2H, $\mathbf{C H}_{2}-\mathrm{CH}_{3}, \mathrm{~J}_{\mathrm{CH} 2-}$ $\left.\mathrm{CH}_{3}=6.9 \mathrm{~Hz}\right), 4.01\left(\mathrm{q}, 1 \mathrm{H}, \mathbf{C H}-\mathrm{CH}_{3}, \mathrm{~J}_{\mathrm{CH}-\mathrm{CH} 3}=7.8 \mathrm{~Hz}\right), 4.05\left(\mathrm{dd}, 1 \mathrm{H}, \mathbf{H}_{4}, \mathrm{~J}_{\mathrm{H} 4-\mathrm{H} 5}=7.8, \mathrm{~J}_{\mathrm{H} 4-}\right.$ $\mathrm{OH}=2.8 \mathrm{~Hz}), 4.15\left(\mathrm{dd}, 1 \mathrm{H}, \mathbf{H}_{\mathbf{6 b}}, \mathrm{J}_{\mathrm{H} 6 \mathrm{~b}-\mathrm{H} 6 \mathrm{a}}=8.7 \mathrm{~Hz}, \mathrm{~J}_{\mathrm{H} 6 \mathrm{~b}-\mathrm{H} 5}=6.3 \mathrm{~Hz}\right), 4.31\left(\mathrm{~m}, 1 \mathrm{H}, \mathbf{H}_{3}\right), 4.32$ $\left(\mathrm{m}, 1 \mathrm{H}, \mathbf{H}_{5}\right), 4.51\left(\mathrm{~d}, 1 \mathrm{H}, \mathbf{H}_{2}, \mathrm{~J}_{\mathrm{H} 2-\mathrm{H} 1-}=3.6 \mathrm{~Hz}\right), 5.92\left(\mathrm{~d}, 1 \mathrm{H}, \mathbf{H}_{1}, \mathrm{~J}_{\mathrm{H} 1-\mathrm{H} 2}=3.6 \mathrm{~Hz}\right)$.

FT-IR (photoacoustic cell PAS $\left(\mathrm{cm}^{-1}\right)$ wavenumbers and their assignments: $2986\left(-\mathrm{CH}_{2}-\right.$, $\left.-\mathrm{CH}_{3}\right), 1737(\mathrm{C}=\mathrm{O}), 1061(\mathrm{C}=\mathrm{S}), 846(\mathrm{C}-\mathrm{S})$.

UV (C=S): $\left(\mathrm{n} \rightarrow \pi^{*}, \lambda_{\max }=380 \mathrm{~nm}\right)$ and $\left(\pi \rightarrow \pi^{*}, \lambda=280 \mathrm{~nm}\right)$ Acetonitrile was used as solvent.

\subsection{7: Synthesis of S-sec propionic acid hydroxylpropyl cellulose xanthate RAFT agent (10)}

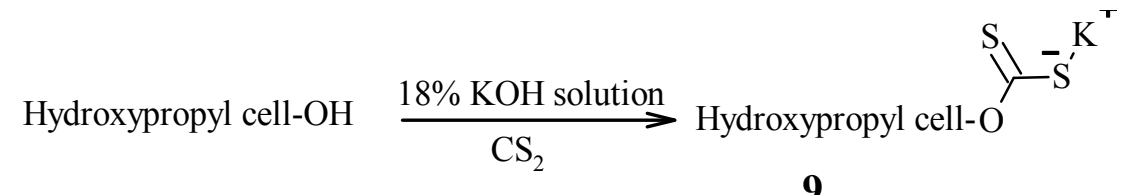

Scheme 3.13: Preparation of hydroxypropyl cellulose potassium xanthate salt (10).

Hydroxypropyl cellulose (2.5 g) was stirred for $30 \mathrm{~min}$ at room temperature in a reaction vessel with an $18 \%$ aqueous potassium hydroxide solution $(30 \mathrm{~mL})$. Carbon disulfide $(30 \mathrm{~mL})$ was then added over $10 \mathrm{~min}$, and the resulting orange-colored solution was stirred for six hours at room temperature. At the end of reaction the product was vigorously stirred for half an hour with distilled water $(50 \mathrm{~mL})$. The highly viscous orange solution of xanthate salt was precipitated in $500 \mathrm{~mL}$ of cold methanol:ether 1:1 mixture. $^{2}$

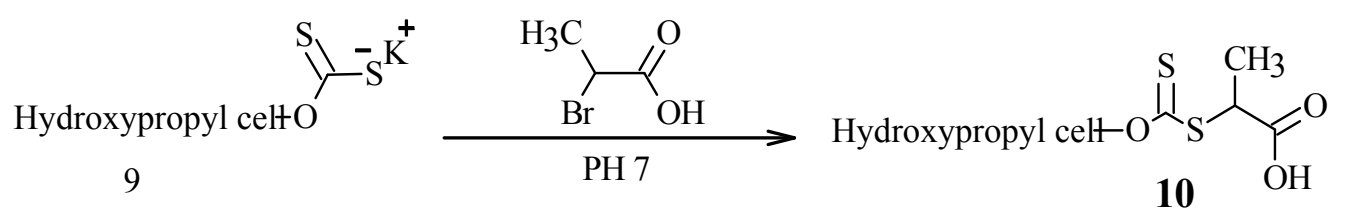

Scheme 3.14: Preparation of S-sec propionic acid hydroxylpropyl cellulose xanthate RAFT agent (10). 


\section{Chapter 3: Synthesis and characterization of xanthate RAFT agents.}

After being washed three times with ether, the yellow xanthate product (9) was dissolved in ice-cold distilled water $(75 \mathrm{~mL})$. 2-Bromopropionic acid (4 g, $2.35 \mathrm{~mL})$, which had been neutralized by a solution of potassium hydroxide $(1.12 \mathrm{~g}, 0.02 \mathrm{~mol})$ in distilled water $(2 \mathrm{~mL})$, was slowly added over 15 minutes at room temperature and the reaction mixture was stirred overnight. Precipitation occurred immediately when the reaction mixture was acidified to $\mathrm{pH} 2-3$, achived by dropwise addition of $1 \mathrm{M}$ hydrochloric acid. The yellow solid S-sec propionic acid hydroxylpropyl cellulose xanthate RAFT agent (10) was washed several times with ether and dried under reduced pressure in a vacuum oven, to yield compound (10) $(3.3 \mathrm{~g}){ }^{2}$

FTIR analysis of the RAFT agent (10) is shown in Figure.3.1:

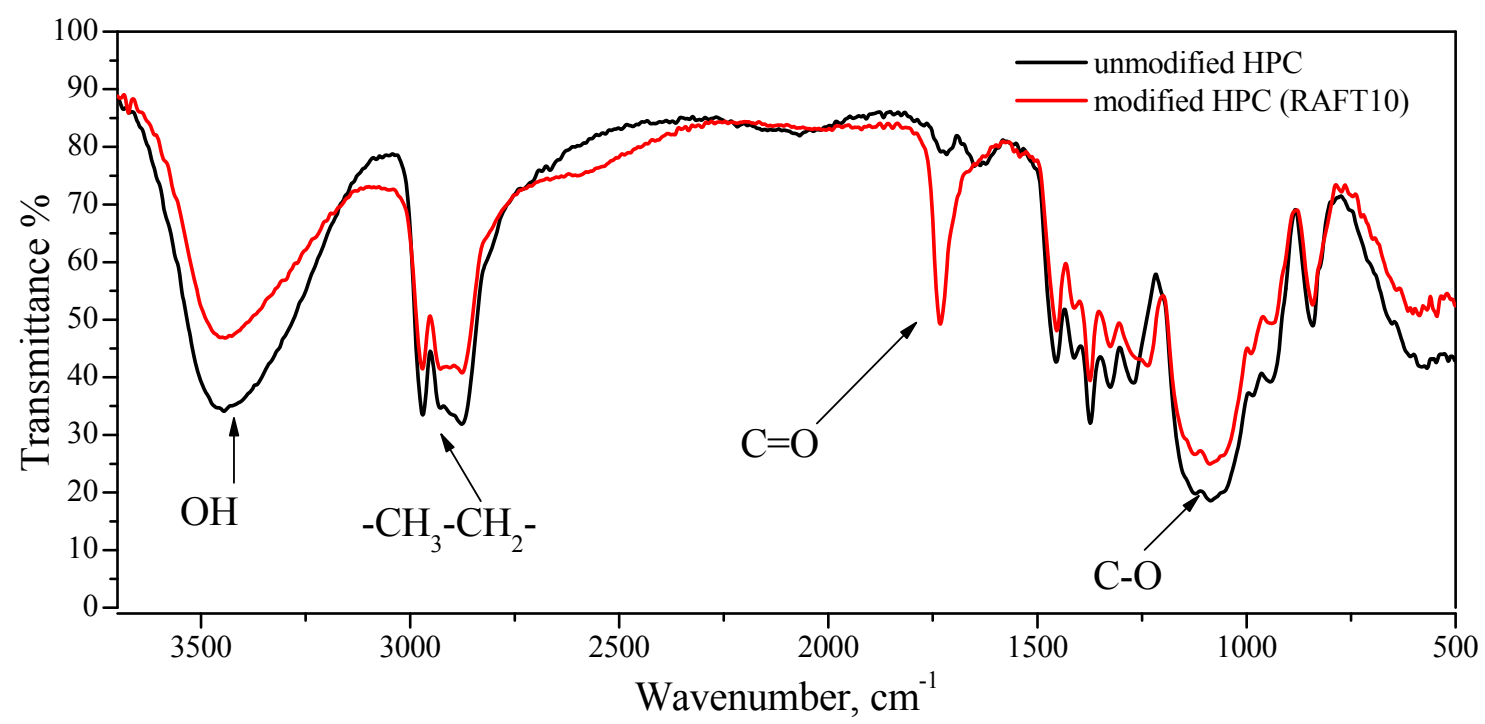

Fig. 3.1: FTIR spectrum of hydroxylpropyl cellulose and S-sec propionic acid hydroxylpropyl cellulose xanthate RAFT agent (10).

FT-IR (photoacoustic cell PAS wavenumbers $\left(\mathrm{cm}^{-1}\right)$ and their assignments: $3452(-\mathrm{OH})$, $2972\left(-\mathrm{CH}_{2-},-\mathrm{CH}_{3}\right), 1737(\mathrm{C}=\mathrm{O}), 1190(\mathrm{C}-\mathrm{O}), 1031(\mathrm{C}=\mathrm{S}), 849$ (C-S).

$\mathrm{UV}(\mathrm{C}=\mathrm{S}):\left(\mathrm{n} \rightarrow \pi^{*}, \lambda_{\max }=376 \mathrm{~nm}\right)$ and $\left(\pi \rightarrow \pi^{*}, \lambda=283 \mathrm{~nm}\right)$. Ethanol was used as solvent. 


\subsection{8: Synthesis of S-sec propionic acid methyl cellulose xanthate RAFT agent (11)}

The procedure used to synthesis RAFT (11) was similar to that described for the synthesis of RAFT (10) as described in Section 3.4.7, the only difference was that now the following quantities of chemicals were used: ${ }^{2}$

methyl cellulose $(2.5 \mathrm{~g}), 18 \%$ aqueous potassium hydroxide solution $(30 \mathrm{~mL})$, carbon disulfide $(30 \mathrm{~mL})$, distilled water $(50 \mathrm{~mL})$, methanol $(250 \mathrm{~mL})$, ether $(250 \mathrm{~mL})$, 2-bromopropionic acid $(4 \mathrm{~g}, 2.35 \mathrm{~mL})$ neutralized by a solution of potassium hydroxide $(0.02 \mathrm{~mol}, 1.12 \mathrm{~g})$ in distilled water $(2 \mathrm{~mL})$. S-sec propionic acid methyl cellulose xanthate RAFT agent (11) $3 \mathrm{~g}$ was isolated.<smiles>CC(SC(=S)OCl)C(=O)O</smiles>

Scheme 3.15: Structure of S-sec propionic acid methyl cellulose xanthate RAFT agent (11)

FTIR analysis of the product RAFT agent (11) showed the following:

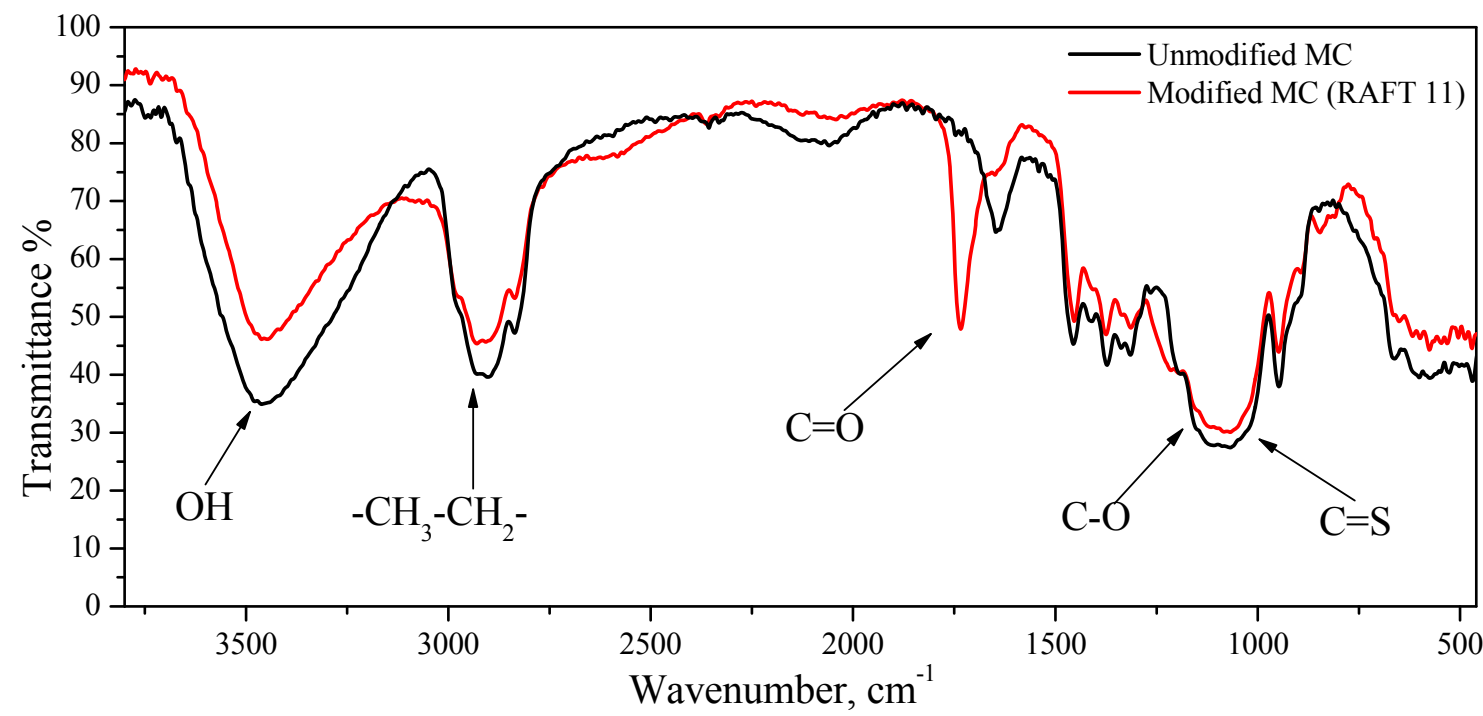

Fig. 3.2: FTIR spectrum of methyl cellulose and S-sec propionic acid methyl cellulose xanthate RAFT agent (11). 


\section{Chapter 3: Synthesis and characterization of xanthate RAFT agents.}

FT-IR (photoacoustic cell PAS wavenumbers $\left(\mathrm{cm}^{-1}\right)$ and their assignments: 3457 (-OH), $2921\left(-\mathrm{CH}_{2^{-}},-\mathrm{CH}_{3}\right), 1733(\mathrm{C}=\mathrm{O}), 1191(\mathrm{C}-\mathrm{O}), 1026(\mathrm{C}=\mathrm{S}), 852(\mathrm{C}-\mathrm{S})$.

$\mathrm{UV}(\mathrm{C}=\mathrm{S}):\left(\mathrm{n} \rightarrow \pi^{*}, \lambda_{\max }=383 \mathrm{~nm}\right)$ and $\left(\pi \rightarrow \pi^{*}, \lambda=287 \mathrm{~nm}\right)$. Dimethylformamide was used as solvent.

\subsection{9: Synthesis of S-sec propionic acid cellulose xanthate RAFT agent} (12)

The procedure used to synthesis RAFT (12) was similar to that described for the synthesis of RAFT (10) as described in Section 3.4.7. The only difference was that now the following quantities of chemicals were used: ${ }^{2}$

cellulose $(2.5 \mathrm{~g}), 18 \%$ aqueous potassium hydroxide solution $(30 \mathrm{~mL})$, carbon disulfide $(30 \mathrm{~mL})$, distilled water $(50 \mathrm{~mL})$, methanol $(250 \mathrm{~mL})$, ether $(250 \mathrm{~mL})$, 2-bromopropionic acid $(4 \mathrm{~g}, 2.35 \mathrm{~mL})$ neutralized by a solution of potassium hydroxide $(0.02 \mathrm{~mol}, 1.12 \mathrm{~g})$ in distilled water $(2 \mathrm{~mL})$. S-sec propionic acid cellulose xanthate RAFT agent (12) $3.1 \mathrm{~g}$ was obtained.<smiles>CC(SC(=S)OCl)C(=O)O</smiles>

Scheme 3.16: Structure of S-sec propionic acid cellulose xanthate RAFT agent (12). 


\section{Chapter 3: Synthesis and characterization of xanthate RAFT agents.}

FTIR analysis of the product RAFT agent (12) showed the following:

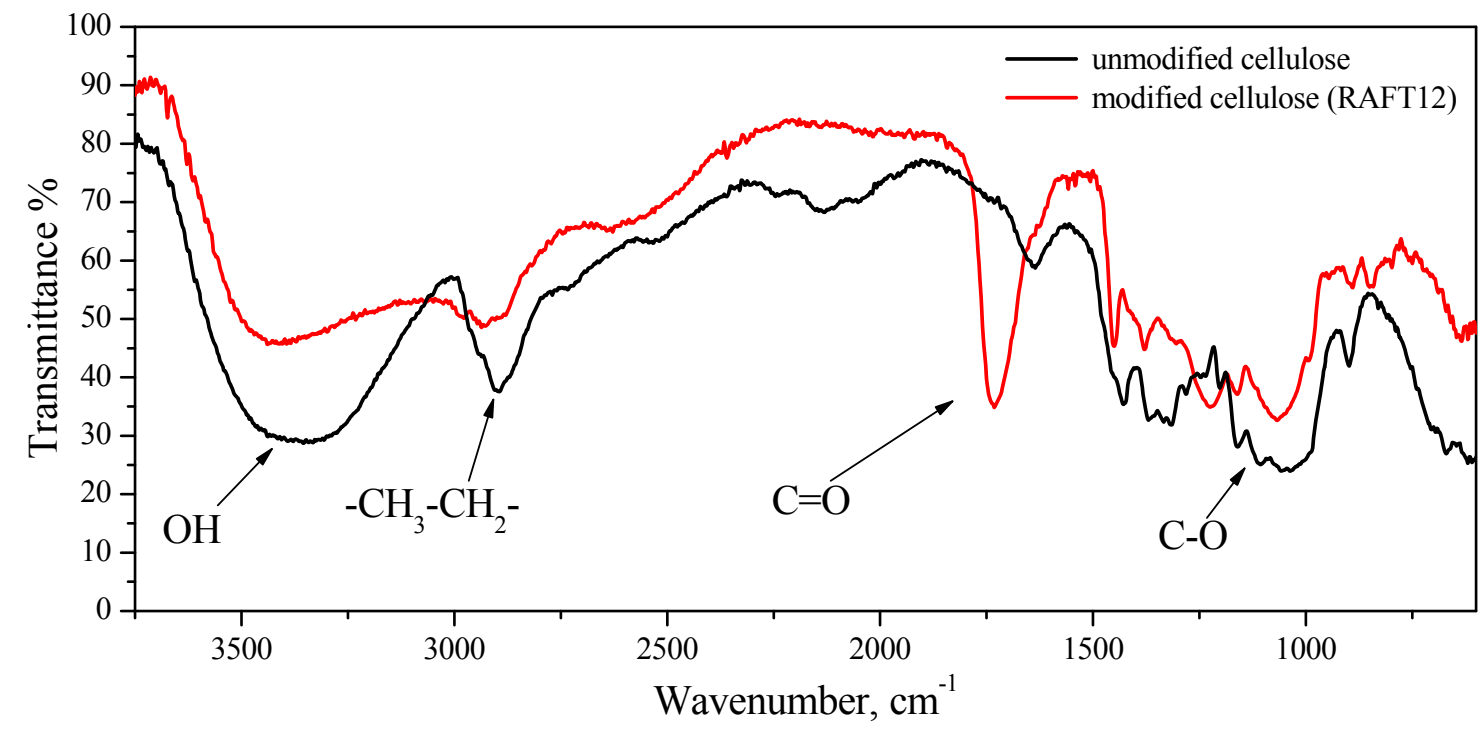

Fig. 3.3: FTIR spectrum of cellulose and S-sec propionic acid cellulose xanthate RAFT agent (12).

FT-IR (photoacoustic cell PAS $\left(\mathrm{cm}^{-1}\right)$ wavenumbers and their assignments: $3455(-\mathrm{OH})$, $2934\left(-\mathrm{CH}_{2^{-}},-\mathrm{CH}_{3}\right), 1734(\mathrm{C}=\mathrm{O}), 1165(\mathrm{C}-\mathrm{O}), 1064(\mathrm{C}=\mathrm{S}), 851(\mathrm{C}-\mathrm{S})$.

$\mathrm{UV}(\mathrm{C}=\mathrm{S}):\left(\mathrm{n} \rightarrow \pi^{*}, \lambda_{\max }=420 \mathrm{~nm}\right)$ and $\left(\pi \rightarrow \pi^{*}, \lambda=284 \mathrm{~nm}\right)$. Dimethylformamide was used as solvent.

\section{5: Discussion of the RAFT syntheses}

FTIR spectroscopy, UV spectroscopy, ${ }^{1} \mathrm{H}-\mathrm{NMR}$ and ${ }^{13} \mathrm{C}-\mathrm{NMR}$ spectroscopy were used to characterize the xanthate RAFT/MADIX agents synthesized as described in Section 3.3. The characteristic absorption peaks for different chemical bonds ( and other specific bonds for each xanthate RAFT agent synthesized in this work) were seen in the infra-red spectra of all RAFT agents. ${ }^{11}$ UV spectroscopy is a method that is used to determine the wavelength of maximum absorption $\left(\lambda_{\max }\right)$ of UV-absorbing species. The xanthate RAFT agents were expected to have an absorbtion maximum in the vicinity of $320 \mathrm{~nm}$ as the thiocarbonyl moiety $(\mathrm{C}=\mathrm{S})$ in the RAFT agents absorbs strongly at this wavelength. ${ }^{12} \mathrm{UV}$ analysis of all the RAFT agents in this work clearly showed a strong absorbtion peak in this region. This strong adsorbtion peak was absent in the 


\section{Chapter 3: Synthesis and characterization of xanthate RAFT agents.}

starting materials (alcohols, diols, triols, tetraols and polyols) from which the xanthate RAFT agents were prepared.

${ }^{1} \mathrm{H}-\mathrm{NMR}$ and ${ }^{13} \mathrm{C}-\mathrm{NMR}$ spectroscopy showed the presence of all the functional groups expected in the spectra for all the xanthate RAFT agents. Spectra were however not obtained for polyol xanthate RAFT agents (10), (11) and (12), which are polymeric RAFT agents. RAFT agents (10) and (11) appeared to disperse in deuterated solvents, but it was not possible to identify most of the peaks in ${ }^{1} \mathrm{H}-\mathrm{NMR}$ experiments, because they do not sufficiently dissolve to give significant NMR signals. This is not unexpected as underivatized cellulose can not be analyzed by solution state NMR due to insolubility of this class of compounds. ${ }^{13}$ 


\section{Chapter 3: Synthesis and characterization of xanthate RAFT agents.}

\section{6: References}

(1) Bernard, J.; Favier, A.; Zhang, L.; Nilasaroya, A.; Davis, T.; Kowollik, C.; Stenzel, M. Macromolecules 2005, 38, 5475-5484.

(2) Whistler, R.; Green, J.; Bemiller, J. In Methods In Carbohydrate Chemistry; Academic Press: London, 1963; Vol. III, pp 238-250.

(3) Furniss, S.; Hannaford, A.; Smith, P.; Tatchell, A. In Text Book of Practical Organic Chemistry, Fifth ed.; Longman Group UK Limited: London, 1989; pp 792-794.

(4) Degani, I.; Fochi, R. Synthesis 1978, 365-368.

(5) Cesare, P.; Gross, B. Synthesis 1980, 714-715.

(6) Houben-Weyl. In Methoden der Orgauischeu Chemie; Eugen, M., Ed.; Georg thieme verlag Stuttgam: Germany, 1967; Vol. 9, p 812.

(7) Feller, R.; wilt, M. In Evaluation of Cellulose Ethers for Conservation, Second ed.; Paul Getty: Canada, 1990; Vol. 3, pp 9-18.

(8) Harwood, L.; Moody, C.; Percy, J. In Experimental Organic Chemistry; Blackwell Science: London, 1999; pp 356-366.

(9) Degani, I.; Fochi, R.; Santi, M. Synthesis 1977, 873-874.

(10) Whistler, R.; Wolfrom, M.; Bemiller, J. In Methods In Carbohydrate Chemistry; Academic Press: London, 1963; Vol. II, pp 319-325.

(11) Socrates, G. In Infrared Characteristic Group Frequencies, Second ed.; John Wiley and Sons: London, 1994; pp 10-30.

(12) Russum, J.; Jones, C. W.; Schork, F. J. Macromolecular Rapid Communications 2004, 25, 1064-1068.

(13) Klemm, D.; Philipp, B.; Heinze, T.; Wagenknecht, W. In Comprehensive Cellulose Chemistry; Wiley-vch, 1998; Vol. 1, pp 186-194. 


\section{Chapter 4: RAFT mediated polymerization}




\section{Chapter 4: RAFT mediated polymerization}

\section{1: Introduction}

Vinyl acetate is a widely used monomer in the adhesives, paints, and concrete additives industries. $^{1,2}$ It is a precursor to polyvinyl alcohol, which can be suitable for pharmaceutical applications. ${ }^{3}$ Thus controlled free radical polymerization of vinyl acetate is of particular technological interest.

As the vinyl acetate propagating radical is relatively unstable and thus highly reactive, it tends to undergo chain transfer and termination reactions. ${ }^{4}$ As a result the control of vinyl acetate polymerization has been considered challenging and it has proved difficult to control vinyl acetate polymerizations using stable free radical living radical systems such as NMP and ATRP. ${ }^{4,5}$ In the case of RAFT mediated polymerization, dithiobenzoates inhibit the polymerization of vinyl acetate. This is because the vinyl acetate propagating radical is a poor homolytic leaving group, therefore the fragmentation of the RAFT adduct radical is very slow. ${ }^{5}$ Controlled polymerization of vinyl acetate has however, been achieved using either dithiocarbamates or xanthates as RAFT agents. ${ }^{6}$ The ability of these compounds to control vinyl acetate polymerization can be correlated to an increase in the electron density at the radical center i.e. the intermediate macro RAFT radical (see Section 2.2.3.2), which destabilizes the RAFT-adduct radical hence increasing the fragmentation rate. ${ }^{5,6}$

Cellulose derivatives as polymer raw material are used for general purposes, but are not easily processed without chemical modification. ${ }^{7}$ They have served mankind as polymers and construction materials in the form of intact wood or in the form of natural textile fibers like cotton or flax. ${ }^{8,9}$

A study of the living character of vinyl acetate polymerization as a function of the xanthate RAFT/MADIX agents that were synthesized as described in Chapter 3 is now presented in this chapter (Section 4.2). The effect of the respective synthesized xanthate RAFT/MADIX agents on the polymerization of vinyl acetate in terms of polydispersity, molar mass and molar mass distribution was evaluated and is discussed. The efficiency of polyol (cellulosic) xanthate RAFT/MADIX agents in terms of control of the grafting of vinyl acetate onto the backbone of the cellulosic materials, and the thermal stability of the graft copolymers was also evaluated and is presented. 


\section{2: Experimental}

\subsection{1: Polymerization of vinyl acetate}

Bulk polymerizations of vinyl acetate were performed in Schlenk tubes (to prevent evaporation of the highly volatile vinyl acetate) at $60{ }^{\circ} \mathrm{C}$, using 2,2 azobis(isobutyronitrile) (AIBN) (which was re-crystallized twice from methanol) as the initiator and xanthates (2), (4), (5), (6), (8) as RAFT agents (the syntheses of which were described in Chapter 3).

Grafting of vinyl acetate onto the backbone of the polysaccharide materials was conducted in solution in Schlenk tubes at $68{ }^{\circ} \mathrm{C}$, using DMF as solvent, AIBN as the initiator and xanthates (10), (11), (12) as RAFT agents. The monomer, vinyl acetate, was first filtered through a column of inhibitor remover packing, polystyrene $1 \%$ crosslinked with divinylbenzene (Stratospheres ${ }^{\circledR}$ ) to remove the radical inhibitor, and then distilled under reduced pressure before utilization.

Before the polymerization reactions were started, the Schlenk tubes were deoxygenated by six consecutive freeze-pump-thaw cycles. All the reactions were conducted under nitrogen gas and samples were withdrawn at specific time intervals via a septum, until the reaction reached its final conversion. Conversions were calculated gravimetrically. The reactions were stopped by cooling in an ice bath. The polymer was isolated by evaporating the residual vinyl acetate, initially in a fume hood and then in a vacuum oven.

Molar masses and molar mass distributions were measured by means of SEC. Graft copolymers were characterized via HPLC. 


\subsection{2: Bulk polymerization of vinyl acetate mediated by xanthate RAFT/MADIX agents}

The quantities of reagents used in the bulk polymerization of vinyl acetate to produce linear and star shaped polyvinyl acetate are given in Table 4.1. All reactions were carried out at $60^{\circ} \mathrm{C}$.

Table 4.1: The quantities of reagents used in bulk polymerization of vinyl acetate.

\begin{tabular}{|c|c|c|c|c|}
\hline Reaction & RAFT agent & $\begin{array}{c}\text { Mass of RAFT } \\
\text { agent (g) }\end{array}$ & $\begin{array}{c}\text { Mass of } \\
\text { AIBN(g) }\end{array}$ & $\begin{array}{c}\text { Mass of } \\
\text { VAc (g) }\end{array}$ \\
\hline 1 & $\begin{array}{c}\text { Monofunctional } \\
\text { xanthate RAFT (2) }\end{array}$ & 0.23 & 0.02 & 20 \\
\hline 2 & $\begin{array}{c}\text { Difunctional } \\
\text { xanthate RAFT (4) }\end{array}$ & 0.48 & 0.06 & 20 \\
\hline 3 & $\begin{array}{c}\text { Trifunctional } \\
\text { xanthate RAFT (5) }\end{array}$ & 0.28 & 0.04 & 20 \\
\hline 4 & $\begin{array}{c}\text { Tetrafunctional } \\
\text { xanthate RAFT (6) }\end{array}$ & 0.25 & 0.04 & 20 \\
\hline 5 & $\begin{array}{c}\text { Monofunctional } \\
\text { xanthate RAFT (8) }\end{array}$ & 0.23 & 0.03 & 20 \\
\hline
\end{tabular}

\section{3: Characterization}

\subsection{1: Size Exclusion Chromatography (SEC)}

Molar masses and molar mass distributions were determined using SEC. Dried samples of the polymer were dissolved in THF of $(5 \mathrm{mg} / \mathrm{mL})$ and filtered through a $0.45 \mu \mathrm{m}$ nylon filter. The SEC instrument consisted of a Waters 117 plus Auto-sampler, Waters $600 \mathrm{E}$ system Controller (run by Millennium ${ }^{32}$ V 3.05 software) and a Waters 610 fluid unit. A Waters 410 differential refractometer and Waters 2487 dual wavelength absorbance detector were used at $30{ }^{\circ} \mathrm{C}$ as detector. THF (HPLC grade) sparged with IR grade helium was used as eluent at a flow rate of $1 \mathrm{~mL} / \mathrm{min}$. the column oven was kept at $30^{\circ} \mathrm{C}$ 


\section{Chapter 4: RAFT mediated polymerization}

and the injection volume was $100 \mu \mathrm{L}$. Two PLgel $5 \mu \mathrm{m}$ Mixed-C columns and a precolumn (PLgel $50 \mu \mathrm{m}$ Guard) were used. The system was calibrated with narrow polystyrene standards ranging from 800 to $2 \times 10^{6} \mathrm{~g} / \mathrm{mol}$. All molar masses were reported as polystyrene equivalents.

\subsection{2: Rates of reaction of vinyl acetate polymerization mediated by xanthate RAFT agents}

Figure 4.1 shows the monomer conversion versus time for reactions (1) to (5). The semilogarithmic kinetic plots in the figure show that there is a first-order monomer consumption rate. The curves indicates that there is a steady-state radical concentration, which means that the rate of radical generation and the rate of radical loss are equivalent during the course of the reactions, while the initiator concentration is sufficient in the system. In other words the number of growing chains (propagating species) is constant throughout the polymerization reactions.

Prominent inhibition periods were observed for reactions (3), (4) and (5), where trifunctional (5), tetrafunctional (6) and monofunctional (8), xanthate RAFT agents were used for the preparation of linear and star shaped polymers. The inhibition periods were barely observed for reactions (1) and (2), where monofunctional (2) and difunctional (4) xanthate RAFT agents were used to prepare the linear shaped polymer.

The inhibition period observed with tetrafunctional xanthate RAFT in reaction (4) (less than $3 \mathrm{~h}$ ) is much less pronounced than in the polymerization mediated by monofunctional reaction (5) and trifunctional xanthate RAFT reaction (3), where inhibition periods of up to $4 \mathrm{~h}$ were observed.

The most likely reason for these inhibition periods is that, proposed by Bernard, ${ }^{10}$ trace levels of impurities, too low to be detected on thin-layer chromatography plates are responsible.

This hypothesis is supported by the relative ease of purification of monofunctional (2) and difunctional (4) xanthate RAFT agents in contrast to monofunctional (8), trifunctional (5) and tetrafunctional (6) xanthate RAFT agents. The latter three could not be purified by recrystallization. 


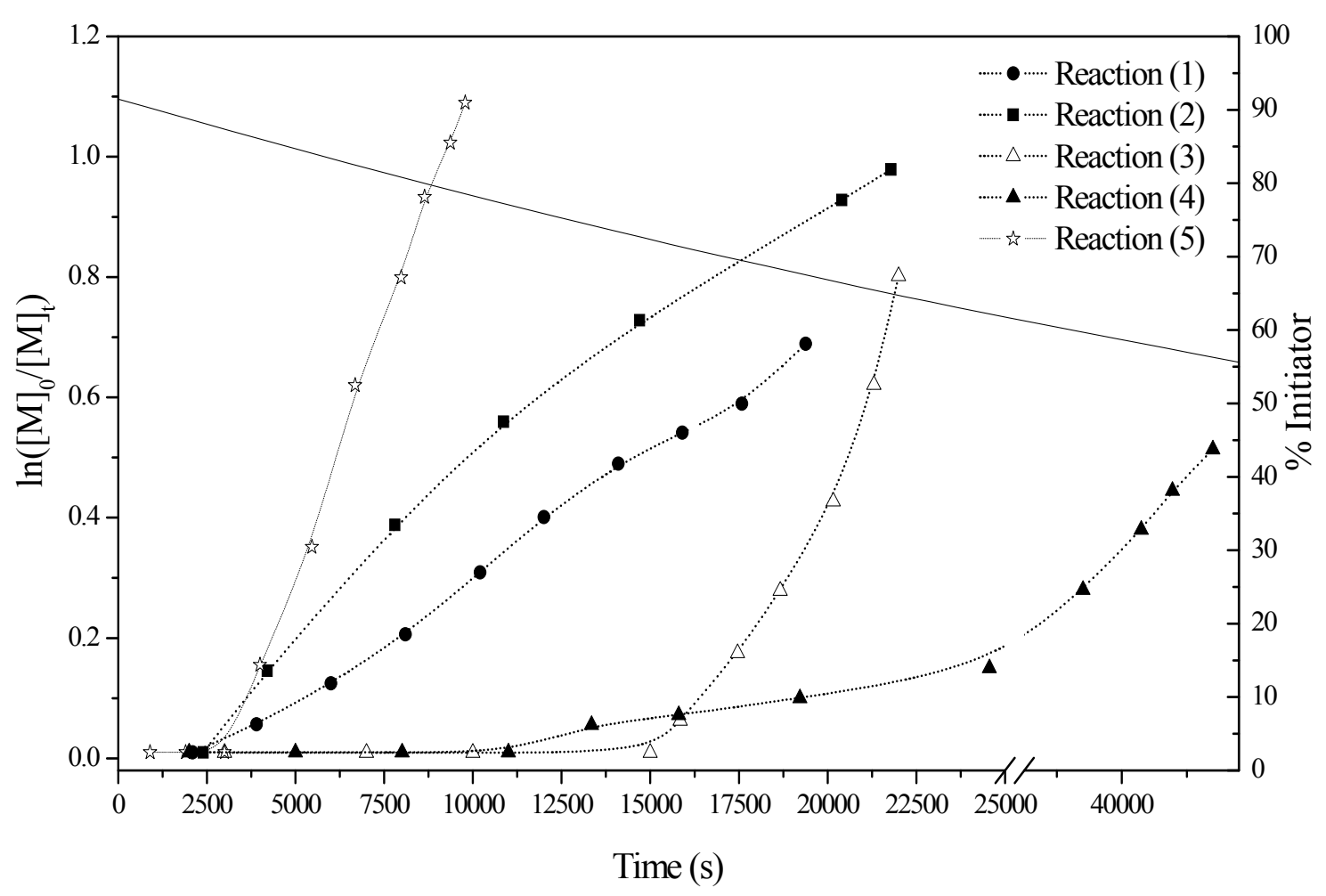

Fig. 4.1: Semilogarithmic plots of fractional conversion versus time for vinyl acetate mediated homopolymerizations by xanthate RAFT agents (2), (4), (5) (6) and (8) (reactions 1, 2, 3, 4 and 5). Dotted lines have been added as guides for the eye All reaction conditions are listed in Table 4.1. 


\subsection{3: Molar mass distribution of polyvinyl acetates as determined by SEC}

The evaluation of experimental molar masses and molar mass distributions with conversion was investigated by SEC analysis for reactions (1) to (5) (see also Figure 4.2). Each chromatogram exhibited a narrow monomodal molar mass distribution, and the molar mass increased linearly with conversion, indicating the successful living polymerization of vinyl acetate. ${ }^{13}$ The presence of low molar mass tailing in the chromatograms corresponds to a proportion of termination products (dead polymers) due to termination reactions among short chains. Figure 4.2 shows molar mass distribution of samples scaled for conversion taken from reactions (1) to (5)
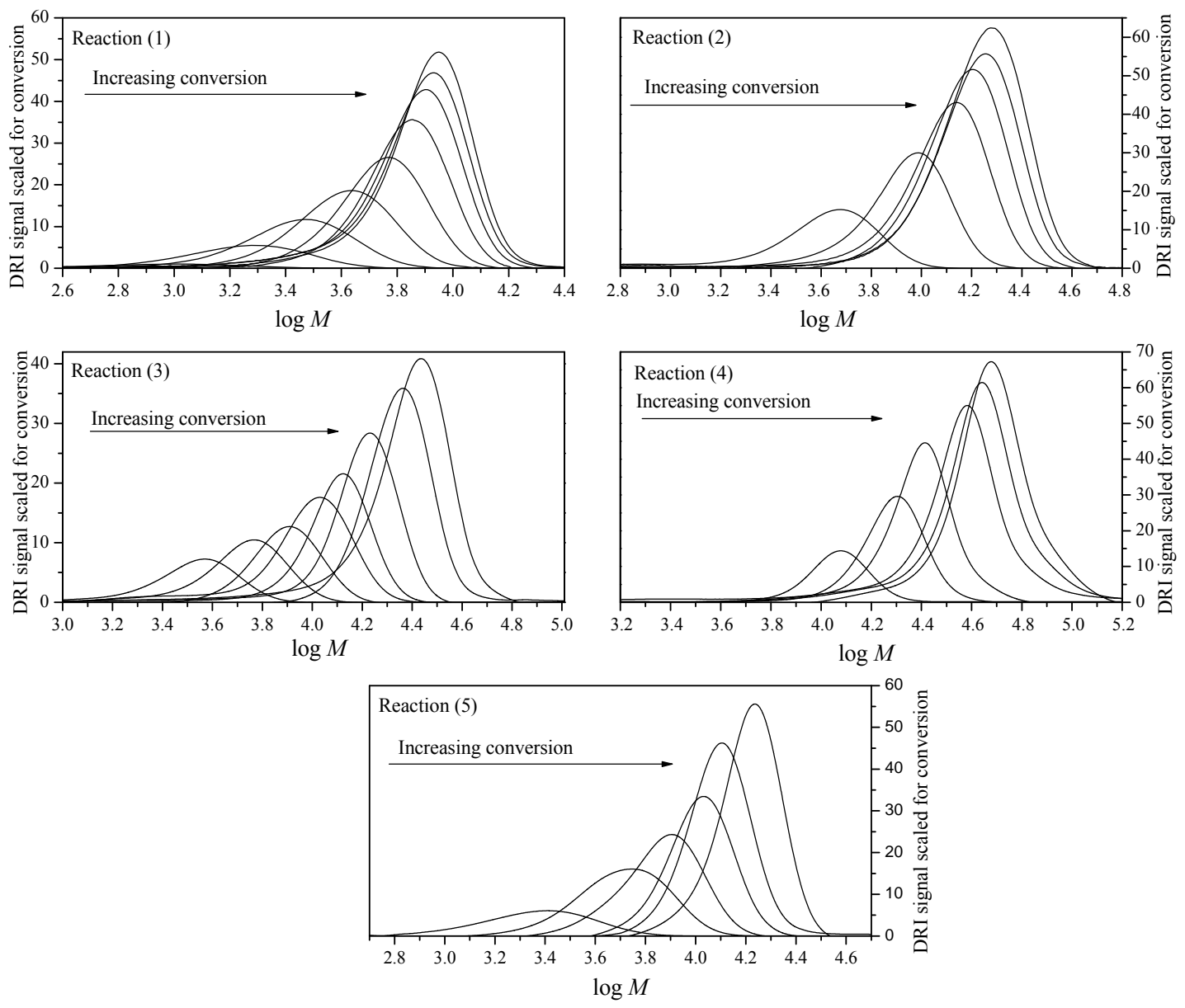

Fig. 4.2: Molar mass distribution of samples scaled for conversion taken from reactions (1) to (5), where RAFT (2), RAFT (4), RAFT (5), RAFT (6) and RAFT (8) were used in reactions $(1,2,3,4$ and 5$)$ respectively. All reactions conditions are listed in Table 4.1. 


\section{Chapter 4: RAFT mediated polymerization}

Figure 4.3 shows that $M_{\mathrm{n}}$ increases linearly as a function of monomer conversion. This is an indication there were a constant number of growing chains during the polymerizations which means there was control over molar mass during the reaction. ${ }^{14}$ The experimental and theoretical $M_{\mathrm{n}}$ values are similar for all the reactions from (1) to (5), although in reaction (1) at higher conversion there was a small deviation of SEC $M_{\mathrm{n}}$ from theoretical $M_{\mathrm{n}}$, which could be due to the presence of oxygen molecules introduced to the reaction while samples were being taken. ${ }^{10}$ In general, there is a possibility of overestimation and underestimation in the theoretical $M_{\mathrm{n}}$ determined by Equation 2.16, (see Section 2.2.3.2). ${ }^{15}$

$$
\bar{M}_{\mathrm{n}, \text { theory }}=\frac{x[\mathrm{M}]_{0} M_{\mathrm{M}}}{[\mathrm{RAFT}]_{0}}+M_{\mathrm{RAFT}}
$$

Overestimation normally occurs when initiator derived chains are neglected.

The lower values of experimental $M_{\mathrm{n}}$ observed in reactions (4) and (5) (see Figure 4.3) could be due to the fact that, as the star polymers have lower hydrodynamic volumes than the equivalent linear polymers, the experimental molar mass of the star polymer observed in reactions (4) and (5) determined by SEC with linear PS standards appeared slightly lower than the theoretical $M_{\mathrm{n}}$ as can be seen in Figure 4.3. ${ }^{10,11}$

Therefore a multi-angle laser light scattering detector (MALLS) was used to determine the absolute molar mass for the star polymers. The molar masses of the star polymers obtained by MALLS (Mn 3arms = 30,000 g/mol, Mn 4arms = 46,000 g/mol), were higher than the molar masses obtained by SEC $(\mathrm{Mn} 3 \mathrm{arms}=24,000 \mathrm{~g} / \mathrm{mol}$, Mn 4arms $=40,000 \mathrm{~g} / \mathrm{mol})$.

The obtained polydispersities of the generated polyvinyl acetates are close to or below 1.2 throughout the reactions, as can be seen from inspection of Figure 4.3. This is a characteristic of living radical polymerization.

In RAFT mediated living radical polymerization systems polydispersity should decrease with conversion, ending close to unity upon full conversion. This is because most of the chains will be growing via the RAFT mechanism and if termination is negligible (i.e. the number of initiator-derived chains is small compared to the number of dormant chains). ${ }^{16}$ 


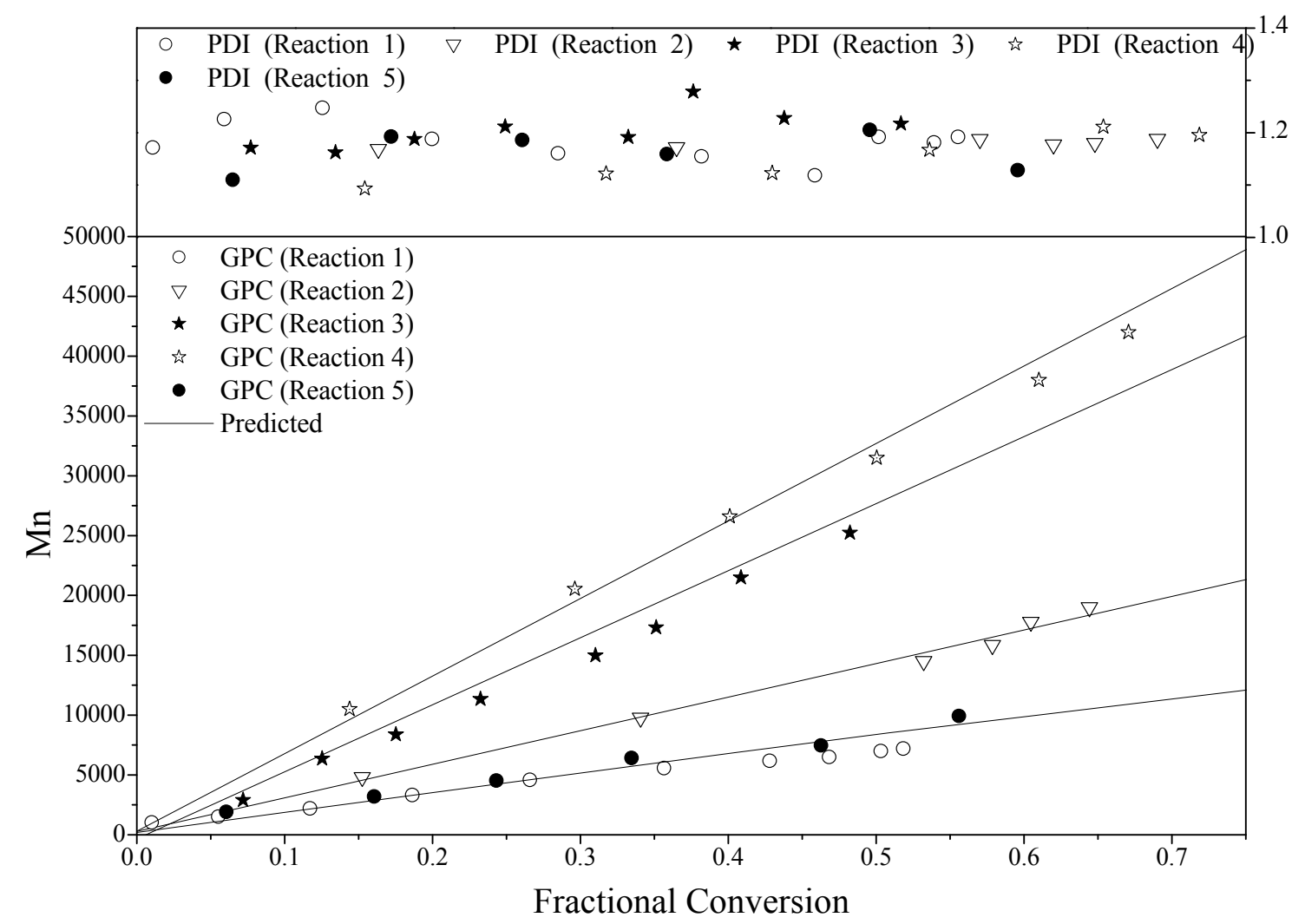

Fig. 4.3: Evaluation of Mn and polydispersity as a function of conversion for RAFT mediated polymerization of vinyl acetate prepared from reactions (1) to (5). Refer to Table 4.1 for reactions conditions.

\subsection{4: UV-RI overlays of polyvinyl acetates as determined by SEC}

The presence of RAFT agent end-group moeties can be examined using dual detection for SEC. UV and RI detectors were used to determine whether the polymer chains have the RAFT end group. The UV detector was set at $320 \mathrm{~nm}$ as the carbonylthio bond $(\mathrm{C}=\mathrm{S})$ of xanthate RAFT agent absorbs strongly at this wavelength, ${ }^{17}$ and the RI is a concentration sensitive detector.

Overlay comparisons of the two signals can indicate whether the RAFT functionality is homogenously or heterogeneously distributed throughout the molar mass distribution curve.

At low molar mass the UV signal observed is very strong due to the fact that the chains are small, resulting in a high concentration of RAFT agent per mass of chain. The graphs 
in Figure 4.4 show that the RAFT moiety was homogenously distributed in most of the polymer chains, as indicated by the UV-RI overlays.
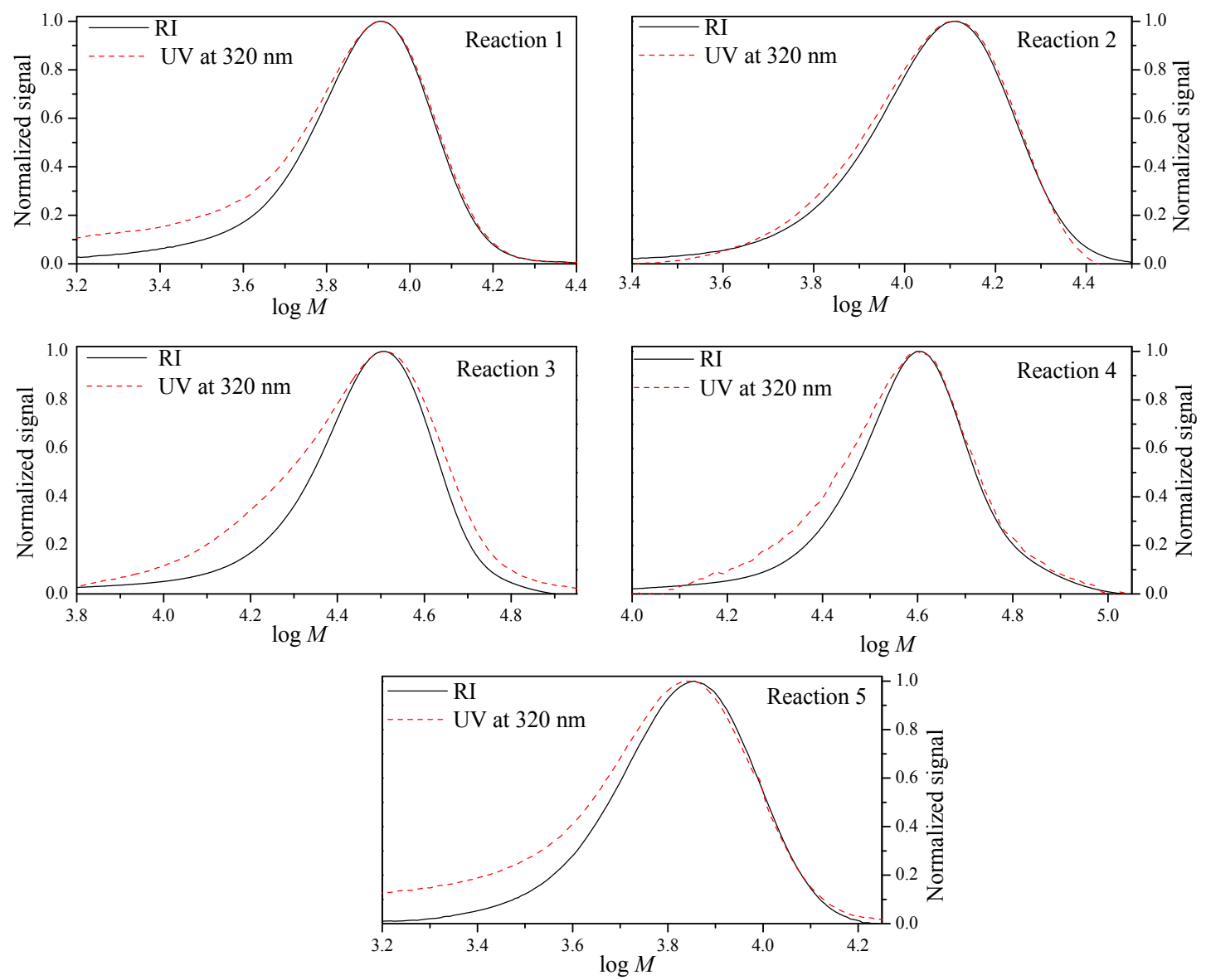

Fig. 4.4: UV-RI overlays for RAFT mediated polymerization of vinyl acetate prepared from reactions (1) to (5), where RAFT (2), RAFT (4), RAFT (5), RAFT (6) and RAFT (8) were used in reactions $1,2,3,4$ and 5 respectively. All reactions conditions are listed in Table 4.1.

\section{4: Grafting of vinyl acetate onto cellulosic materials}

\subsection{1: Experimental}

The quantities of reagents used in the graft polymerization of vinyl acetate onto cellulosic materials to produce comb-like graft copolymers are given in Table 4.2. All the reactions were carried out at $68{ }^{\circ} \mathrm{C}$. The only suitable solvent for the grafting procedure proved to be dimethylformamide (DMF). DMF however suffers from a high chain transfer coefficient, which limits the molar mass in conventional polymerizations in this solvent. 


\section{Chapter 4: RAFT mediated polymerization}

To limit the effect of transfer reactions low molar mass grafts $(15,000 \mathrm{~g} / \mathrm{mol})$ were targeted.

Table 4.2: The quantities of reagents used in graft polymerization of vinyl acetate onto cellulosic materials.

\begin{tabular}{|c|c|c|c|c|c|}
\hline $\begin{array}{c}\text { Reaction } \\
\text { number }\end{array}$ & $\begin{array}{c}\text { RAFT } \\
\text { agent }\end{array}$ & $\begin{array}{c}\text { Mass of } \\
\text { RAFT (g) }\end{array}$ & $\begin{array}{c}\text { Mass of } \\
\text { AIBN (g) }\end{array}$ & $\begin{array}{c}\text { Mass of } \\
\text { VAc (g) }\end{array}$ & $\begin{array}{c}\text { Mass of } \\
\text { Prod. (g) }\end{array}$ \\
\hline 6 & $\begin{array}{c}\text { polyol xanthate } \\
\text { RAFT (10) }\end{array}$ & 1.0 & 0.06 & 10 & 4.2 \\
\hline 7 & $\begin{array}{c}\text { polyol xanthate } \\
\text { RAFT (11) }\end{array}$ & 1.0 & 0.04 & 10 & 3.0 \\
\hline 8 & $\begin{array}{c}\text { polyol xanthate } \\
\text { RAFT (12) }\end{array}$ & 1.0 & 0.06 & 10 & 3.4 \\
\hline
\end{tabular}

\section{5: Analysis of graft copolymers}

Graft copolymers are complex multi-component materials with a molar mass distribution as well as a chemical composition distribution. The determination of the CCD is essential in the characterization of copolymers, but it is not an elementary task. For the past 20 years the use of HPLC has been the tool of choice for unravelling the molecular heterogeneity of complex polymers. ${ }^{18}$ In this study, the choice of a suitable chromatographic system for amphiphilic graft copolymers is challenging due to the opposing chemical nature of the different moieties (cellulosic materials, and VAc). One of the other difficulties associated with the characterization of amphiphilic copolymers using water as solvent is the removal of hydrophobic fragments from the aqueous surrounding resulting in the formation of micelles consisting of a hydrophobic core stabilized by hydrophilic chains exposed into the water. ${ }^{19,20}$

\subsection{1: Size Exclusion Chromatography (SEC)}

Information on the chemical structure of graft copolymers can be obtained by SEC. Since PVAc does not absorb UV light at $320 \mathrm{~nm}$, where xanthate (RAFT/MADIX) agents (10) and (11) do absorb UV light (the thiocarbonyl moiety $(\mathrm{C}=\mathrm{S})$ in the RAFT agents absorbs 


\section{Chapter 4: RAFT mediated polymerization}

strongly at this wavelength) ${ }^{17}$ SEC employing UV detection is a useful tool for characterization of such graft copolymers. Some information on the molar mass, molar mass distribution and chemical heterogeneity can be gained by using dual RI/UV detection.

Figures $4.5 \mathrm{~A}$ and $4.5 \mathrm{C}$ show the molar mass distributions of unmodified HPC, modified HPC (RAFT 10) and modified MC (RAFT 11) (it should be noted unmodified MC is not THF soluble). It is observed that the molar masses of pure cellulosic materials are decreased dramatically as expected when treated with a strong base in order to obtain RAFT agents (10) and (11). This is due to the fact that the basic reagents break down (i.e. degrade) the cellulosic materials, decreasing the degree of polymerization (DP) as has been suggested by Klemm and coworkers. ${ }^{21}$

UV analysis of reactions mediated by RAFT agents (10) and (11) clearly showed a strong absorbtion peak at $320 \mathrm{~nm}$ in the chromatograms, whereas HPC and MC do not absorb UV light in this region (see Section 3.4) This indicates that some of the hydroxyl groups of HPC and MC were converted into thiocarbonyl-thio (xanthate) chain transfer agents, which were used to mediate the RAFT polymerization of VAc.

Molar mass and molar mass distributions of PVAc-g-HPC and PVAc-g-MC are shown in Figures $4.5 \mathrm{~B}$ and $4.5 \mathrm{C}$. In both chromatograms it is clearly seen that the low molar mass peaks $(M \mathrm{p}=19,000$ and 4,000 $\mathrm{g} / \mathrm{mol}$ respectively) of the bimodal distributions are not RAFT functional since they do not absorb UV at $320 \mathrm{~nm}$, suggesting that these peaks correspond to PVAc homopolymer. It should however be noted that the high molar mass peaks of the bimodal distribution in Figures $4.5 \mathrm{~B}$ and $4.5 \mathrm{C}$ correspond to the graft copolymers PVAc-g-HPC and PVAc-g-MC respectively. Evidence for this assumption is provided by the strong UV absorbtion, in addition to the observation that the molar masses of the modified HPC RAFT agent (10), which started at $M \mathrm{p}=64,000 \mathrm{~g} / \mathrm{mol}$, and modified MC RAFT agent (11), at $M \mathrm{p}=32,000 \mathrm{~g} / \mathrm{mol}$ have increased dramatically $(M \mathrm{p}=450,000$ and $600,000 \mathrm{~g} / \mathrm{mol}$ respectively $)$ due to the grafting of PVAc. 

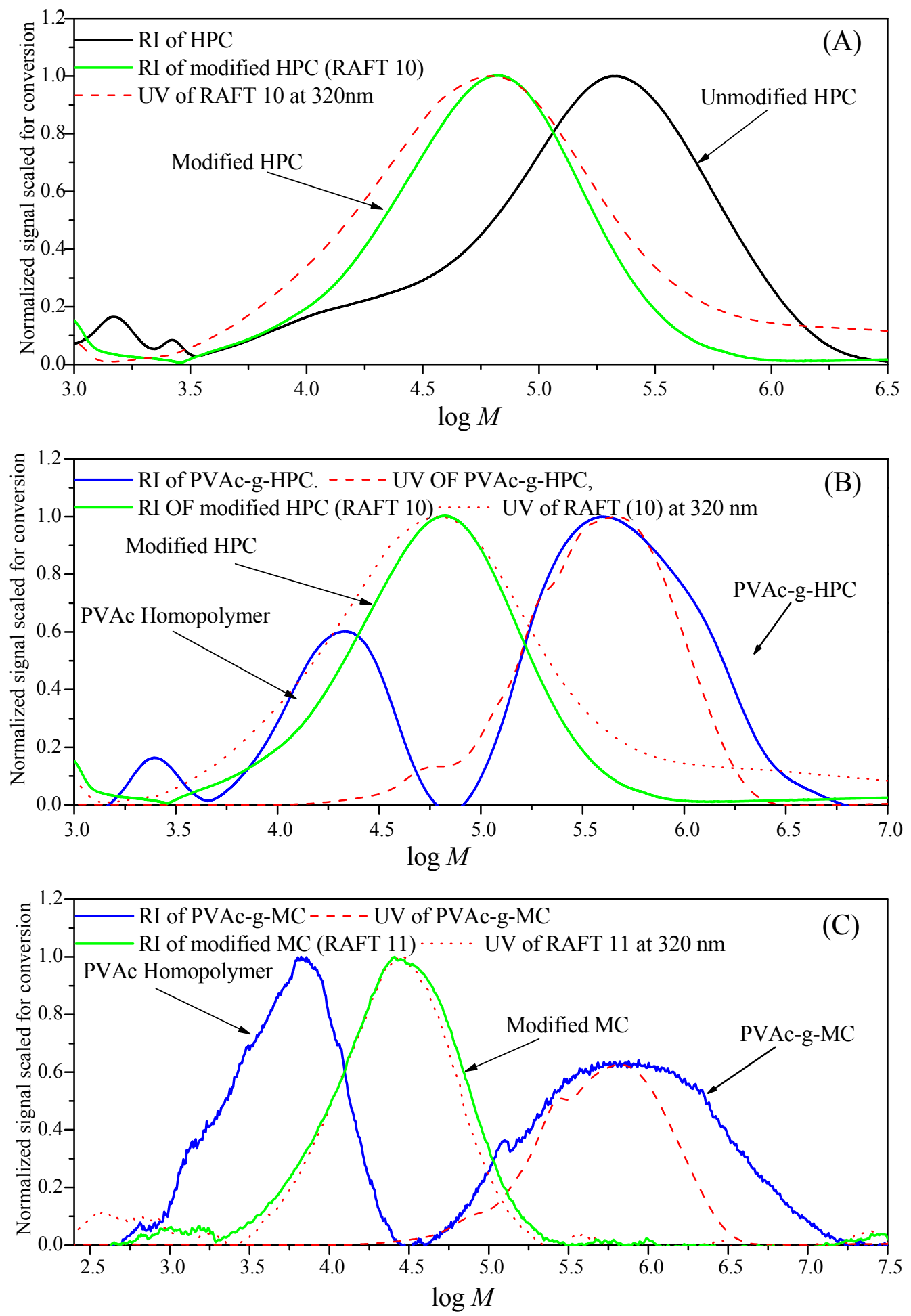

Fig. 4.5: Molar mass distribution of polyvinyl acetate grafted cellulosic materials; (A) molar mass distribution of unmodified and modified HPC, (B) comparison of molar mass distribution of modified HPC (RAFT 10) and grafted HPC from reaction (6), (C) comparison of molar mass distribution of modified MC (RAFT11) and grafted MC from reaction (7). Refer to Table 4.2 for reactions conditions. 


\section{Chapter 4: RAFT mediated polymerization}

\subsection{2: Gradient HPLC}

Graft copolymers were analyzed by liquid adsorption chromatography (LAC) in order to investigate the composition distribution since the technique allows the chains to be separated according to their composition, regardless of molar mass. The separation mechanism is based on the differences in solubility between copolymer fractions with different chemical compositions. ${ }^{22}$

The chromatographic system used for gradient analysis consisted of a Waters 2690 Alliance separation module equipped with a Phenomex Luna C18 100Å, $5 \mathrm{~mm}$ average particle size, $250 \times 4.6 \mathrm{~mm}$ column, was used. The column oven temperature was $30^{\circ} \mathrm{C}$ and the flow rate of the solvent was $1 \mathrm{~mL} / \mathrm{min}$. The evaporative light scattering detector ELSD was operated at $90{ }^{\circ} \mathrm{C}$ with a nitrogen carrier gas flow rate of 1.5 SLM (standard liters per minute). A gradient method using a mobile phase (acetonitrile: water consisting of $0.1 \%$ formic acid) was developed to ensure retention of the highly polar compounds (cellulosic materials) as well as the hydrophobic species (PVAc).

The mobile phase in the gradient was the following: acetonitrile/water (v/v) $=50 / 50(0$ to $1 \mathrm{~min}$ ), $50 / 50$ to $100 / 0$ ( 1 to $25 \mathrm{~min}$ ), 100/0 (25 to $30 \mathrm{~min}$ ), 100/0 to 50/50 (30 to $33 \mathrm{~min}$ ). Data collection was done with PSS-WINGPC7 from Polymer Standards Service (PSS; Mainz, Germany).

\subsubsection{1: Separation of standards}

For the optimization of the gradient HPLC analysis, the polarity of the polymeric species has to be taken into consideration. In the present case modified HPC and modified MC are more polar than PVAc. Therefore when using a reversed phase column (Phenomex Luna $\mathrm{C} 18$ ) the modified HPC and modified MC are expected to elute first in a high polar solvent (water) followed by the PVAc. This can be clearly seen in the chromatogram in Figure 4.6 when standard samples were analyzed by gradient HPLC. The three visible elution peaks can be assigned to PVAc, modified HPC and modified MC standards. Modified cellulose (RAFT 12) is not soluble in the solvent system and therefore could not be analyzed by using HPLC. 


\subsubsection{2: Analysis of PVAc-g-HPC and PVAc-g-MC by gradient HPLC}

The chromatographic separation of the reaction products of PVAc-g-HPC is presented in Figure 4.6A. In the chromatograph very prominent free polyvinyl acetate peaks can be seen eluting at $19 \mathrm{~mL}$ (peak 1) but there is no peak corresponding to residual modified HPC. This means that most of the vinyl acetate monomer in the reaction polymerized to form PVAc homopolymer instead of grafting onto modified HPC. It should however be noted that the elution volume of the free PVAc homopolymer peak (1) coincides with the elution volume of high molar mass PVAc standard, thus pointing to and confirming the formation PVAc homopolymer in the reaction product. Based on the assumption of the elution order and comparison with the starting materials, peak (2) which eluted at $22 \mathrm{~mL}$ can be assigned to PVAc-g-HPC. It is significantly retained due to the strong interaction between the PVAc part of the polymer and the stationary phase, while the eluent is not good enough to elute the product from the packing.

The new peak which appeared after the elution of modified MC and PVAc standards in Figure 4.6B shows the elution of PVAc-g-MC. The assignment of the peak was carried out by comparison with the chromatographic behavior of the starting materials. There is no residual modified MC detected, as can be seen in the chromatogram. The absence of a clear PVAc homopolymer (which was formed in the reaction) peak is due to the broadness of the PVA-g-MC peak; overlapping between the peaks can be taking place obscuring parts of the sample.
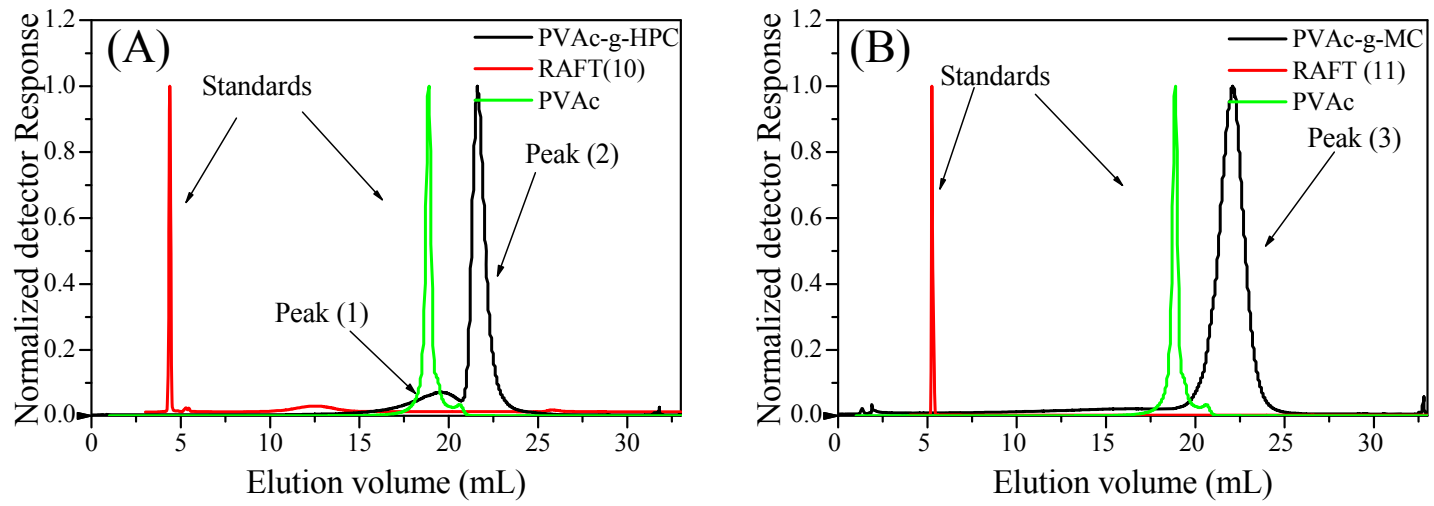

Fig. 4.6: Gradient HPLC for the separation of graft copolymers (A) separation of standard modified HPC (RAFT 10), PVAc homopolymer and PVAc-g-HPC prepared from reaction (6), (B) separation of standard modified MC (RAFT 11), PVAc homopolymer and PVAc-g-MC prepared from reaction (7). Refer to Table 4.2 for reactions conditions. 


\section{Chapter 4: RAFT mediated polymerization}

Two-dimensional liquid chromatography involves the combination of HPLC and SEC, where separations in diverging directions are combined. In most cases HLPC is used as the first separation step with regard to chemical composition, followed by SEC which is sensitive towards hydrodynamic volume. Neither gradient HPLC nor SEC alone can give as detailed information on the chemical heterogeneity of samples as two-dimensional liquid chromatography. ${ }^{23} \mathrm{~A}$ modular chromatographic system comprising two chromatographs connected via electrically driven eight-port injection valve (Valco) and two storage loops were used.

For the first dimension, the same set-up was used as described for the gradient HPLC (see Section 4.5.2) analysis. However, for the second dimension, a Waters 515 HPLC pump was used. The column was PSS SDV linear M high-speed, 5- $\mu \mathrm{m}$ average particle size, 50x20 (ID) mm (Polymer Standards Service), and the mobile phase was THF at a flow rate of $4 \mathrm{~mL} / \mathrm{min}$. The detector was an evaporative light scattering detector (ELSD) PL-ELS 1000 from Polymer Laboratories and the calibration was based on linear monodisperse polystyrene standards (EasiVial PS from Polymers Laboratories). The operation of the coupled injection valves was controlled by PSS-WINGPC7, which was also used for data collection and processing (software obtained from Polymer Standards Service, Mainz, Germany). In the 3D presentations in Figures 4.7A and 4.7B, the results of two-dimensional separations of the two graft products are presented. The separation in the vertical direction corresponds to the chemical composition type separation and the horizontal direction depicts the separation with regard to molar mass. The concentration profile (signal intensity) is coded by different colours, with lighter colours indicating higher concentration. The 3D plots indicate two fractions which are different in chemical composition and molar mass. The assignment of the fractions is straightforward and based on gradient HPLC separation. Fractions 1 and 3 corresponded to PVAc-g-HPC and PVAc-g-MC respectively while fraction 2 and 4 corresponded to PVAc homopolymer. Figure 4.7 clearly shows that there is a substantially higher amount of homopolymer polyvinyl acetate in reaction (6) (24\%) with respect to reaction (7) (16\%). 

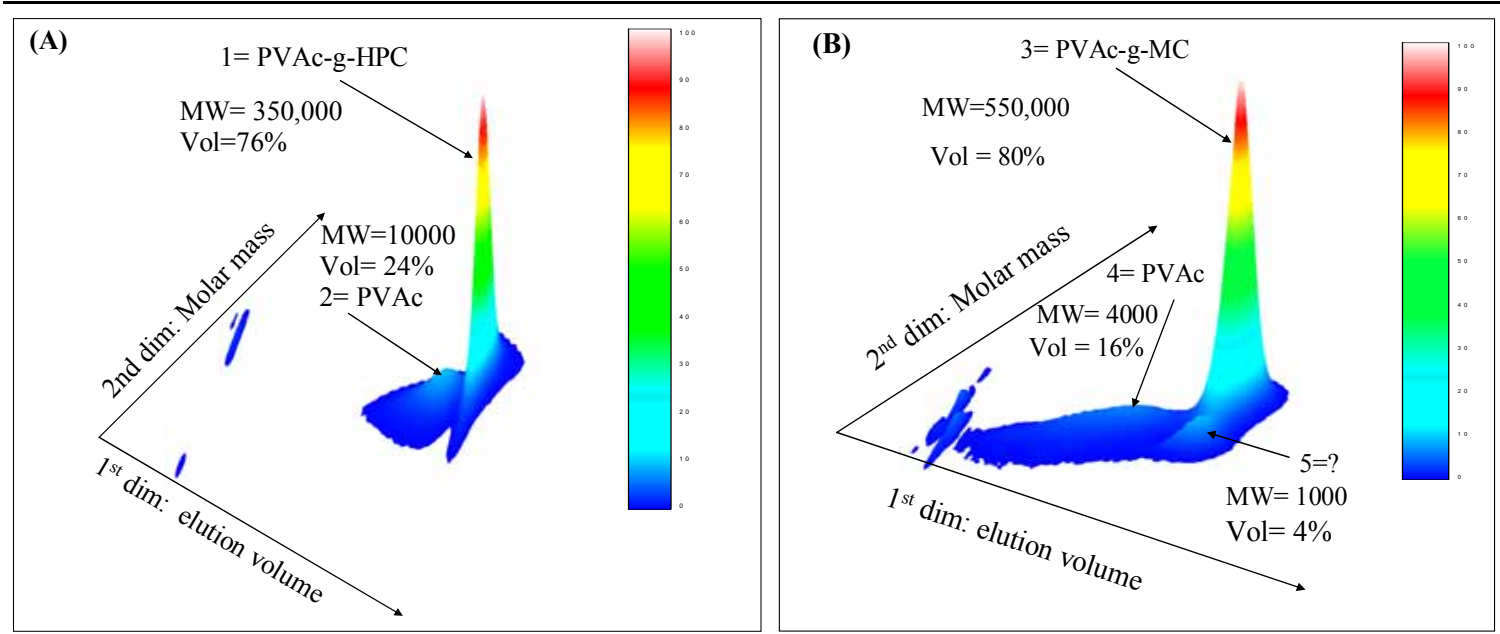

Fig. 4.7: 3-D chromatogram plot for the two-dimensional separation of graft copolymers, (A) separation of the polymers prepared from reaction (6) where RAFT (10) was used, which are PVAc-g-HPC and PVAc homopolymer, (B) separation of the polymers prepared from reaction (7) where RAFT (11) was used which are PVAc-g-MC and PVAc homopolymer. Refer to Table 4.2 for reactions conditions.

The grafting efficiency (GE, wt \%) is defined as the ratio between the quantity of grafted monomer and the total polymerized monomer. ${ }^{8,24-26}$

$$
G E=100\left[\frac{W_{3}-W_{1}}{W_{2}-W_{1}}\right]
$$

where $\mathrm{W}_{1}$ is the initial weight of the modified cellulosic material (RAFT), $\mathrm{W}_{2}$ is the dry weight of the polymerized sample before homopolymer extraction and $W_{3}$ is the dry weight of the polymerized sample after homopolymer extraction.

The amount of homopolymer is quantified according to the following relationship: homopolymer $(\%)=100$-grafting efficiency $(\mathrm{GE})$.

The grafting yield $\left(G_{y}\right.$, wt \%) was calculated using the following formula: ${ }^{8,24-26}$

$$
G_{\mathrm{y}}=100\left[\frac{W_{3}-W_{l}}{W_{1}}\right]
$$


The analytical details for PVAc-g-HPC, PVAc-g-MC and PVAc-g-cellulose are tabulated in Table 4.3.

Table 4.3: Graft polymerization of VAc onto cellulosic materials and the results of gravimetric measurements of the grafted cellulosic materials.

\begin{tabular}{|c|c|c|c|c|c|c|c|}
\hline Reaction & $\begin{array}{c}\mathrm{W}_{1} \\
(\mathrm{~g})\end{array}$ & $\begin{array}{c}\mathrm{W}_{2} \\
(\mathrm{~g})\end{array}$ & $\begin{array}{c}\mathrm{W}_{3} \\
(\mathrm{~g})\end{array}$ & $\begin{array}{c}\mathrm{GE} \\
(\%)\end{array}$ & $\begin{array}{c}\mathrm{G}_{\mathrm{y}} \\
(\%)\end{array}$ & $\begin{array}{c}\text { Mass \% } \\
\text { graft (VAc) }\end{array}$ & $\begin{array}{c}\text { Homopolymer } \\
(\%)\end{array}$ \\
\hline 6 & 1.0 & 4.2 & 3.24 & 70 & 224 & 69 & 30 \\
\hline 7 & 1.0 & 3 & 2.6 & 80 & 160 & 61 & 20 \\
\hline 8 & 1.0 & 3.4 & 2.58 & 66 & 158 & 61 & 34 \\
\hline
\end{tabular}




\section{Chapter 4: RAFT mediated polymerization}

\subsection{3: Fourier Transform Infrared (FTIR)}

Fourier Transform Infrared (FTIR) is a method that is used to analyze the chemical composition of graft copolymers and is typically employed to monitor the presence of the chemical functional groups of the graft copolymers. Figure 4.8 is a typical example of an infrared spectrum of one of the cellulosic materials (HPC) before and after modification. A very strong band for a typical carbonyl group $\mathrm{C}=\mathrm{O}$ group at $1735 \mathrm{~cm}^{-1}$ was clearly observed for the graft copolymers as well as for the modified cellulosic materials (polyol xanthate RAFT (10), RAFT (11) and RAFT (12)) but not for the unmodified HPC, demonstrating the successful formation of the polyol xanthate RAFT agents.

In principle, as the graft ratio of polyvinyl acetate on the cellulosic materials increases so the intensity or the area under the $\mathrm{C}=\mathrm{O}$ group band will increase as well. This effect is related to the amount of PVAc on the modified cellulosic materials. ${ }^{8}$ Based on this information a calibration curve was used to determine the percentage of the graft polyvinyl acetate on the cellulosic materials. PVAc and polyol xanthate RAFT agents were blended using physical mixing, using varying percentages of incorporation ratios (10 to $100 \%$ PVAc). FTIR analysis was then performed on these samples and the area under the $\mathrm{C}=\mathrm{O}$ group band was measured from the infrared spectra.

Plots of the areas under the $\mathrm{C}=\mathrm{O}$ group versus the concentration of PVAc in the physical mixed samples were constructed and these plots are shown in Figure 4.9. Since the drawback of graft polymerization is the simultaneous and inevitable formation of the homopolymer, ${ }^{8,25}$ it was removed from the grafted cellulosic materials products by continuous extraction with acetone for $30 \mathrm{~h}$ to ensure the complete removal of the byproduct homopolymer polyvinyl acetate. After PVAc homopolymer was considered to be fully extracted from the grafted cellulosic materials products, a corresponding percentage of PVAc on the cellulosic materials was determined from the calibration curves. 

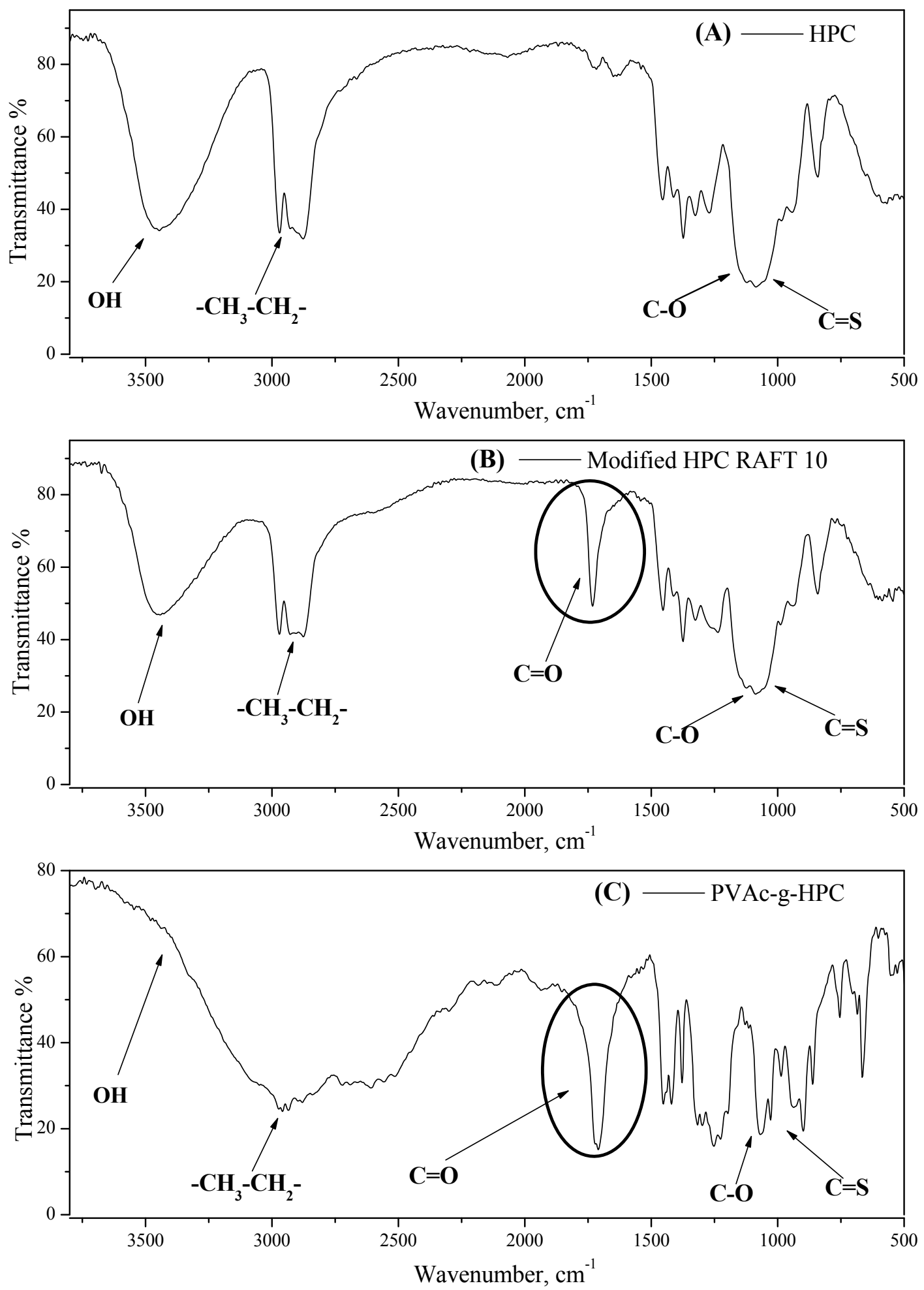

Fig. 4.8: A typical example of an infrared spectrum of: (A) unmodified HPC, (B) modified HPC (RAFT 10), (C) PVAc-g-HPC after extraction of PVAc homopolymer. 
As can be seen in Figure 4.9 the percentages of polyvinyl acetate in PVAc-g-HPC, PVAc-g-MC and PVAc-g-Cellulose were 64\% (Figure 4.9A), 57\% (Figure 4.9B) and $52 \%$ (Figure 4.9C) respectively. These correlate with the mass measurements of $69 \%$, $61 \%$ and $61 \%$ in Table 4.3 .
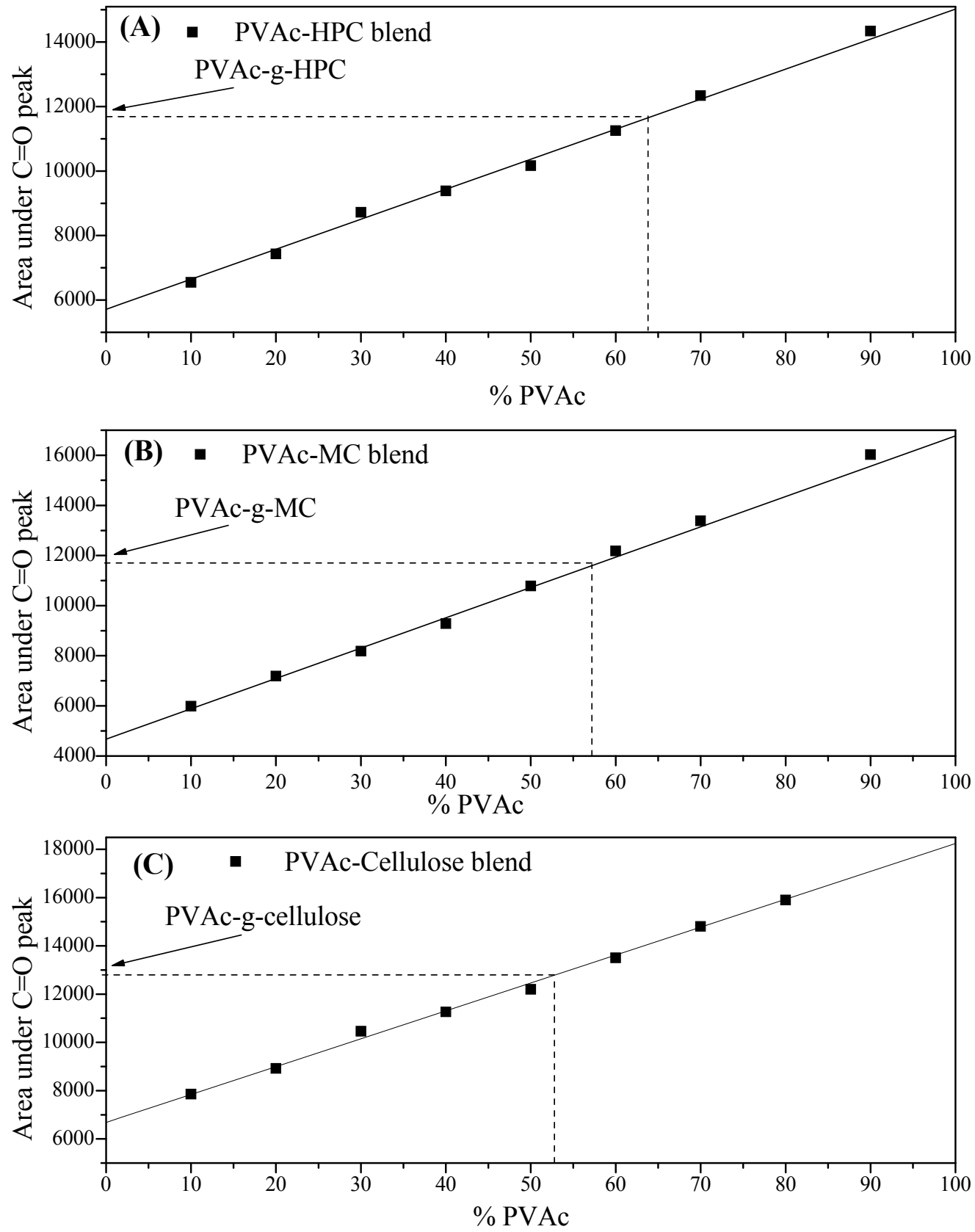

Fig. 4.9: Calibration curves for the determination of the percentage PVAc in the grafted cellulosic materials prepared from reactions (6), (7) and (8), where (A) calibration curve of blended PVAc/modified HPC (RAFT 10), (B) calibration curve of blended PVAc/modified MC (RAFT 11), (C) calibration curve of blended PVAc/modified cellulose (RAFT 12). 


\section{6: Cleaving PVAc chains from grafted cellulosic materials}

To quantify the molar mass and molar mass distribution of the polyvinyl acetate chains that become attached to the cellulosic material surface, polyvinyl acetate chains were cleaved from the cellulosic surface under basic conditions.

The fragile xanthate links located between the cellulosic material backbone and PVAc arms were cleaved by aminolysis with isopropyl amine. ${ }^{10}$

In the hydrolysis experiments, the graft product $(500 \mathrm{mg})$ was dissolved in THF $7 \mathrm{~mL}$ and then isopropyl amine $1 \mathrm{~mL}$ was added, after which the solution was stirred for 2 days at room temperature. The reaction mixture was filtered in order to separate the cleaved PVAc arms from the backbone of the cellulosic materials, the solvent in the filtrate was evaporated off using a rotary evaporator and the product finally dried in a vacuum oven. The resulting linear PVAc was dissolved in THF $(5 \mathrm{mg} / \mathrm{mL})$ and the molar masses and molar mass distributions were analyzed by SEC.

The complete absence of the cellulosic backbone was confirmed by SEC, as can be seen in Figures 4.10B and 4.10D. There was no indication of higher molar mass byproduct PVAc homopolymer that may have originated from arm-arm coupling, as can be observed in Figures 4.10A and 4.10C. It should be noted that the molar masses of the cleaved arms ( $M \mathrm{p}=19,000$ and 4,000 g/mol), with polydispersity 1.9 and 1.6 (in Figures $4.10 \mathrm{~B}$ and $4.10 \mathrm{D}$ respectively) corresponded to the molar masses of the PVAc homopolymer. This correspondence is expected as the grafting onto method was used to make these grafted polymers.

FTIR was used to confirm the degree of success in cleaving the arms. The infrared spectra of the cellulosic materials obtained after continuous extraction of cleaved PVAc arms still showed absorption characteristic of the carbonyl $\mathrm{C}=\mathrm{O}$ group attributed to PVAc. The area under the carbonyl $\mathrm{C}=\mathrm{O}$ absorption peak corresponded to $12 \%$ and $7 \%$ (by mass) remnant PVAc for the HPC and MC products respectively as determined from the calibration curves in Figure 4.9. The cleavage efficiency was $80 \%$ and $88 \%$ for the HPC and MC products respectively. This remnant PVAc is attributed to non-cleaved PVAc arms even after an extensive continuous extraction procedure where. $30 \mathrm{~h}$ were used. 

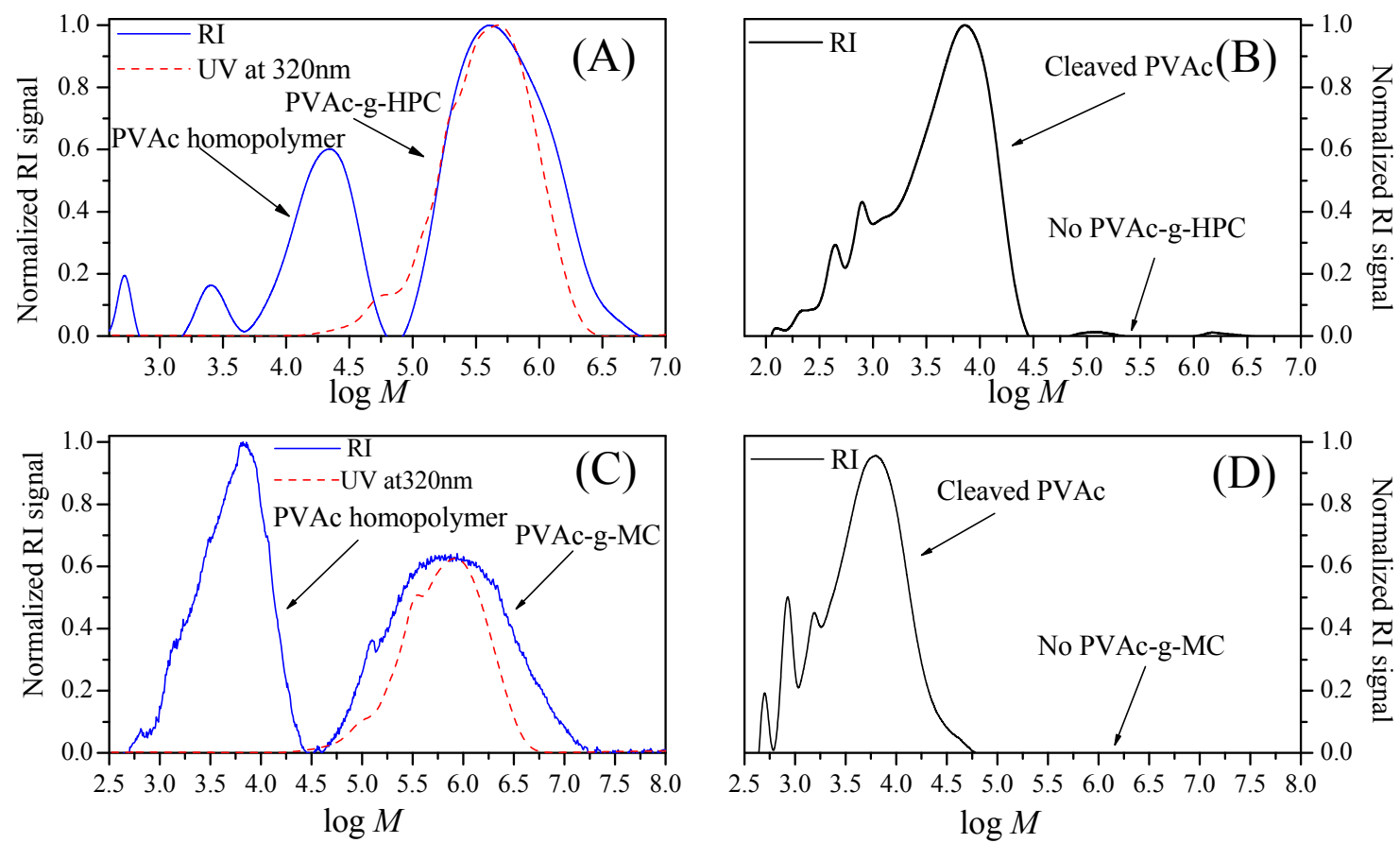

Fig. 4.10: Molar mass distribution of polyvinyl acetate grafted cellulosic materials; (A) and (C) molar mass distribution of PVAc-g-HPC and PVAc-g-MC respectively before hydrolysis process, (B) and (D) molar mass distribution of PVAc-g-HPC and PVAc-g-MC respectively after hydrolysis process.

The grafting frequencies of $\mathrm{HPC}$ and $\mathrm{MC}$ were 0.055 and 0.14 respectively (i.e. 1 graft in 18 repeat units and 1 graft in 7 repeat units respectively (see section A10)).

\section{7: Thermogravimetric analysis (TGA)}

Thermal decomposition studies were carried out on a TGA-50 SHIMADZU thermogravimetric instrument with a TA-50WSI thermal analyzer connected to a computer, under flowing nitrogen at the heating rate $2.5-10^{\circ} \mathrm{C} / \mathrm{min}$.

TGA was performed in order to evaluate the effect of the chemical modification with PVAc on the decomposition patterns and thermal stability of cellulosic materials. It was also used to verify the success of the grafting process. Figure 4.11 shows the thermal degradation profiles for PVAc, cellulosic materials, modified cellulosic materials and grafted cellulosic materials. It can be observed that PVAc degraded in two stages at $323{ }^{\circ} \mathrm{C}$ and $452{ }^{\circ} \mathrm{C}$, corresponding to the deacetylation and disintegration of the polyolefinic backbone respectively. ${ }^{2,27}$ It can also be seen that modified cellulosic 


\section{Chapter 4: RAFT mediated polymerization}

materials (RAFT-synthesized polymers) show a two-step degradation profile, with the first degradation step due to elimination of the thiocarbonyl-thio moiety (xanthate) at $195-250{ }^{\circ} \mathrm{C}$, followed by the backbone breakage in the second stage. These results are in good agreement with results published by Roy and Postma et al. ${ }^{24,28}$ Grafted cellulosic materials show two different degradation steps, the first is assigned to the decomposition of the modified cellulosic backbone and this is shifted to a higher temperature in comparison with unmodified cellulosic materials. The second degradation step is related to the grafted PVAc as it degrades at $420-150{ }^{\circ} \mathrm{C}$.
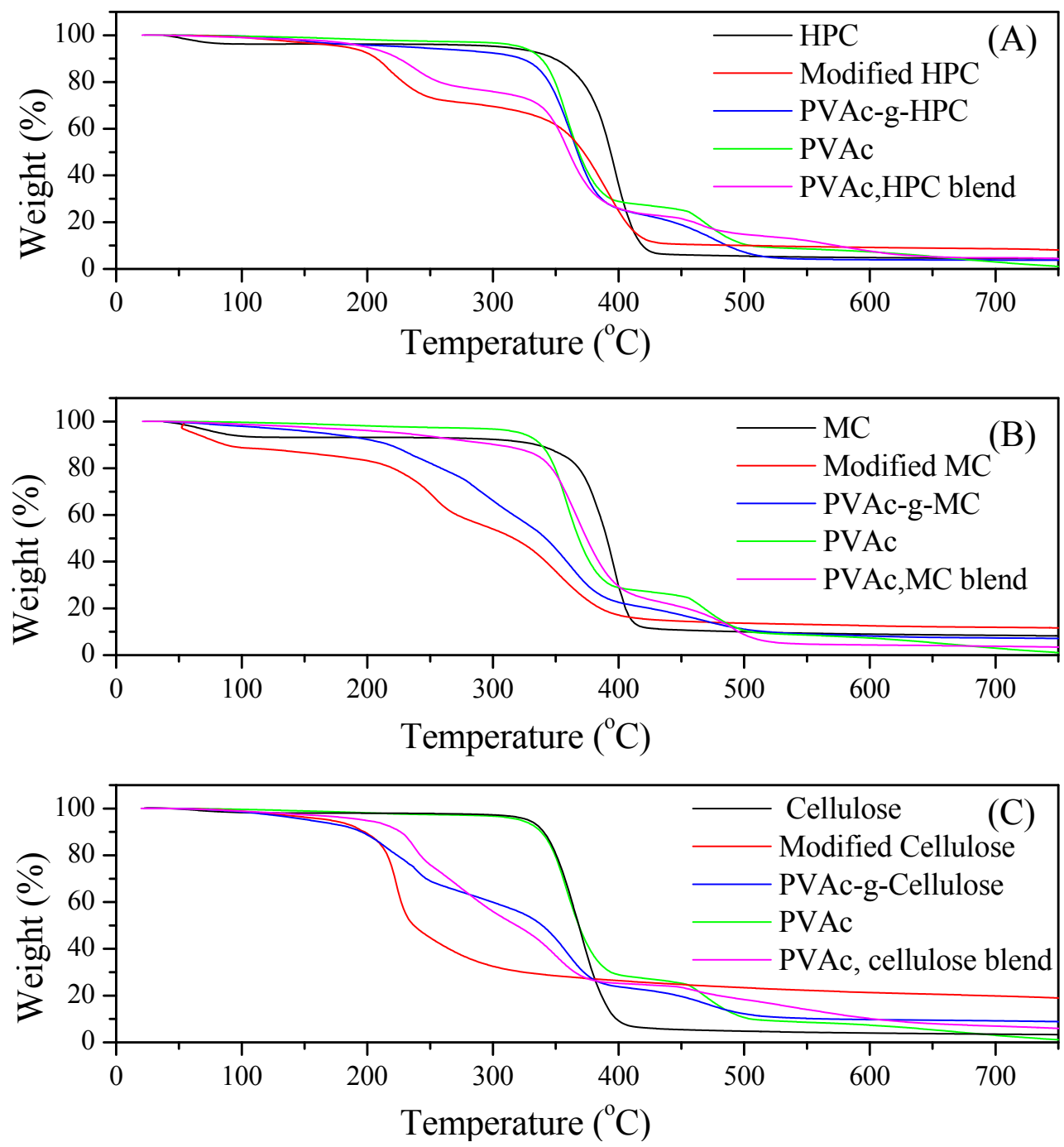

Fig. 4.11: TGA curves of (A) unmodified HPC, modified HPC (RAFT 10), PVAc homopolymer and PVAc-g-HPC (B) unmodified MC, modified MC (RAFT 11), PVAc homopolymer and PVAc-g-MC.(C) unmodified cellulose, modified cellulose (RAFT 12), PVAc homopolymer and PVAc-g-cellulose. 


\section{Chapter 4: RAFT mediated polymerization}

The evaluation of the thermal stability of the grafted cellulosic materials Figure 4.11 indicated clearly the presence of PVAc on the cellulosic materials. However, it is not evident whether or not there was a chemical interaction between them. Taking this into account, physical mixtures of homopolyvinyl acetate and modified cellulosic materials (RAFT-synthesized polymers) were analyzed by TGA. The physical mixtures showed different TGA thermograms from those obtained from grafted cellulosic materials and confirmed the true covalent grafting of PVAc onto the cellulosic materials. ${ }^{24}$ It is believed that these differences are related to the way in which the PVAc and the cellulosic materials are linked in each case. For example, in the grafted cellulosic materials one end of the PVAc chains is chemically bonded to the cellulosic materials, where as in the physical mixtures there is only a superficial interaction between phase separated domains of each of the cellulosic materials and PVAc. ${ }^{8}$ 


\section{Chapter 4: RAFT mediated polymerization}

\section{8: References}

(1) Favier, A.; Barner-Kowollik, C.; Davis, T.; Stenzel, M. Macromol. Chem. Phys. 2004, 205, 925-936.

(2) Sivalingam, G.; Karthik, R.; Madras, G. J. Ind. Eng. Chem. 2003, 42, 3647-3653.

(3) Stenzel, M. H.; Davis, T. P.; Barner-Kowollik, C. Chem. Comm. 2004, 15461547.

(4) Wakioka, M.; Youl Beak, K.; Ando, T.; Kamigaito, M.; Sawamoto, M. Macromolecules 2002, 35, 330-333.

(5) Coote, M.; Radom, L. Macromolecules 2004, 37, 590-596.

(6) Stenzel, M.; Cummins, L.; Evan Roberts, G.; Davis, T.; Vana, P.; BarnerKowollik, C. Macromol. Chem. Phys. 2003, 204, 1160-1168.

(7) Stepanik, T.; Ewing, D.; Whitehouse, R. Radiat. Phys. Chem. 2000, 57, 377-379.

(8) Roman-Aguirre, M.; Marquez-Lucero, A.; Zaragoza-Contreras, E. Carbohydr. Polym. 2004, 55, 201-210.

(9) Karlsson, J.; Henriksson, A.; Michalek, J.; Gatenholm, P. Polymer 2000, 41, 1551-1559.

(10) Bernard, J.; Favier, A.; Zhang, L.; Nilasaroya, A.; Davis, T.; Kowollik, C.; Stenzel, M. Macromolecules 2005, 38, 5475-5484.

(11) Stenzel, M. H.; Davis, T. P.; Fane, A. G. J. Mater. Chem. 2003, 13, 2090-2097.

(12) Stenzel, M. H.; Davis, T. P. J. Polym. Sci. Part A: Polym Chem 2002, 40, 44984512 .

(13) Quirk, R. P.; Lee, B. Polymer International 1992, 27, 359-367.

(14) Antonietti, M.; Landfester, K. Prog. Polym. Sci. 2002, 27, 689-757.

(15) de Brouwer, H.; Tsavalas, J. G.; Schork, F. J.; Monteiro, M. J. Macromolecules 2000, 33, 9239-9246.

(16) Tsavalas, J. G.; Schork, F. J.; de Brouwer, H.; Monteiro, M. J. Macromolecules 2001, 34, 3938-3946.

(17) Russum, J.; Jones, C. W.; Schork, F. J. Macromol. Rapid Comm. 2004, 25, 10641068. 


\section{Chapter 4: RAFT mediated polymerization}

(18) Pasch, H.; Trathnigg, S. In HPLC Of Polymers, Springer- Verlag Berlin Heidelberg ed.: Berlin, 1998; pp 80-116.

(19) Mira, F.; Mariella, P.; Francoise, M. J. Controlled Release 2003, 93, 59-68.

(20) Gao, Z.; Eisenberg, A. Macromolecules 1993, 26, 7353-7360.

(21) Klemm, D.; Philipp, B.; Heinze, T.; Wagenknecht, W. In Comprehensive Cellulose Chemistry; Wiley-vch, 1998; Vol. 2, pp 150-160.

(22) Degoulet, C.; Perrinaud, R.; Ajdari, A.; Prost, J.; Benoit, H.; Bourrel, M. Macromolecules 2001, 34, 2667-2676.

(23) Graef, S.; Van Zyl, A.; Sanderson, R.; Klumperman, B.; Pasch, H. J. Polym. Sci. 2003, 88, 2530-2538.

(24) Roy, D.; Guthrie, J. T.; Perrier, S. Macromolecules 2005, 38, 10363-10372.

(25) Princi, E.; Vicini, S.; Pedemonte, E.; Mulas, A.; Franceschi, E.; Luciano, G.; Trefiletti, V. Thermochim. Acta 2005, 425, 173-179.

(26) Princi, E.; Vicini, S.; Proietti, N.; Conatella, C. Eur. Polym. J. 2005, 41, 11961203.

(27) Sivalingam, G.; Madras, G. J. App. Polym. Sci. 2004, 93, 1378-1383.

(28) Postma, A.; Davis, T.; Moad, G.; O'Shea, M. Macromolecules 2005, 38, 53715374. 


\section{Chapter 5: Conclusions and recommendations}




\section{Chapter 5: Conclusions and recommendations}

\section{1: Conclusions}

1. The syntheses of five xanthate (MADIX)/RAFT agents, monofunctional RAFT agents (2) and (8), difunctional RAFT agent (4), trifunctional RAFT agent (5) and tetrafunctional RAFT agent (6) of the form $\mathrm{S}=\mathrm{C}(\mathrm{O}-\mathrm{Z})-\mathrm{S}-\mathrm{R}$, with different leaving groups and different activating moieties, were successfully carried out as confirmed by NMR, FTIR and UV spectroscopy.

2. The chain transfer ability of the above five xanthate (MADIX)/RAFT agents to induce living characteristics in free radical polymerization of vinyl acetate was investigated with respect to molar mass control and kinetic behavior. These five compounds, S-sec propionic acid O-ethyl xanthate RAFT agent (2), 1,2:5,6-DiO-isopropylidene- $\alpha$-D-glucofuranose-3-(S-sec ethyl propionoate) xanthate RAFT agent (8), 1,4 di(S-sec propionic acid xanthate) butane RAFT agent (4), 1,1,1 tri(S-sec ethyl propionoate O-methylene xanthate) ethane RAFT agent (5) and 1,1,1,1 tetra(S-sec ethyl propionoate O-methylene xanthate) methane RAFT agent (6), were identified as suitable xanthate (RAFT MADIX) agents, yielding linear and star (three arms and four arms) shaped polyvinyl acetate with low polydispersities and molar masses ranging from 1,000 to 40,000 g/mol. The ability of these compounds to control vinyl acetate polymerization can be correlated with increasing electron density on the center carbon atom of the respective xanthates.

3. The molar masses of the polyvinyl acetates were measured using SEC calibrated with linear polystyrene standards. The molar mass growth of linear polyvinyl acetate in the presence of RAFT agents (2), (4) and (8) was similar to predicted mass (calculated using equation 2.16). In contrast, the molar mass of the three and four arm polyvinyl acetates displayed a slight deviation from predicted molar mass. This was attributed to the altered hydrodynamic volumes of star polymers compared to linear polymers as well as to the reduced accessibility of the RAFT group at higher conversion of the polymerization. There was However a reasonable agreement between the predicted and experimental molar 


\section{Chapter 5: Conclusions and recommendations}

mass values until a conversion of about $35 \%$ was attained, after which the deviation became increasingly pronounced.

4. Three of the suitable xanthate (RAFT MADIX) agents, RAFT agents (5), (6) and (8), exhibited an extended period of inhibition, this was attributed to a trace level of impurities; the very high reactivity of the vinyl acetate propagating radical makes it vulnerable to such impurities.

5. Reversible Addition-Fragmentation chain Transfer agents were applied through the use of viscose process procedure to make RAFT agent (10), RAFT agents (11) and (12), where the xanthate esters were formed directly on a cellulosic substrate and subsequent alkylated. Some of the hydroxyl groups of the hydroxypropyl cellulose, methyl cellulose and cellulose were successfully converted into thiocarbonyl-thio (xanthate) MADIX/RAFT agents (10), (11) and (12), as confirmed by FTIR, UV spectroscopy and SEC.

6. Graft copolymerization of vinyl acetate onto the modified (RAFT) cellulosic materials, RAFT agents (10), (11) and (12), is performed in solution to produce amphiphilic graft copolymers. The results obtained from SEC, gradient HPLC and two-dimensional chromatography confirmed that grafting of vinyl acetate was successful on the surface of the modified cellulosic material. By performing gradient HPLC and two-dimensional chromatography, it was shown that through correct solvent composition selection it is possible to separate PVAc homopolymer from grafted cellulosic materials.

7. The effect of the chemical modification of the cellulosic material grafted with polyvinyl acetate on the thermal stability was investigated by TGA. Results showed that the grafted cellulosic materials were less thermally stable than unmodified cellulosic materials.

8. The fragile xanthate links located between the cellulosic material backbone and PVAc arms were cleaved by aminolysis with isopropyl amine, the SEC chromatography of the cleaved PVAc, previously grafted onto the cellulosic materials HPC and MC, demonstrated that the molar masses of the cleaved PVAc were predictable. 


\section{Chapter 5: Conclusions and recommendations}

9. FTIR was used to confirm the degree of success in cleaving the arms. The infrared spectra of the cellulosic materials obtained after continuous extraction of cleaved PVAc arms still showed absorbtion characteristic of the carbonyl $\mathrm{C}=\mathrm{O}$ group attributed to PVAc. The cleavage efficiency was $80 \%$ and $88 \%$ for the HPC and MC products respectively as obtained from FTIR calibration curves. 


\section{2: Recommendations for future work}

1. RAFT graft polymerization conditions need optimization to obtain predictable lower or higher graft ratios, better graft efficiency, and more uniform distribution of graft onto the cellulosic materials.

2. Estimate the degree of hydrophilicity of the grafted cellulosic materials by static contact angle measurements in order to see the differences of the hydrophilicity between unmodified, modified and grafted cellulosic materials.

3. The surface morphology of the cellulosic materials before and after grafting should be observed by Scanning Electron Microscopy (SEM) to provide more another evidence that the grafted cellulosic materials have different structural features compared with the unmodified and modified cellulosic materials.

4. Synthesize other multifunctional xanthate (MADIX)/RAFT agents based on D-glucose and D (+) cellobiose which will be further used to mediate the RAFT polymerization of vinyl acetate to obtain polyvinyl acetate with star structure. The reason for this choice of substrate is the structural simplicity of these compounds, which enables us to examine specific aspects during the synthesis of the RAFT without the complications of the large polysaccharide environment.

5. Work needs to be done on the effect of the lignin content on grafting yields as well as the characteristics and properties of the resulting grafts, since most of the research has concentrated on pure forms of cellulose and its derivatives. Therefore the use of the whole wood pulp without separating the lignin as grafting substrates should be explored.

6. Finally, cost effectiveness of the resulting products is important. A reasonable economic analysis of various controlled methods of grafting with various substrates is required. 


\section{Appendix A: Detailed spectroscopic data of compounds used in this study}




\section{A 1: S-sec propionic acid O-ethyl xanthate RAFT agent (2)}<smiles>CCOC(=S)SC(C)C(=O)O</smiles>
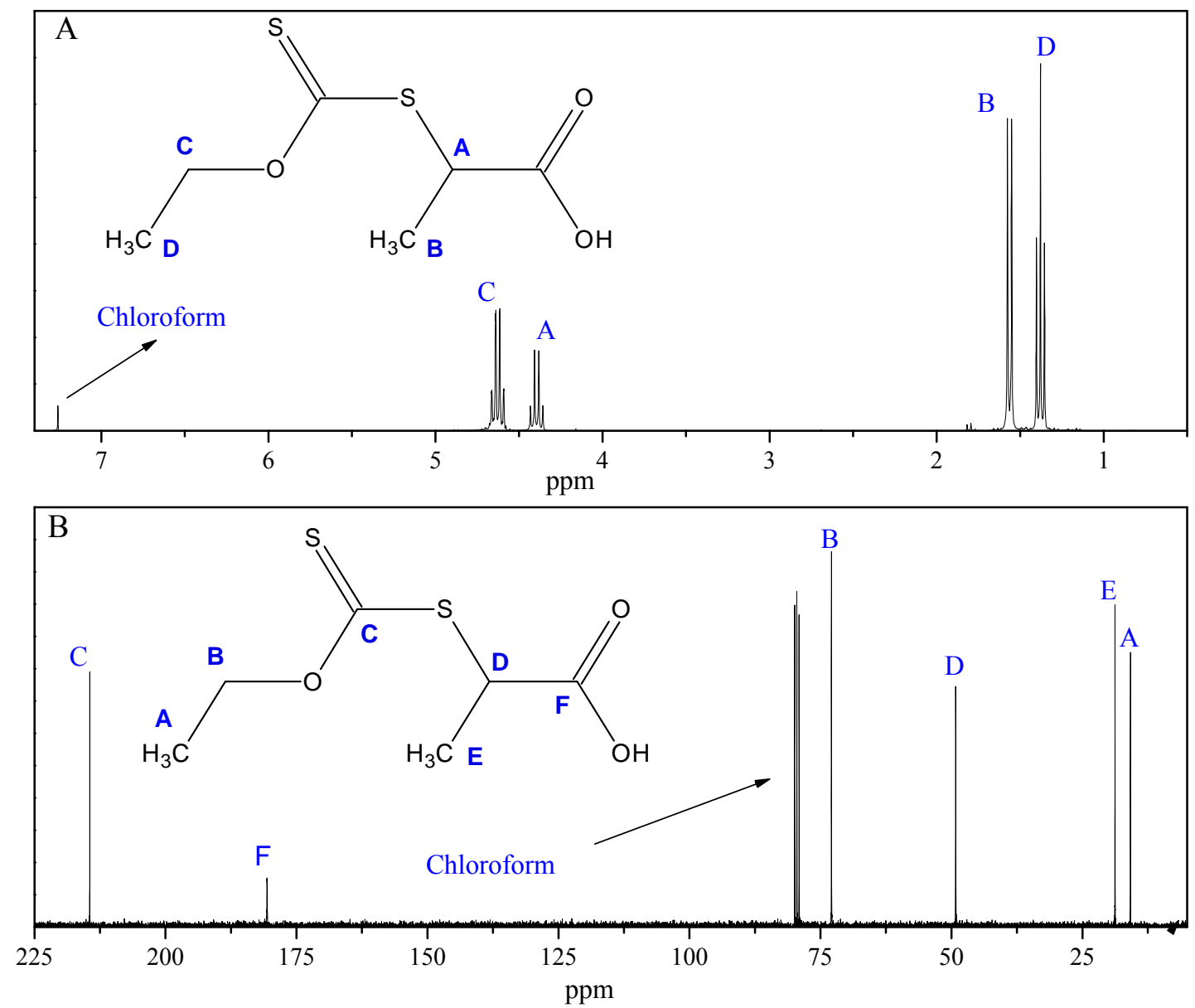

Fig. A1: ${ }^{1}$ H-NMR (A) and ${ }^{13}$ C-NMR (B) spectra of RAFT agent 2 in chloroform-d. 


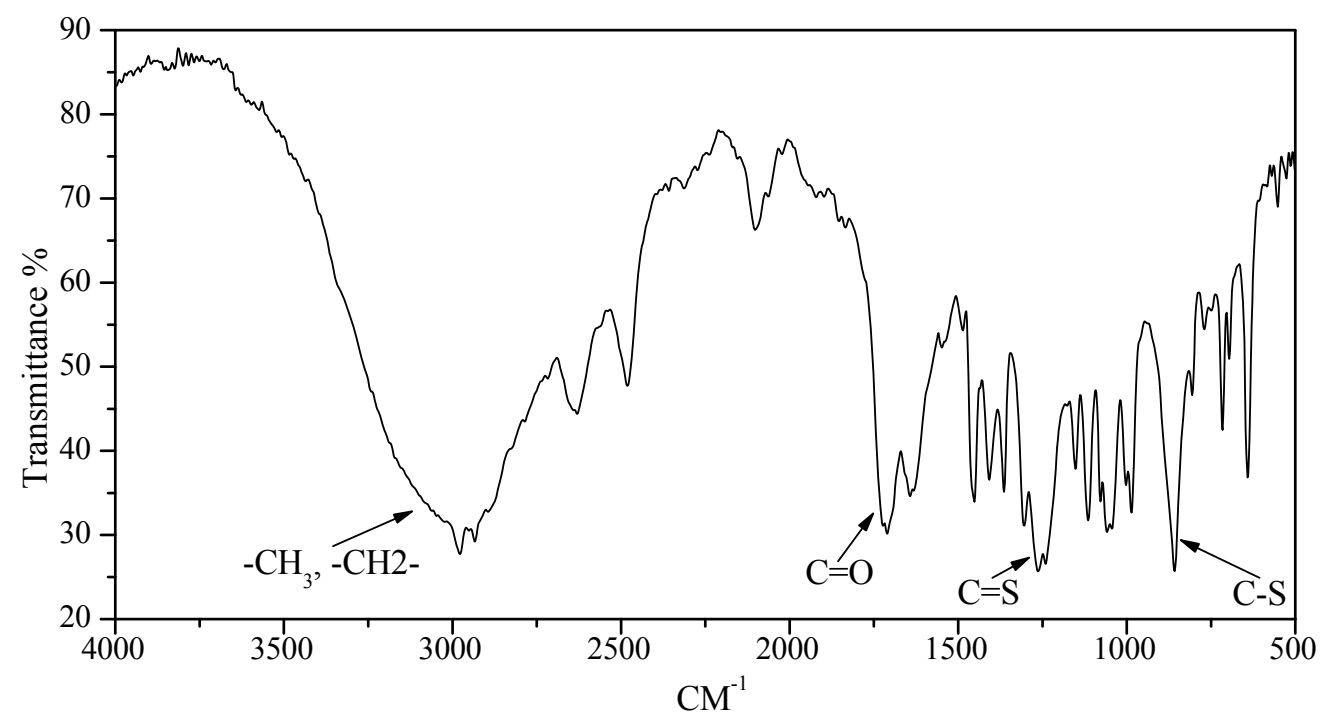

Fig. A2: Infrared spectrum of RAFT agent 2.
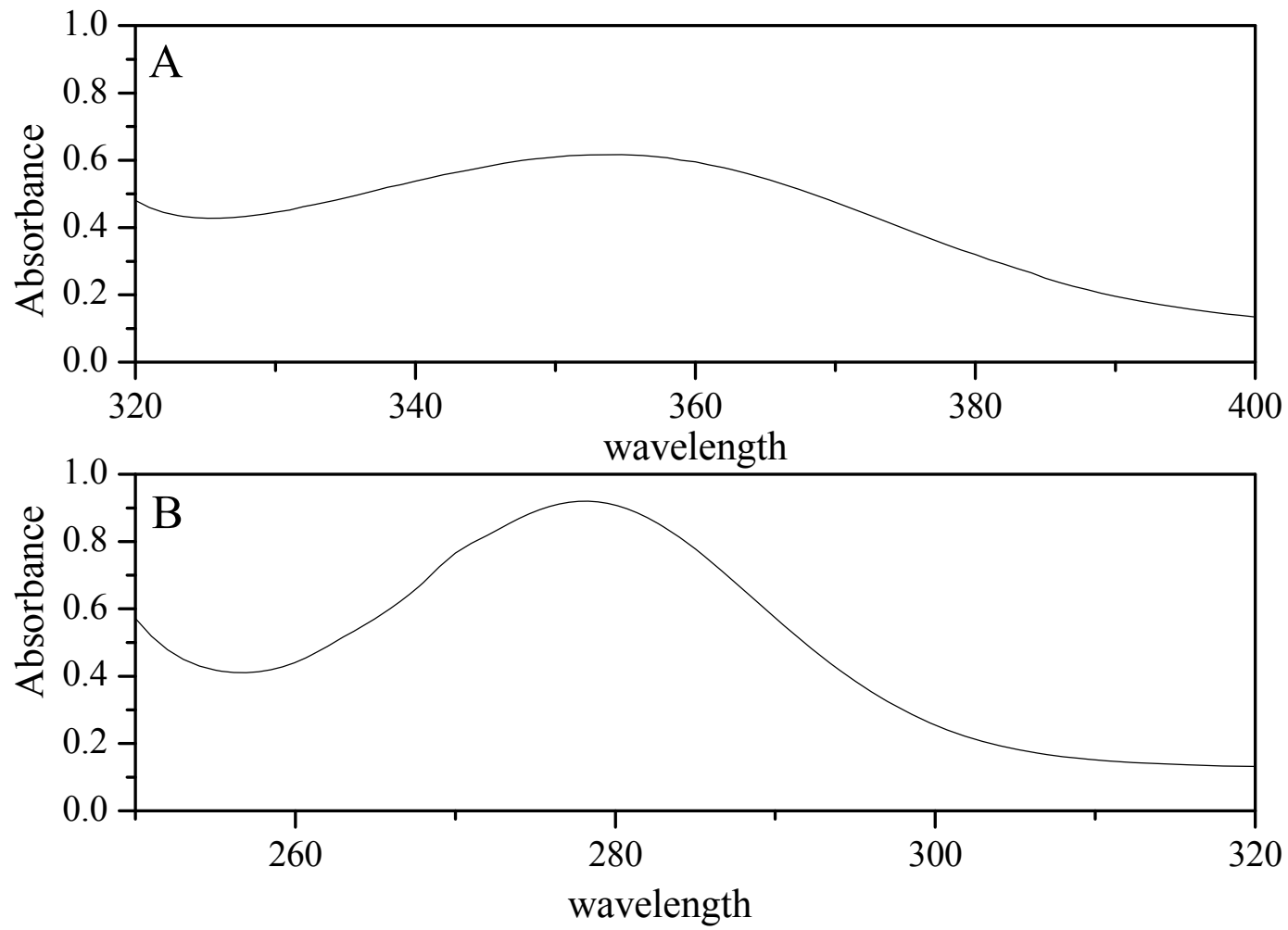

Fig. A3: UV absorbance spectrum of RAFT agent 2 in acetonitrile. $B$ is $\left(\mathbf{n} \rightarrow \pi^{*}\right.$, $\left.\lambda_{\max }=354 \mathrm{~nm} \mathrm{~L}, C=4.3555 \times 10^{-4} \mathrm{~mol} / \mathrm{L}\right)$ and $A$ is $\left(\pi \rightarrow \pi^{*}, \lambda=278 \mathrm{~nm}, C=1.132 \mathrm{x}\right.$ $\left.10^{-2} \mathrm{~mol} / \mathrm{L}\right)$. 


\section{A 2: 1,4 di(S-sec propionic acid xanthate) butane RAFT agent (4)}<smiles>CC(SC(=S)OCCCCOC(=S)SC(C)C(=O)O)C(=O)O</smiles>
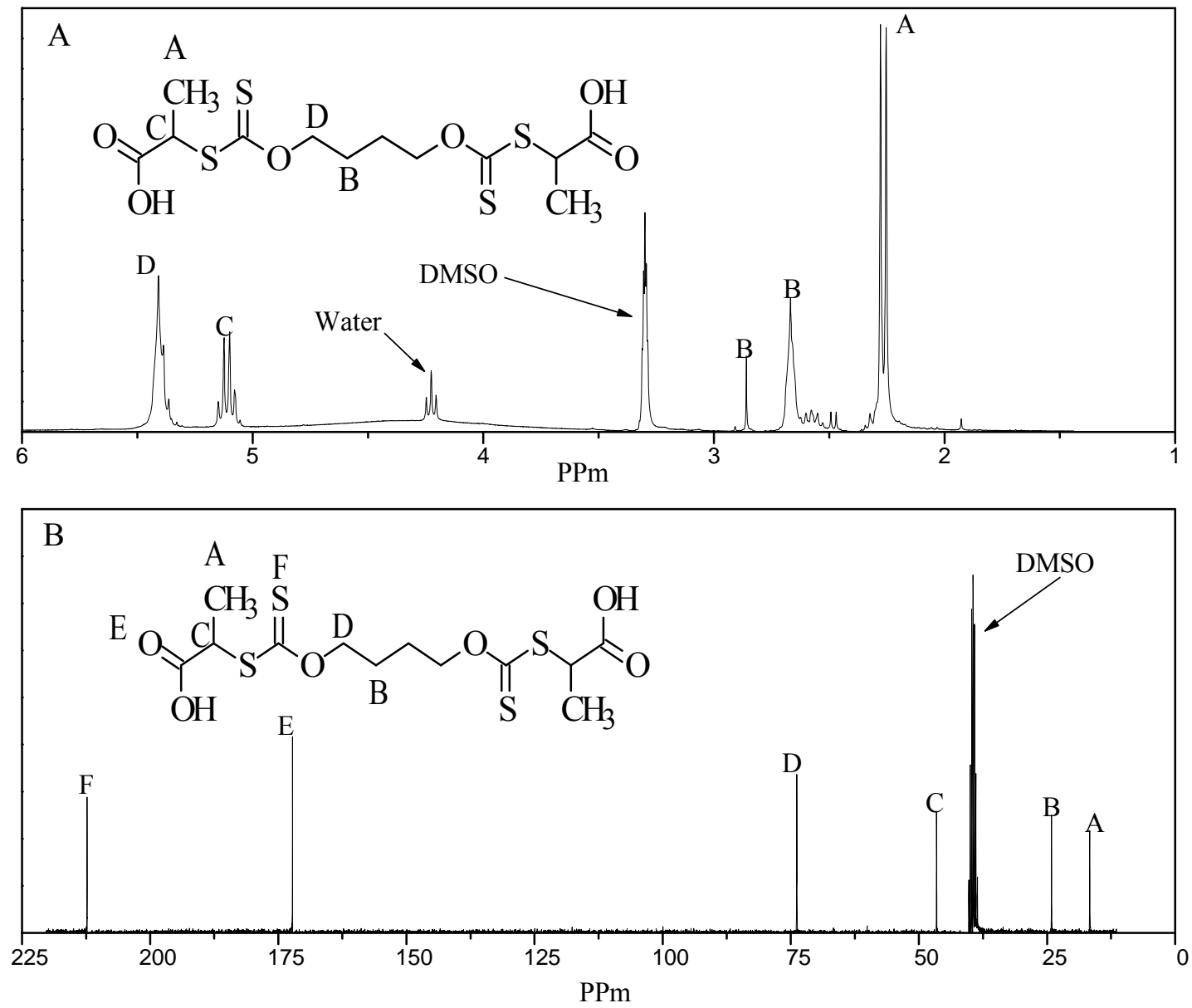

Fig. A4: ${ }^{1} \mathrm{H}-\mathrm{NMR}$ (A) and ${ }^{13} \mathrm{C}-\mathrm{NMR}$ (B) spectra of RAFT agent 4 in DMSO-d. 


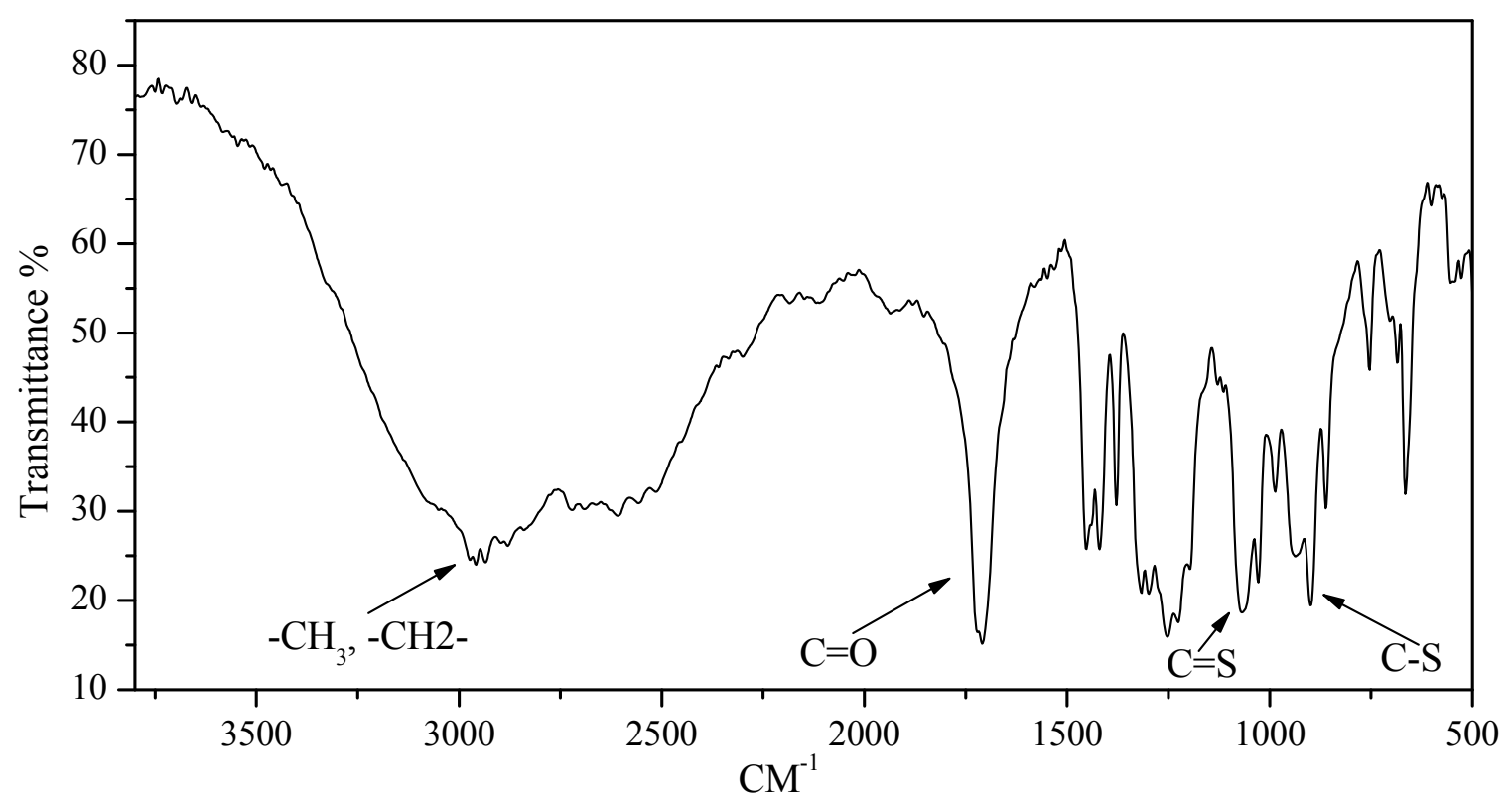

Fig. A5: Infrared spectrum of RAFT agent 4.
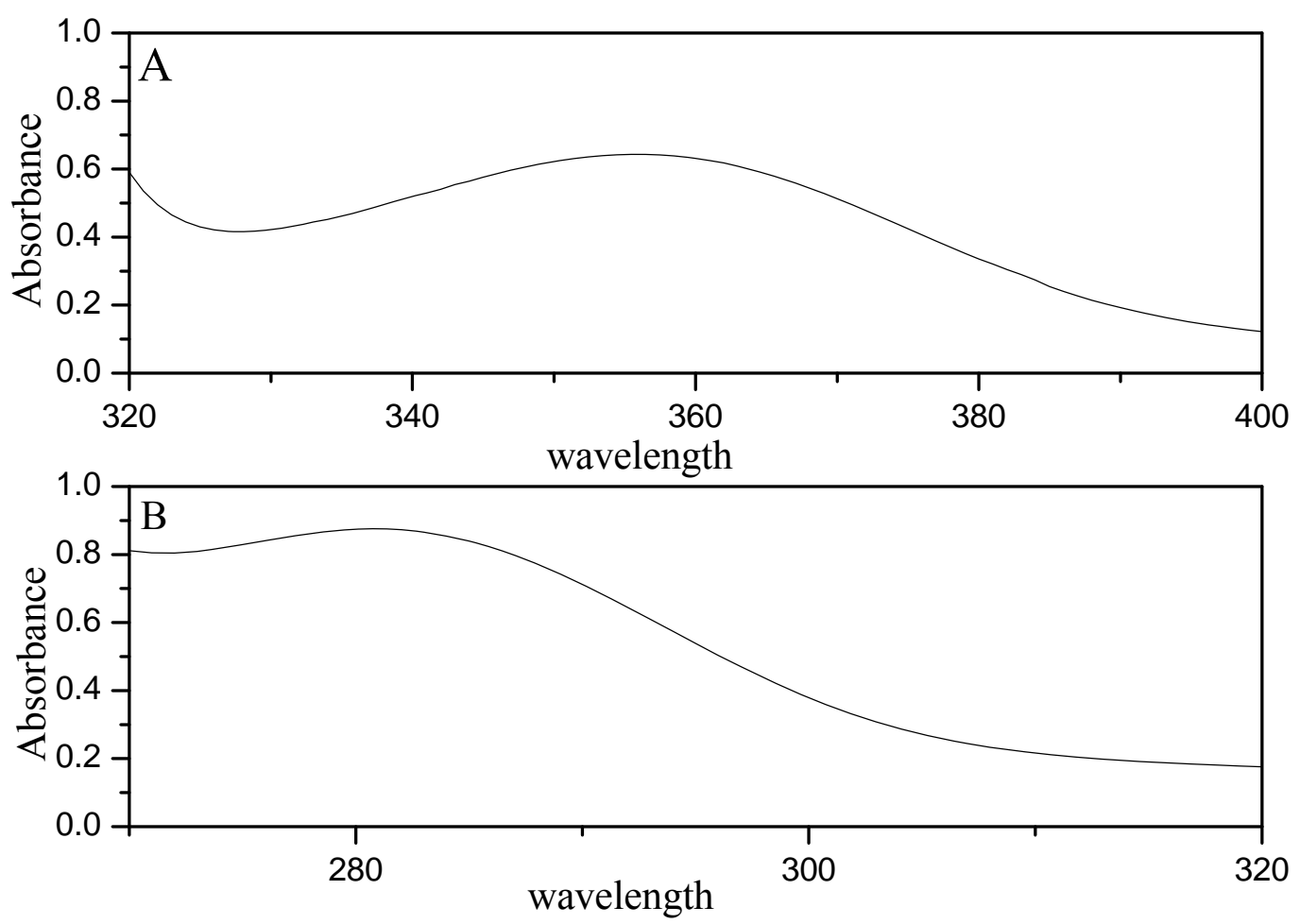

Fig. A6: UV absorbance spectrum of RAFT agent 4 in acetonitrile. $B$ is $\left(n \rightarrow \pi^{*}\right.$, $\left.\lambda=28 \mathrm{~nm}, C=1.5705 \times 10^{-6} \mathrm{~mol} / \mathrm{L}\right)$ and $A$ is $\left(\pi \rightarrow \pi^{*}, \lambda_{\max }=356 \mathrm{~nm}, C=5.0259 \times 10^{-3}\right.$ $\mathrm{mol} / \mathrm{L})$. 
A 3: 1,1,1 tri(S-sec ethyl propionoate O-methylene xanthate) ethane RAFT agent (5)<smiles>CCOC(=O)C(C)SC(=S)OCC(C)(COC(=S)SC(C)C(=O)OCC)COC(=S)C(C)SC(=O)C(C)C</smiles>
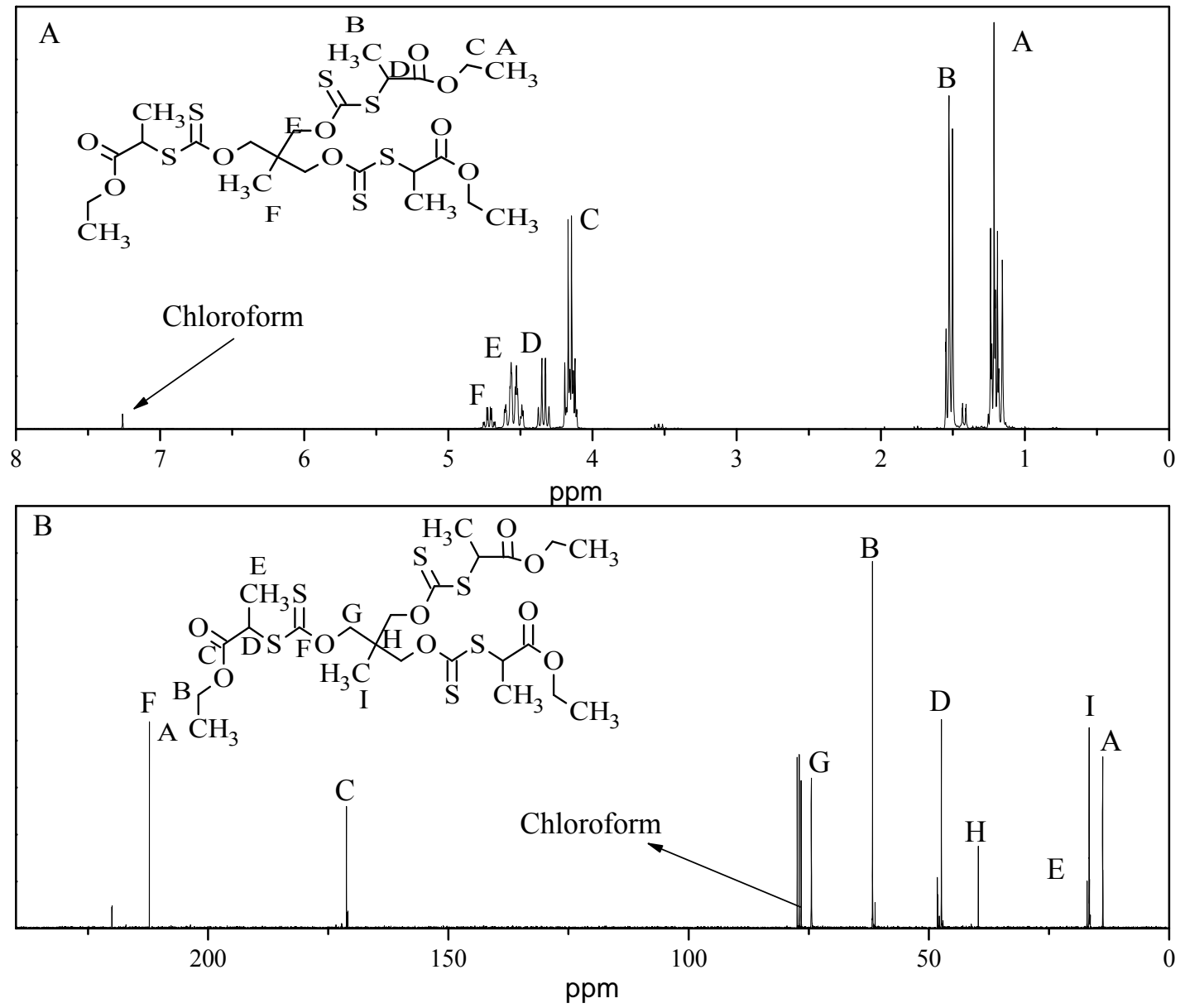

Fig. A7: ${ }^{1}$ H-NMR (A) and ${ }^{13}$ C-NMR (B) spectra of RAFT agent 5 in chloroform-d. 


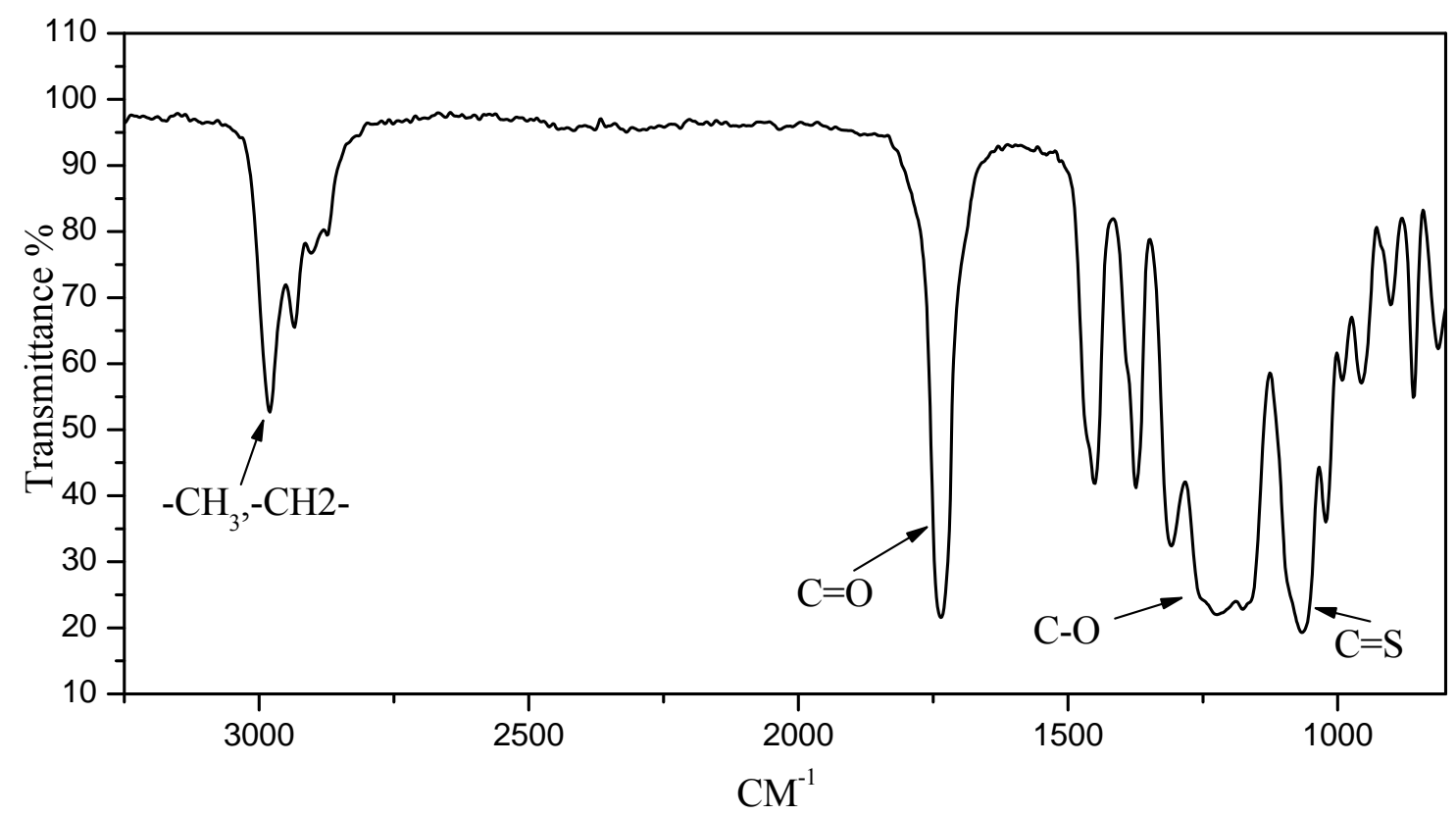

Fig. A8: Infrared spectrum of RAFT agent 5.
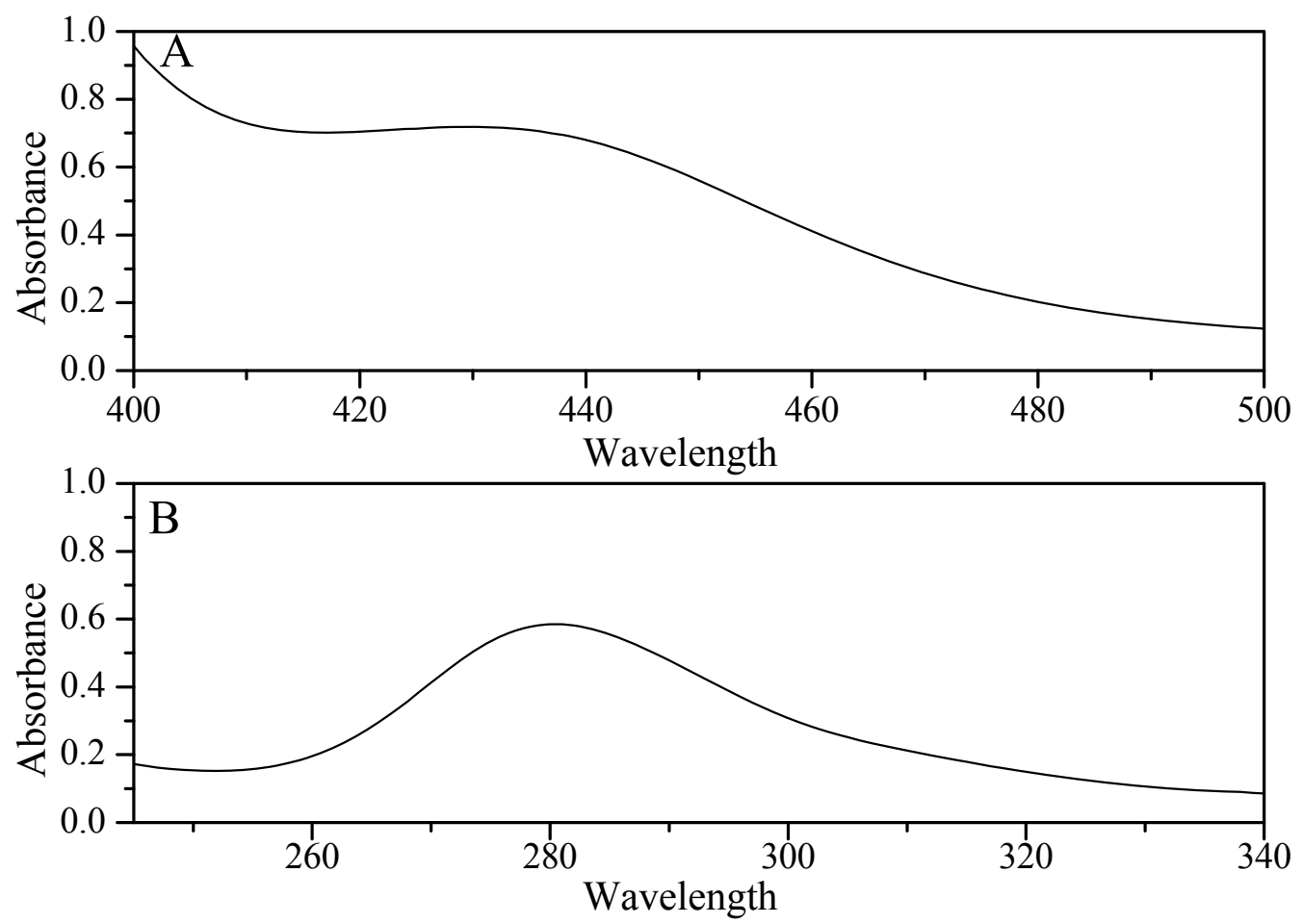

Fig. A9: UV absorbance spectrum of RAFT agent 5 in acetonitrile. B is $\left(\pi \rightarrow \pi^{*}\right.$, $\left.\lambda=280 \mathrm{~nm}, C=5.7755 \times 10^{-4} \mathrm{~mol} / \mathrm{L}\right)$ and $A$ is $\left(\mathrm{n} \rightarrow \pi^{*}, \lambda_{\max }=431 \mathrm{~nm}, C=2.59 \times 10^{-3}\right.$ $\mathrm{mol} / \mathrm{L})$. 


\section{A 4: 1,1,1,1 tetra(S-sec ethyl propionoate O-methylene xanthate)} methane RAFT agent (6)
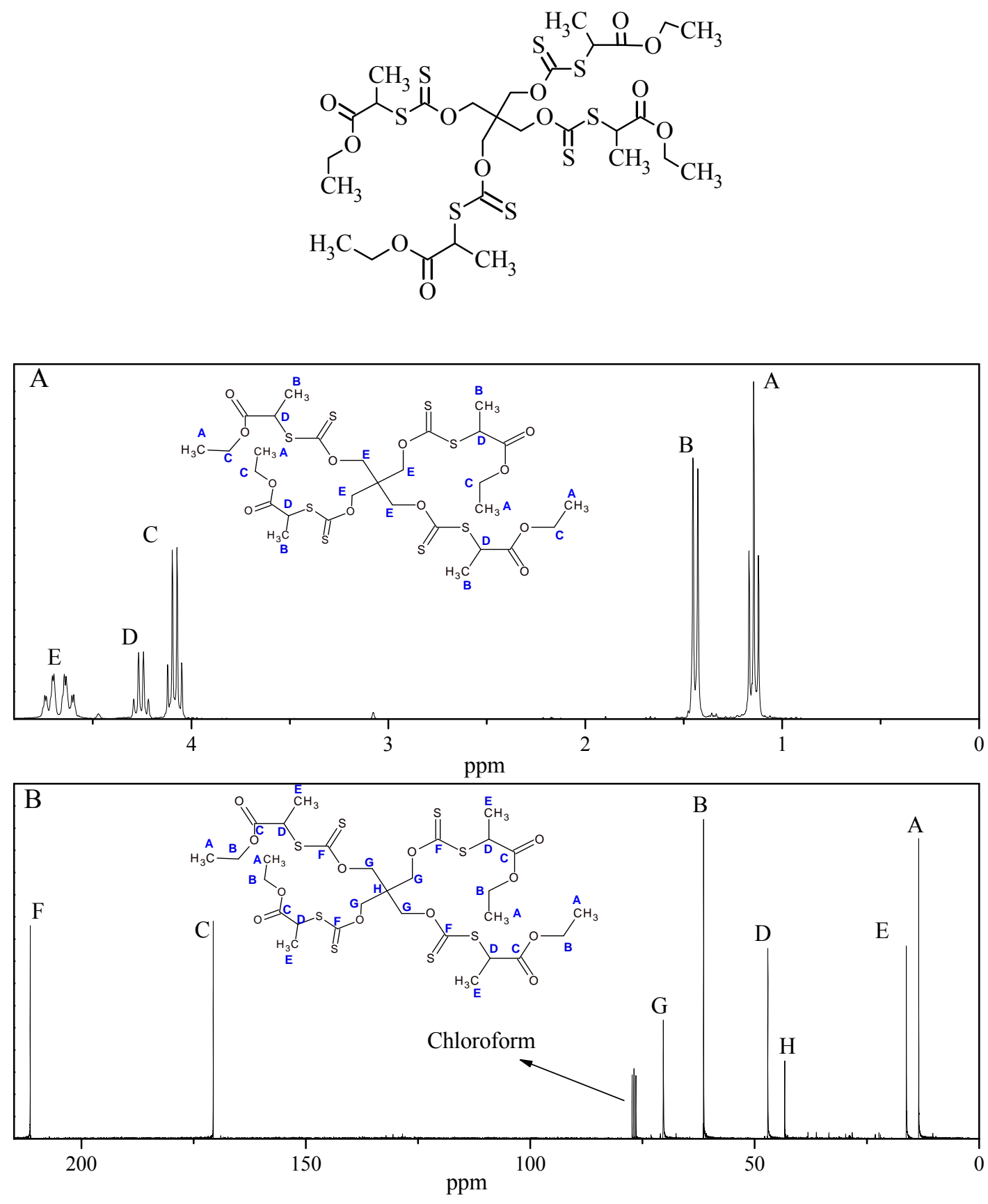

Fig. A10: ${ }^{1} \mathrm{H}-\mathrm{NMR}$ (A) and ${ }^{13} \mathrm{C}-\mathrm{NMR}$ (B) spectra of RAFT agent 6 in chloroform-d. 


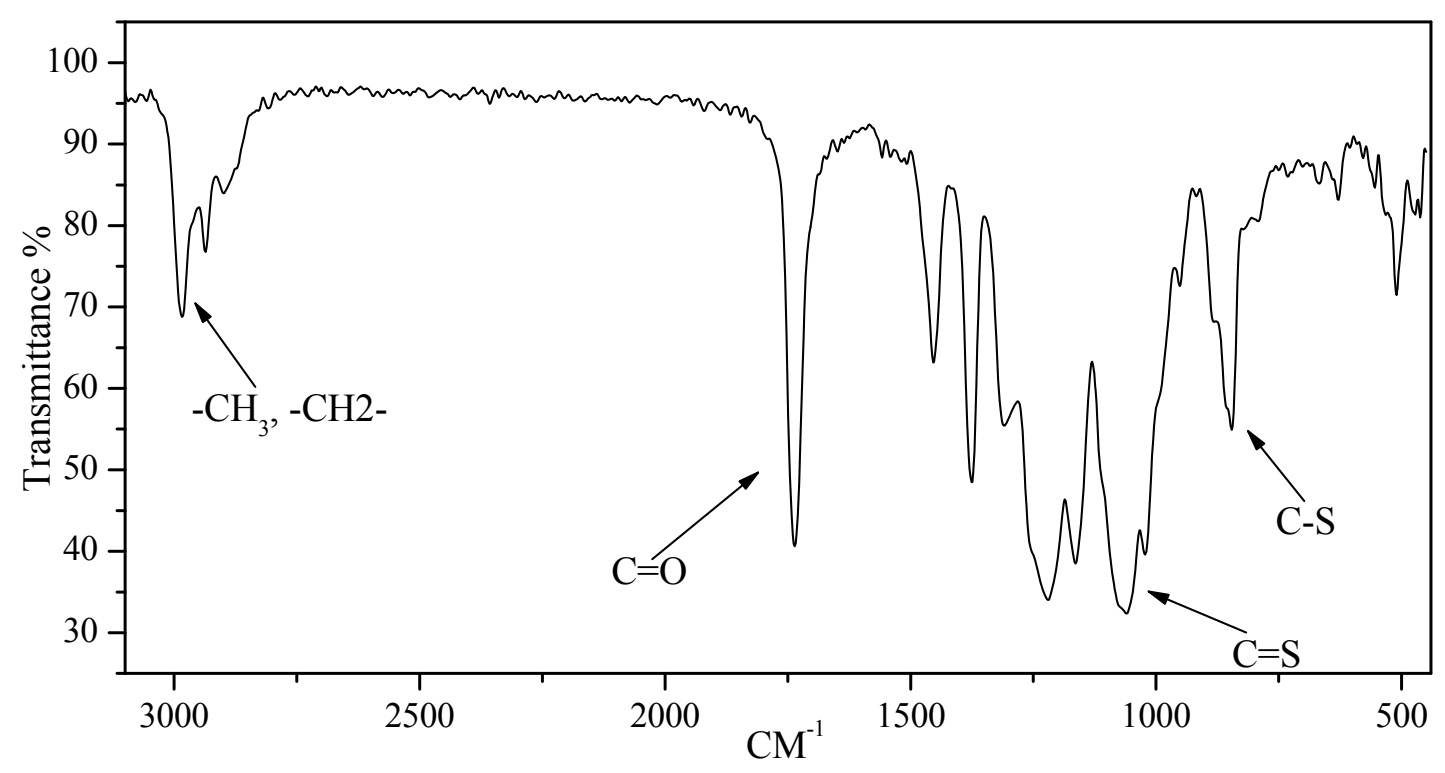

Fig. A11: Infrared spectrum of RAFT agent 6.
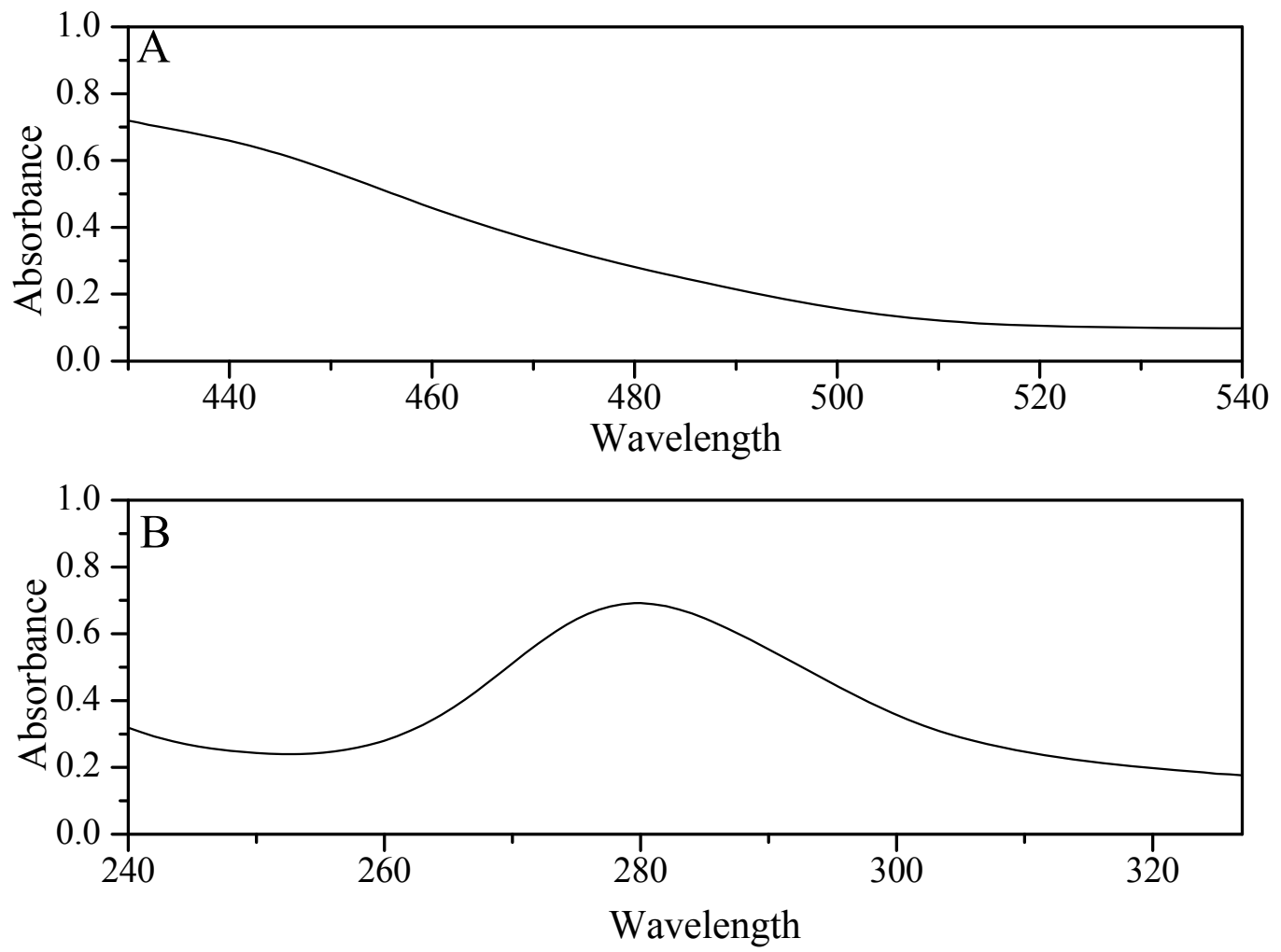

Fig. A12: UV absorbance spectrum of RAFT agent 6 in acetonitrile. $B$ is $\left(\pi \rightarrow \pi^{*}\right.$, $\left.\lambda=280 \mathrm{~nm}, C=2.698 \times{ }^{10-4} \mathrm{~mol} / \mathrm{L}\right)$ and $A$ is $\left(n \rightarrow \pi^{*}, \lambda_{\max }=440 \mathrm{~nm}, C=1.365 \times 10^{-2}\right.$ $\mathrm{mol} / \mathrm{L})$. 


\section{A 5: Compound 7: 1,2:5,6-Di-O-isopropylidene- $\alpha$-D-glucofuranose}
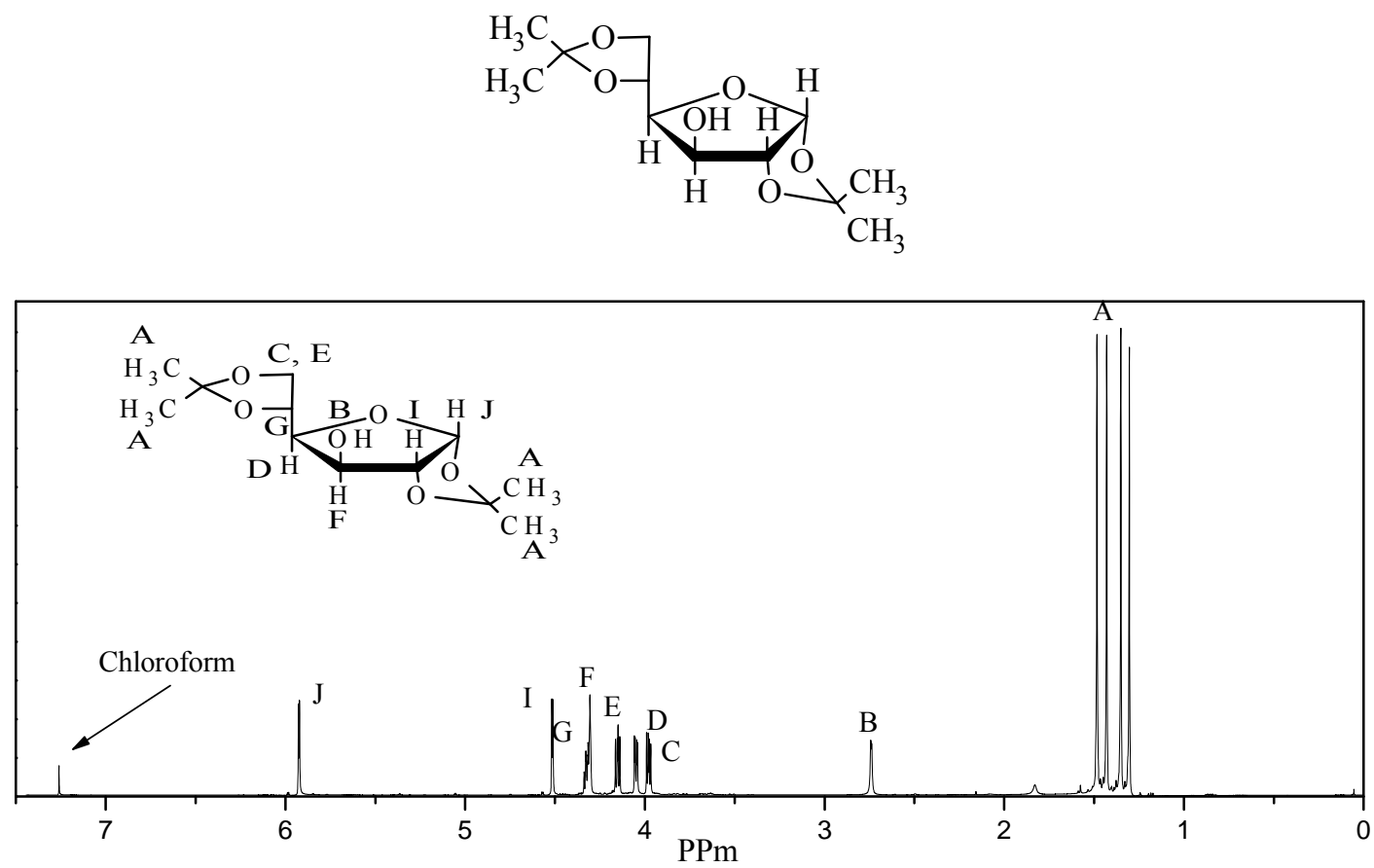

Fig. A13: ${ }^{1} \mathrm{H}-\mathrm{NMR}$ spectrum of 1,2:5,6-di-O-isopropylidene- $\alpha$-D-glucofuranose in chloroform-d.

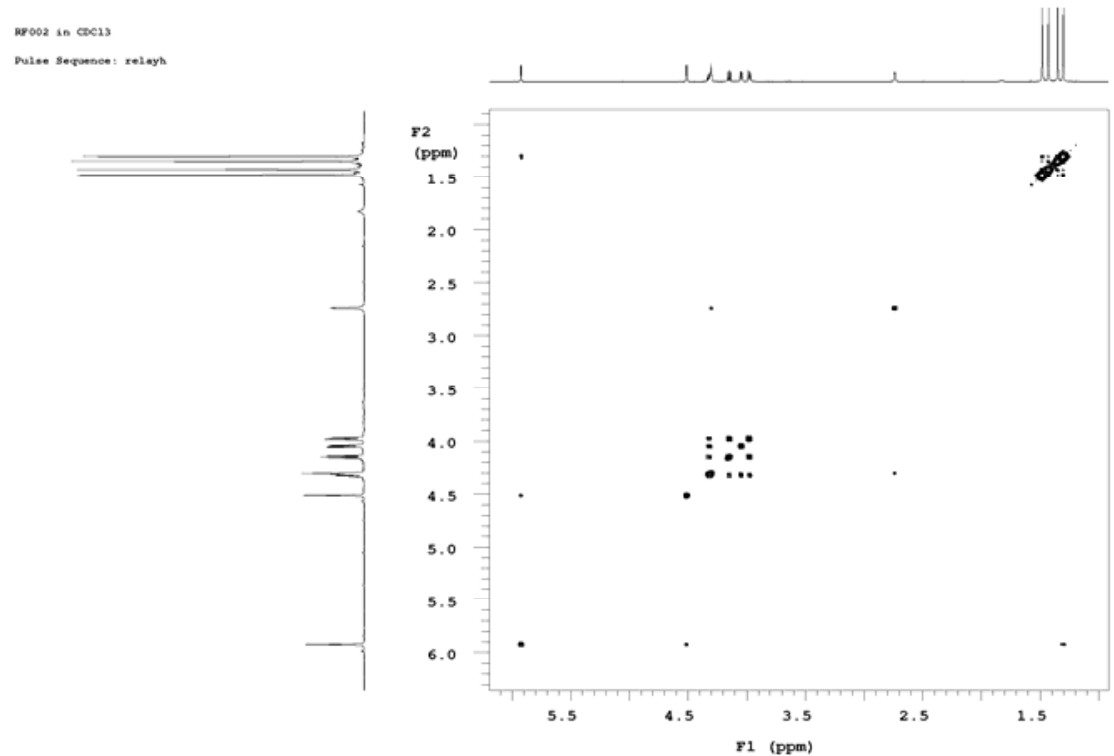

Fig. A14: The COSY plots (1H, 1H) NMR of 1,2:5,6-di-O-isopropylidene- $\alpha-D-$ glucofuranose in chloroform-d. 
A 6: 1,2:5,6-Di-O-isopropylidene- $\alpha$-D-glucofuranose-3-(S-sec ethyl propionoate) xanthate RAFT agent (8)
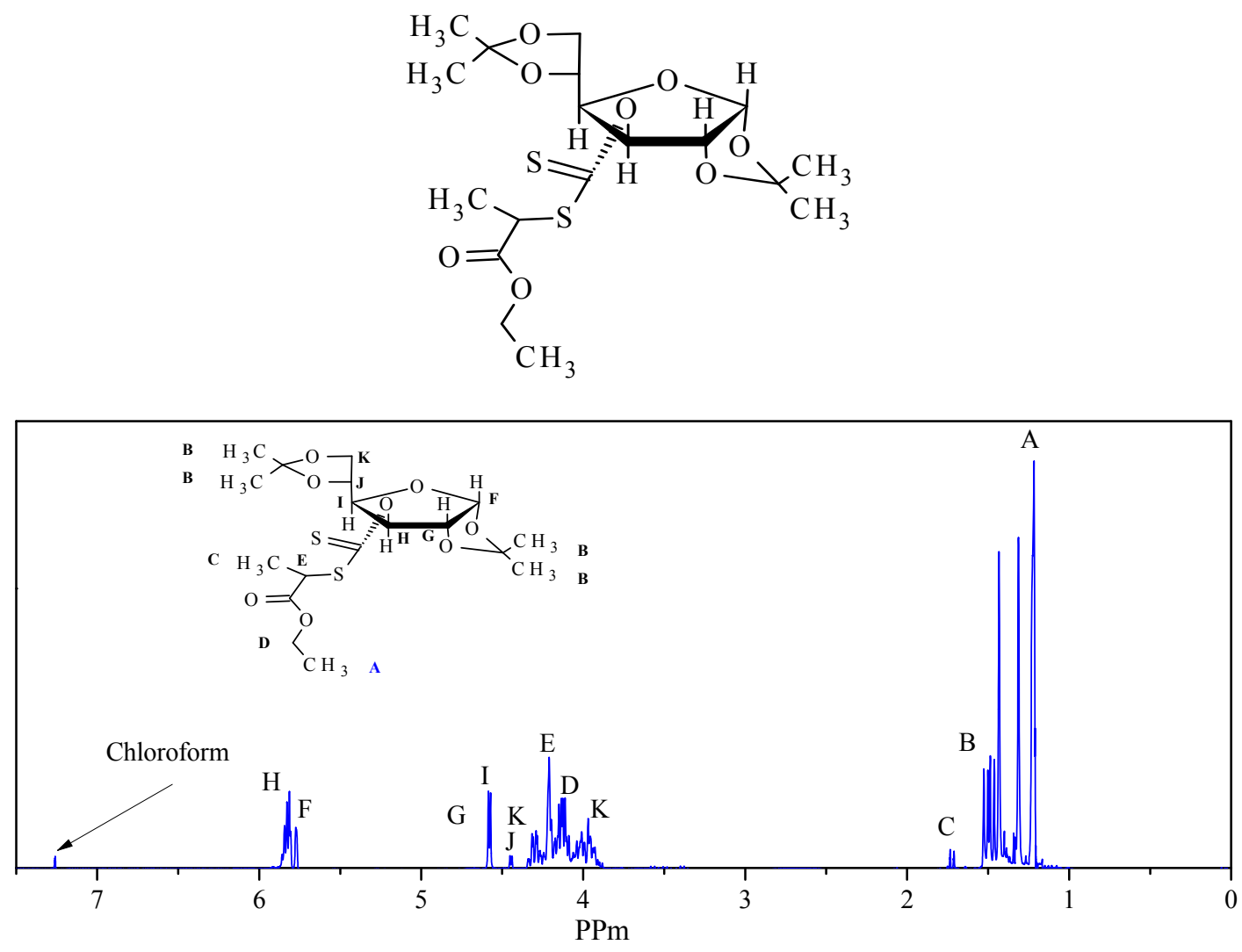

Fig. A15: ${ }^{1}$ H-NMR spectrum of RAFT agent 8 in chloroform-d. 


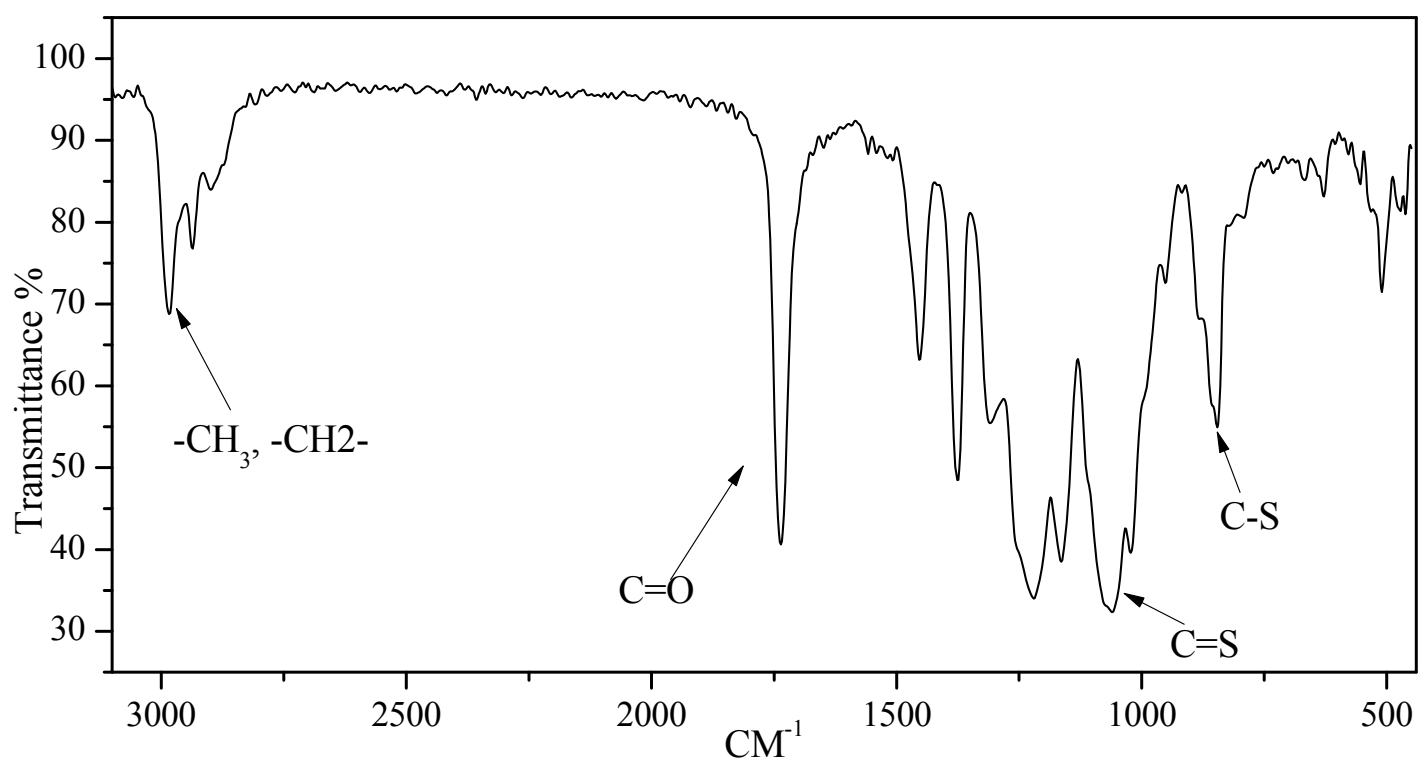

Fig. A16: Infrared spectrum of RAFT agent 8.
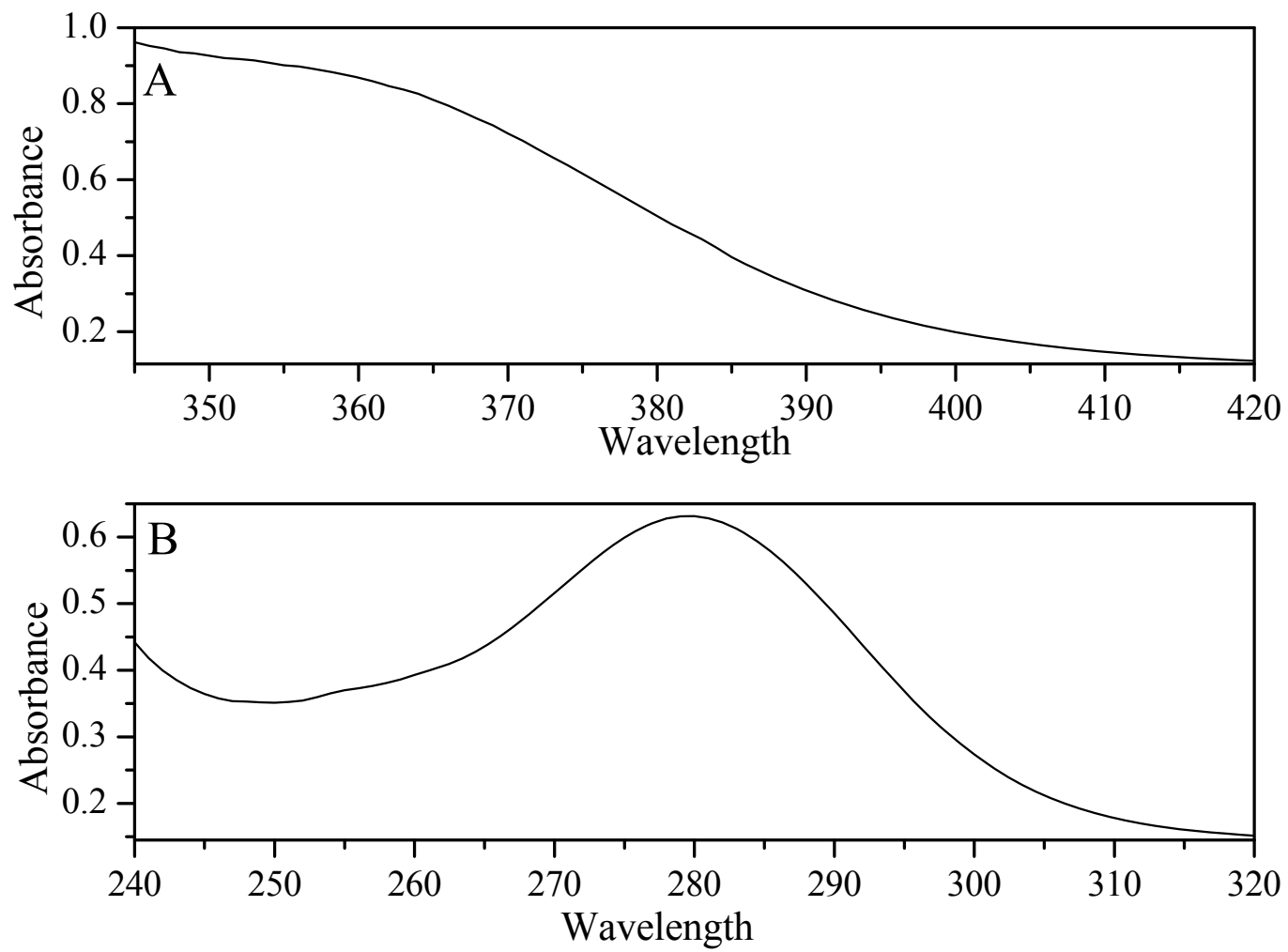

Fig. A17: UV absorbance spectrum of RAFT agent 8 in acetonitrile. $B$ is $\left(\pi \rightarrow \pi^{*}\right.$, $\left.\lambda=280 \mathrm{~nm}, \mathrm{C}=3.2 \times 10^{-5} \mathrm{~mol} / \mathrm{L}\right)$ and $A$ is $\left(\mathrm{n} \rightarrow \pi^{*}, \lambda_{\max }=380 \mathrm{~nm}, C=1.48 \times 10^{-2}\right.$ $\mathrm{mol} / \mathrm{L})$. 


\section{A 7: S-sec propionic acid hydroxylpropyl cellulose xanthate RAFT agent (10)}
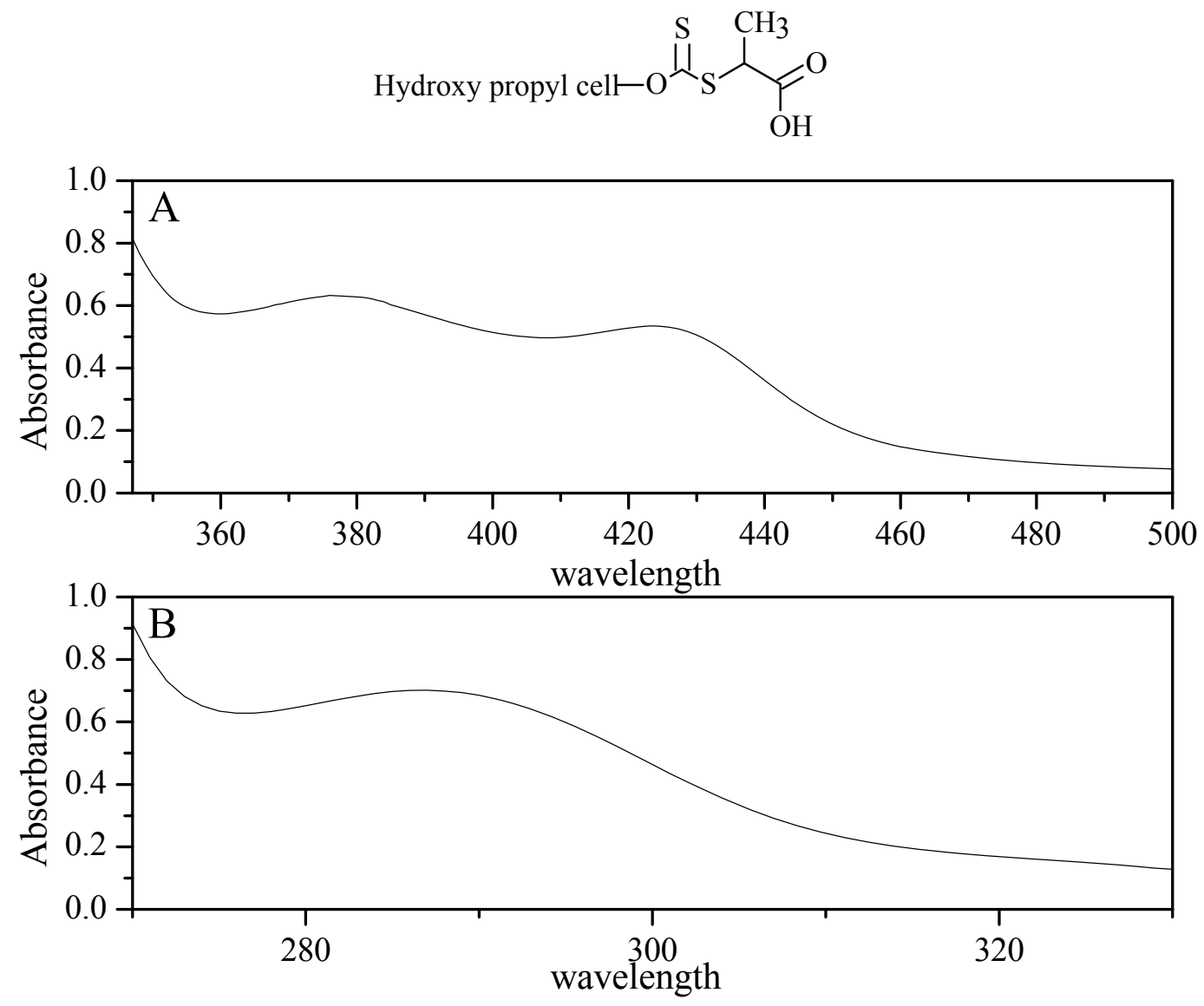

Fig. A17: UV absorbance spectrum of RAFT agent 10 in ethanol. $B$ is $\left(\pi \rightarrow \pi^{*}\right.$, $\lambda=283 \mathrm{~nm}, C=0.011 \mathrm{~g} / 9 \mathrm{~mL})$ and $A$ is $\left(\mathrm{n} \rightarrow \pi^{*}, \lambda_{\max }=376 \mathrm{~nm}, C=0.06 \mathrm{~g} / 2 \mathrm{~mL}\right)$. 


\section{A 8: Structure of S-sec propionic acid methyl cellulose xanthate RAFT agent (11)}
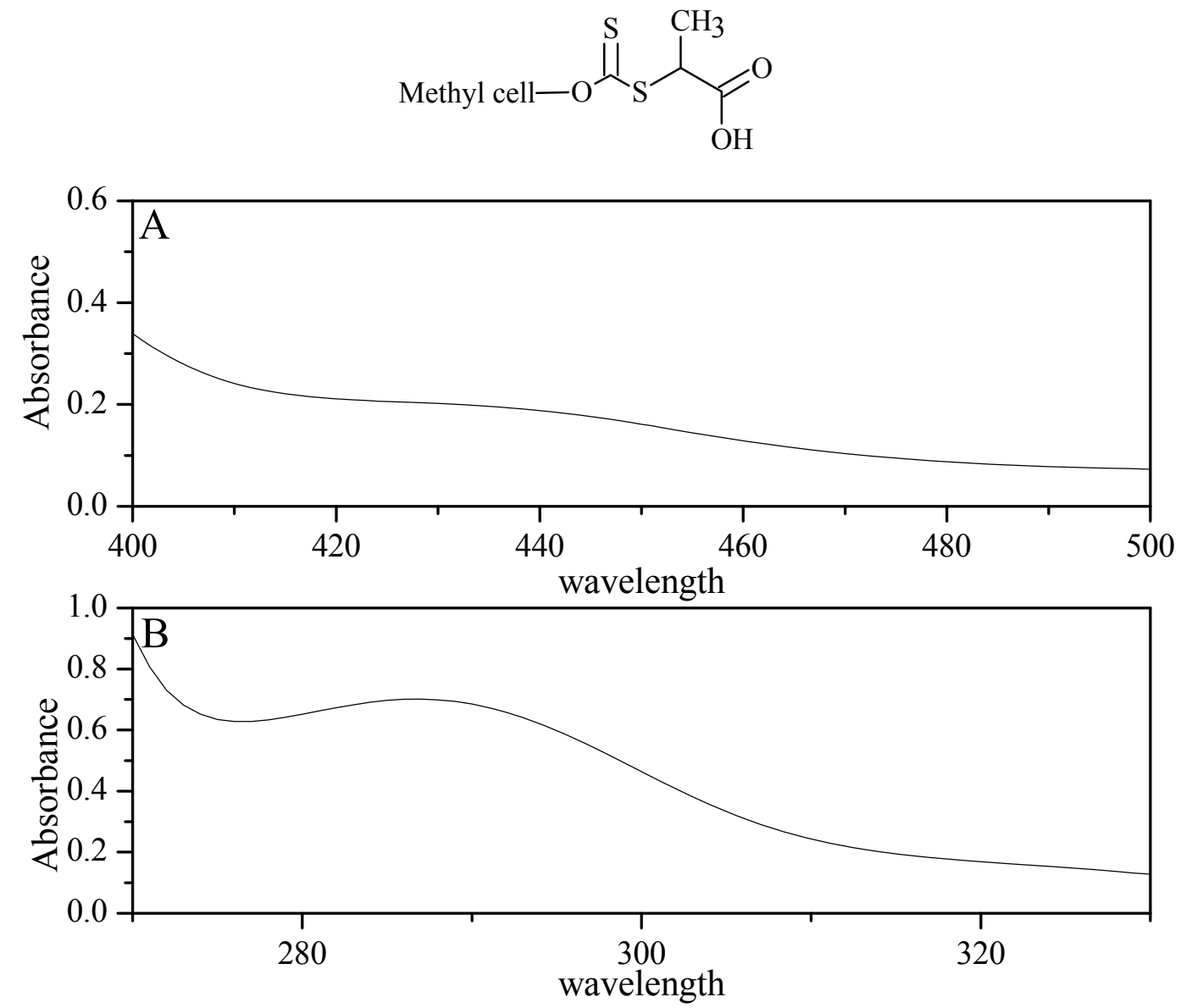

Fig. A18: UV absorbance spectrum of RAFT agent 11 in dimethylformamide. $B$ is $\left(\pi \rightarrow \pi^{*}, \lambda=287 \mathrm{~nm}, C=5 \times 10^{-3} \mathrm{~g} / 7 \mathrm{~mL}\right)$ and $A$ is $\left(\mathrm{n} \rightarrow \pi^{*}, \lambda_{\max }=383 \mathrm{~nm}\right.$, $\mathrm{C}=0.05 \mathrm{~g} / 5 \mathrm{~mL})$. 
A 9: S-sec propionic acid cellulose xanthate RAFT agent (12)<smiles>CC(SC(=S)OCl)C(=O)O</smiles>
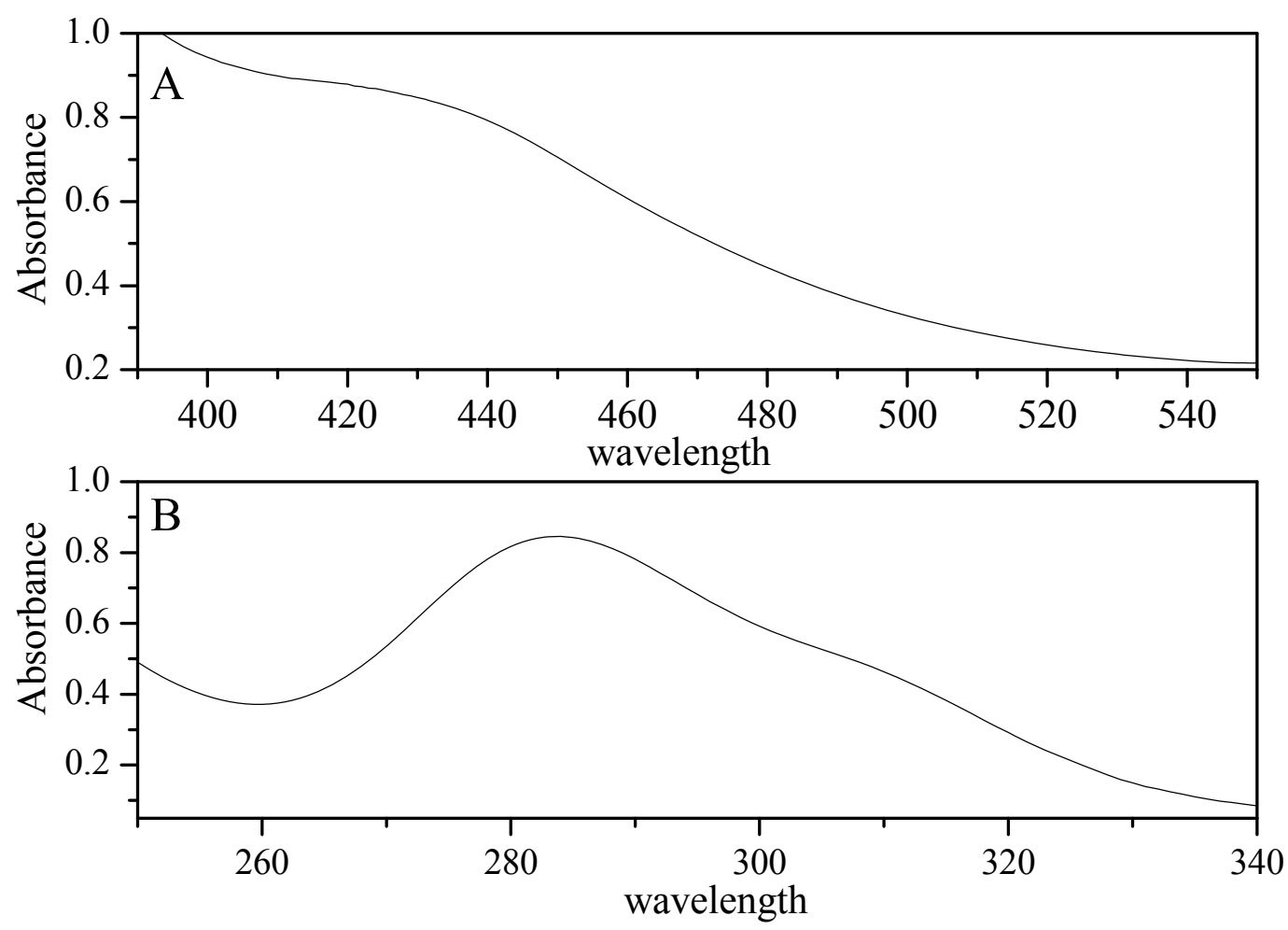

Fig. A19: UV absorbance spectrum of RAFT agent 12 in dimethylformamide. $B$ is $\left(\pi \rightarrow \pi^{*}, \lambda=284 \mathrm{~nm}, C=3 \times 10^{-3} \mathrm{~g} / 6 \mathrm{~mL}\right)$ and $A$ is $\left(\mathrm{n} \rightarrow \pi^{*}, \lambda_{\max }=420 \mathrm{~nm}\right.$, $\mathrm{C}=0.03 \mathrm{~g} / \mathbf{5 m L})$. 


\section{A 10: Calculations of the grating frequency}

\section{The grafting frequency for PVAc-g-HPC}

In a $100 \mathrm{~g}$ sample of the grafted material we would have:

$36 \mathrm{~g}$ backbone cellulosic material $/ 56,000 \mathrm{~g} / \mathrm{mol}($ determined from SEC) $=0.00064 \mathrm{~mol}$

$64 \mathrm{~g}$ of Poly vinyl acetate arms $/ 19,000 \mathrm{~g} / \mathrm{mol}($ determined from SEC) $=0.00336 \mathrm{~mol}$

The number of arms /backbone $=5.25$

The degree of polymerization or DP $=$ MMW of backbone/MMW of substituted anhydroglucose unit

$\mathrm{DP}=56,000 / 607=92$ units of substituted anhydroglucose unit

The grafting frequency is 1:18 (PVAc arm: HPC anhydroglucose unit)

The grafting frequency for PVAc-g-MC

In a $100 \mathrm{~g}$ sample of the grafted material we would have:

$39 \mathrm{~g}$ backbone cellulosic material $/ 32,000 \mathrm{~g} / \mathrm{mol}($ determined from SEC) $=0.00121 \mathrm{~mol}$

$61 \mathrm{~g}$ of Poly vinyl acetate arms $/ 4,000 \mathrm{~g} / \mathrm{mol}($ determined from SEC) $=0.01525 \mathrm{~mol}$

The number of arms $/$ backbone $=12.5$

The degree of polymerization or DP $=$ MMW of backbone/MMW of substituted anhydroglucose unit

$\mathrm{DP}=32,000 / 366=87$ units of substituted anhydroglucose unit

The grafting frequency is 1:7 (PVAc arm: HPC anhydroglucose unit. 